ALISSON CARRARO BORGES

\title{
Avaliação da remoção e transporte do herbicida ametrina em sistemas alagados construídos
}

Tese apresentada à Escola de Engenharia de São Carlos da Universidade de São Paulo como parte dos requisitos para a obtenção do título de Doutor em Engenharia Hidráulica e Saneamento.

Orientadora: Professora Titular Maria do Carmo Calijuri

São Carlos 
AUTORIZO A REPRODUÇÃO E DIVULGAÇÃO TOTAL OU PARCIAL DESTE TRABALHO, POR QUALQUER MEIO CONVENCIONAL OU ELETRÔNICO, PARA FINS DE ESTUDO E PESQUISA, DESDE QUE CITADA A FONTE.

Ficha catalográfica preparada pela Seção de Tratamento da Informação do Serviço de Biblioteca - EESC/USP

B732a

Borges, Alisson Carraro alagados construídos / Alisson Carraro Borges; orientadora Maria do Carmo Calijuri. -- São Carlos, 2007.

Tese (Doutorado-Programa de Pós-Graduação e Área de Concentração em Hidráulica e Saneamento) -- Escola de Engenharia de São Carlos da Universidade de São Paulo, 2007.

1. Ametrina. 2. Escoamento subsuperficial.

3. Hidrodinâmica. 4. Taboa. 5. Terras úmidas.

6. Toxicidade. I. Título. 
Candidato: Engenheiro ALIŚSON CARRARO BORGES

Tese defendida e julgada em 30/11/2007 perante a Comissão Julgadora:
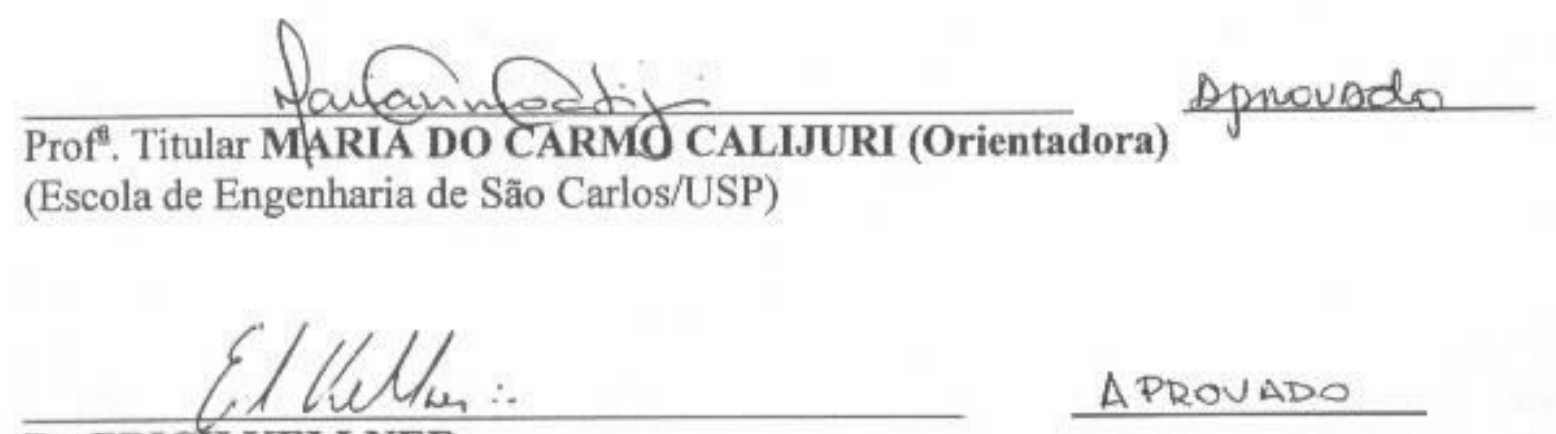

Dr. ERICH KELLNER

(Pós-Doutorando/CNPq)

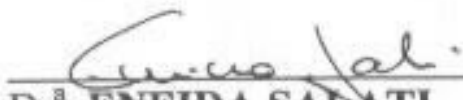

Dr $r^{3}$. ENEIDA SAIATI

(Koltec Consultores Associados)

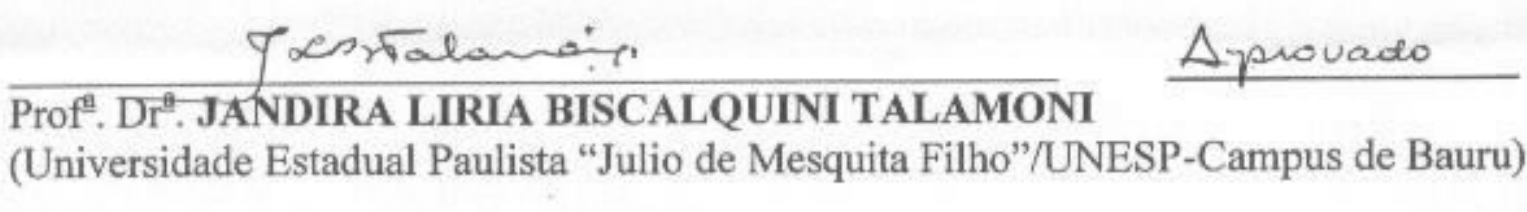

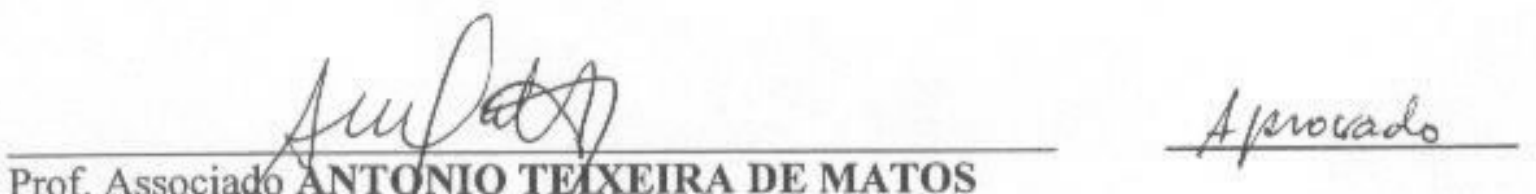

Prof. Associaglo ANTONIO TEXXEIRA DE MATOS

(Universidade Federal (de Viçosa/UFV)

DRQOUADO 

DEDICATÓRIA

Aos Carraro Borges, com grande admiração e gratidão pelo exemplo de fé, esperança e caridade e por todo o incansável apoio nesses anos de estudo. "Minha casa é minha casa, minha casa é meu lar...” 



\section{AGRADECIMENTOS}

A Deus, o Justo Juiz, por tudo. "É bom louvar ao Senhor e cantar salmos ao vosso nome, ó Altíssimo; proclamar, de manhã, a vossa misericórdia, e, durante a noite, a vossa fidelidade." (Salmos, 91, 1-3).

À Maria Santíssima, que sob seu manto acolhe todos aqueles que à vossa intercessão recorrem, obrigado pela proteção à minha amada família.

À Maria do Carmo Calijuri, exemplo de dedicação à pesquisa, obrigado pela amizade, aprendizado, orientação segura e competente e pelo apoio e confiança no desenvolvimento do estudo.

Ao amigo Antonio Teixeira de Matos, pelo coleguismo, pela indispensável ajuda e supervisão no decorrer da pesquisa, pelos ensinamentos, incentivo e pelo exemplo de dedicação ao trabalho.

À Universidade de São Paulo, à Universidade Federal de Viçosa e à Universidade Federal de Ouro Preto, instituições de ensino superior público e de qualidade, minha gratidão pela oportunidade de formação e desenvolvimento profissional.

Os manuais de redação de documentos científicos recomendam que na seção "agradecimentos" presente nas teses e dissertações, devam ser registrados os nomes de pessoas ou instituições que, de maneira efetiva, contribuírem para a realização do estudo. Sem delongas, eis a lista:

Natália dos Santos Renato "Borges", Alexandre Kepler Soares, Alexandre Silveira, Alfredo Ohuma Júnior, Aline Márcia Carraro Borges, Aloízio Soares. Ferreira e Família, Altair Anastácio, Ana Paula Carraro Borges, André Luiz da Silva Salgado Coelho, Antonio Alberto da Silva, Antonio Alves Soares, Antonio Augusto Neves, Antonio José da Silva Filho†, Aristéa Alves Azevedo, Artur Valadares Véras Siqueira Cruvinel, Brunela Silva dos Santos, Camila Soares Braga, Carlos Henrique da Silva†, Celso Bandeira de Melo Ribeiro, Cleber Lima Pereira, Cleyton Santana da Silva, Conselho Nacional de Desenvolvimento Científico e Tecnológico, Coordenação de Aperfeiçoamento de Pessoal de Nível Superior, Corpo Discente do DEA/CCA/UFV, Cristian Ferreira Martins, Cristiano Luchesi Niciura, Débora Astoni Moreira, Demetrius David da Silva, Denilce Menezes Lopes, Docentes do DEA/CCA/UFV, Eduardo Luís da Silva, Eduardo Mario Mendiondo, Elisabeth Moraes, Eloísa Pozzi Gianotti, Eneida Salati, Erich Kellner, Estéfano Aparecido Vieira, 
Eterna República Pif-Paf, Fábio Lavor Teixeira, Família Carraro, Família Pereira Pinto, Família Renato, Família Violeira, Fátima Aparecida Resende Luiz, Filipy Henrique Bonfim Andrade, Francisco Borges Pinto, Francisco Viana Teixeria, Fundação de Amparo à Pesquisa do Estado de Minas Gerais, Fundação de Amparo à Pesquisa do Estado de São Paulo, Gabriel Henrique Horta Oliveira, Gilberto Estanislau dos Santos, Giovanni Chaves Penner, Gustavo de Castro Gonçalves, Harry Edmar Schulz, Iolanda Cristina Duarte, Janaína Monti Silveira, Jandira Liria Biscalquini Talamoni, João Sérgio Fajardo Roldão, Jorge Adílio Penna, José Alberto Domingues Rodrigues, José Galinari Sobrinho, José Roberto Oliveira, Juvercino José da Costa, Karina Querne de Carvalho, Katt Regina Lappa, Lara Steil, Leonardo Dias de Carvalho, Leonardo Henrique Soares Damasceno, Leonardo Vieira Soares, Lucas Borges Hanusch, Luís Mauro Balbino, Luisa Azevedo Scudeller, Luiz Cláudio Costa, Luiz Romariz Duarte†, Luiz Hamilton Pospissil Garbossa, Lyda Patrícia Sabogal Paz, Marcelo de Júlio, Marcelo Eustáquio de Carvalho, Marcelo Zaiat, Marcílio Souza Rocha Freitas, Márcio Mota Ramos, Marcos da Silva Magalhães, Marcos Rogério Tótola, Marcos von Sperling, Margarida de Jesus Carraro Borges, Maria Aparecida Catarino Ventura†, Maria Auxiliadora Campos Altieri Pin, Maria José Cruz da Silva, Maria Eliana Lopes Ribeiro de Queiroz, Maria Lúcia Calijuri, Maria Magdalena Ferreira Ribas, Maria Olímpia de Oliveira Rezende, Mauro Sérgio de Oliveira Leite, Monique Toledo Salgado, Mozart da Silva Brasil, Núcleo Integrado de Bacias Hidrográficas, Pavlovna Damião Rocha Bueno, Pedro José Machado e Família, Pedro Lyra de Toledo e Gazel, Pós Graduandos do PPG/SHS/EESC/USP, Priscila dos Anjos Pereira, Professores e funcionários do SHS/EESC/USP, Programa Especial de Treinamento, Renato Ribeiro Siman, República Kelvinator, República Tijolinho, Ricardo Martins Oliveira, Rodrigo de Arruda Camargo, Romeu Gadotti, Ronaldo Fia, Ronan Cléber Contrera, Rosemeire Aparecida de Jesus, Rubens Miranda Benini e Família, Ruth de Gouvêia Duarte, Roberto Antônio Bezerra Júnior, Rubens Alves de Oliveira, Rubens de Miranda Benini, Scharmack Alessandro Dias Vieira e Família, Sérgio Brasil Abreu, Sérgio Hermínio Brommonschenkel, Sérgio Luís Siebra Moreira, Sérgio Silva Abrahão, Sílvio Crestana, Simone Pellini, Sipcam Agro S/A, Sofia Barbosa Arantes, Suzana Maria Ratusznei, Taís Costa Pereira, Técnicos-Administrativos do DEA/CCA/UFV, Tibério Pinheiro, Vinícius Carvalho Rocha, Wallisson da Silva Freitas, Woodrow Nelson Lopes Roma.

Às demais pessoas que, mesmo não citadas, colaboraram de alguma maneira ao longo desses anos para a concretização deste trabalho, minha sincera gratidão, afinal: nunca se vence uma guerra lutando sozinho... 
"O que importa é a cultura, o meio ambiente e os peixes". Piracumã Yawalapiti 



\section{RESUMO}

BORGES, A. C. Avaliação da remoção e transporte do herbicida ametrina em sistemas alagados construídos. 2007. 134f. Tese (Doutorado em Engenharia Hidráulica e Saneamento) - Escola de Engenharia de São Carlos, Universidade de São Paulo, São Carlos.

O uso de agroquímicos pode causar uma grande variedade de impactos negativos em ambientes aquáticos. Em áreas de exploração agrícola, onde são usados tais produtos, há uma demanda por sistemas de bioremediação que conjuguem baixos custos e simplicidade operacional. Na presente tese são apresentados os resultados da pesquisa que consistiu em se investigar o destino ambiental do agroquímico ametrina quando adicionado a alagados construídos. Foram utilizados sistemas em micro e mesoescala, construídos em Viçosa-MG, que consistiam de macrófitas aquáticas (T. latifolia) plantadas sobre um leito de brita. Para melhor avaliação dos mecanismos nos alagados foi realizado um estudo hidrodinâmico e observou-se que as células operam com boa eficiência hidráulica. No experimento em mesoescala verificou-se a retenção/remoção de $39 \%$ da massa de ametrina aplicada, não sendo observadas diferenças significativas entre as 4 unidades utilizadas. No estudo em microcosmo, não foram observadas variações em relação ao teor de nutrientes e a morfoanatomia das macrófitas. Tal fato pode ser interpretado positivamente, visto que mesmo sob perturbação ambiental a planta adulta conseguiu manter suas características. Como fator a ser considerado, verificou-se que o desenvolvimento inicial da $T$. latifolia pode ser prejudicado por reduzidas concentrações de ametrina. De uma maneira geral, observou-se que sistemas alagados construídos operando sob escoamento subsuperficial poderão vir a ser usados na mitigação da contaminação de águas por praguicidas.

PALAVRAS-CHAVE: ametrina, escoamento subsuperficial, hidrodinâmica, taboa, terras úmidas, toxicidade. 



\begin{abstract}
BORGES, A. C. Evaluation of ametryn fate and transport in constructed wetlands systems. 2007. 134f. Thesis (Doctorate in Hydraulics and Sanitation Engineering) - School of Engineering of São Carlos, University of São Paulo.

Pesticides can cause a great spectrum of negative impacts in aquatic environmental. In agricultural lands, these products are largely used and in these regions there is a demand for low costs and simple bioremediation systems. In the present thesis, the results of the research about ametryn environmental fate in subsurface flow constructed wetlands systems are presented. The wetlands cells were built in microcosms and mesocosms scales at Viçosa city, Minas Gerais state. The experimental system was consisted of aquatic macrophytes ( $T$. latifolia) cultivated on a porous gravel bed. A hydrodynamic study was performed for the better knowledge of the mechanisms of pesticide transport. The cells presented good hydraulic efficiency and in mesocosms wetlands were observed that $39 \%$ of ametryn amended was removed/retained. No statistical difference among the 4 cells performances was registered. At green house (microcosm) tests, no effects in nutrients and morpho-anatomy were observed. This fact can be interpreted positively, because ever under environmental disturbance, the macrophyte maintained its characteristics. However, aqueous 10-d germination and growth experiment indicate possible ametryn harmful effects to T. latifolia development. In general way, it was observed that vegetated constructed wetlands can be used in depollution of pesticides-contaminated waters.
\end{abstract}

KEYWORDS: ametryn, subsurface flow, hydrodynamic, cattail, wetlands, toxicity. 



\section{LISTA DE FIGURAS}

Figura 2.1 Grupos ecológicos de macrófitas aquáticas 13

Figura 2.2 Ilustrações esquemáticas referentes a aspectos morfológicos de macrófitas emergentes, flutuantes e submergentes

Figura 2.3 Diagramas esquemáticos referentes a: (a) SAC de escoamento superficial; (b) lagoa de aguapés; (c) SAC de escoamento horizontal subsuperficial e (d) SAC de escoamento vertical

Figura 3.1 Planta de situação da AETR

Figura 3.2 Fotografias das áreas experimentais utilizadas: (a) vista da Área Experimental de Tratamento de Resíduos e (b) casa de vegetação localizada nos fundos do Laboratório de Hidráulica

Figura 3.3 Diagrama esquemático de uma unidade do SAC: (a) dispositivo de distribuição do afluente; (b) zona de entrada; (c) geomembrana impermeável; (d) zona de saída; (e) dispositivo de extravazão para os reservatórios efluentes; (f) meio suporte e (g) pontos de coleta de amostras do líquido residente

Figura 3.4 Leitos preenchidos com brita antes do plantio da taboa

Figura 3.5 Fotografias de vistas parciais dos sistemas alagados construídos .50

Figura 3.6 Detalhes: (a) do sistema de distribuição dos afluentes nas unidades e (b) reservatórios de coletas posicionados a jusante

Figura 3.7 Volume dos alagados construídos em função das diferenças de declividade de fundo

Figura 3.8 Fotografias correspondentes a: (a) detalhe do tanque cilíndrico utilizado como SAC; (b) vista parcial do experimento

Figura 3.9 Fotografias referentes a: (a) plantio dos rizomas; (b) comparação do comprimento dos rizomas implantados

Figura 3.10 Fotografia referente à montagem do teste de germinação da taboa. .53

Figura 3.11 Estrutura (armário) usada para a germinação das sementes (controle de temperatura da água entre $20{ }^{\circ} \mathrm{C}$ e $24{ }^{\circ} \mathrm{C}$ ) 
Figura 4.1 Estrutura química dos corantes fluorescentes utilizados no estudo (a) rodamina WT e (b) fluorescina sódica

Figura 4.2 Curvas de calibração utilizadas para quantificação da concentração dos traçadores fluorescentes

Figura 4.3 Concentrações dos traçadores florescentes na saída do SAC A......................72

Figura 4.4 Concentrações dos traçadores florescentes na saída do SAC C ......................73

Figura 4.5 Concentrações dos traçadores florescentes na saída do SAC D......................73

Figura 4.6 Balanço hídrico obtido pelo monitoramento dos volumes efluentes ..............75

Figura 4.7 Comparação entre os perfis de saída para as funções $C_{\theta}$ e $C_{\phi}$ versus o tempo normalizado ou volume ponderado normalizado 75

Figura 4.8 Perfis de concentração de rodamina WT plotados usando o volume ponderado normalizado $\phi$ : comparação de SACs com diferentes inclinações de fundo e cargas hidráulicas aplicadas

Figura 4.9 Perfis de concentração de fluorescina sódica plotados usando o volume ponderado normalizado $\phi$ : comparação de SACs com diferentes inclinações de fundo e cargas hidráulicas aplicadas

Figura 5.1 Diagrama esquemático das unidades experimentais construídas na Área Experimental de Tratamento de Resíduos, UFV, Viçosa-MG.

Figura 5.2 Contribuição hídrica, considerados os valores de evaporação no tanque classe A subtraídos das precipitações, e temperatura média do ar no período de experimentação

Figura 5.3 Influência do balanço hídrico nos valores de $\tau_{\mathrm{N}}$ no SAC C

Figura 5.4 Médias móveis referentes às quantidades de ametrina adicionadas e recuperadas nos SACs

Figura 5.5 Conteúdo de nutrientes na parte superior das macrófitas plantadas nos SACs B (controle) e C .99

Figura 6.1 Ilustração da macrófita Typha sp.

Figura 6.2 Diagrama esquemático do experimento realizado em microcosmo: os números correspondem às concentrações de ametrina $\left(\mathrm{mg} \mathrm{L} \mathrm{L}^{-1}\right)$ adicionadas às wetlands vegetadas (pontos verdes) e não vegetadas. 
Figura 6.3 Perda de líquido residente no período de experimentação, os números contidos no eixo das abscissas denotam as concentrações de ametrina aplicadas inicialmente

Figura 6.4 Variação dos valores de: (a) potencial hidrogeniônico e (b) condutividade elétrica nos 8 SACs vegetados e nos 3 SACs não vegetados

Figura 6.5 Lâmina foliar de Typha latifolia, visão geral; LA: lacuna aerífera, DI:

Diafragma

Figura 6.6 Lâmina foliar de Typha latifolia, face abaxial; LA: lacuna aerífera, ID: idioblasto do diafragma, PP: parênquima paliçádico, Fi: fibras, EV: elemento de vaso, ES: estômato, EPB: epiderme abaxial

Figura 6.7 Lâmina foliar de Typha latifolia, face adaxial; LA: lacuna aerífera, PP: parênquima paliçádico, Fi: fibras, EV: elemento de vaso, ES: estômato, EPA: epiderme adaxial

Figura 6.8 Valores médios da taxa de evolução de $\mathrm{CO}_{2}$ na rizosfera de alagados vegetados com T. latifolia.

Figura 6.9 Fotografia das plântulas após 10 dias de desenvolvimento 



\section{LISTA DE TABELAS}

Tabela 2.1 Principais plantas usadas em SACs para estudos dea remediação de praguicidas

Tabela 2.2 Propriedades dos praguicidas citados no texto

Tabela 2.3 Toxicidade de herbicidas ao ganho de biomassa para Lemna minor e Selenastrum capricornutum

Tabela 3.1 Métodos e/ou equipamentos usados no monitoramento de variáveis rotineiras no LQA/DEA

Tabela 4.1 Números de dispersão em reatores

Tabela 4.2 Equações de modelos matemáticos usadas para obtenção do número adimensional de dispersão

Tabela 4.3 Traçadores usados nos ensaios

Tabela 4.4 Valores de tempos de residência nominais, experimentais, tempos de pico, variância adimensional e eficiência hidráulica obtidos para SACs de diferentes declividades

Tabela 4.5 Valores do número adimensional d, obtidos para os modelos de dispersão de pequena e grande intensidade.

Tabela 5.1 Propriedades físicas, químicas e destino ambiental da ametrina

Tabela 5.2 Resumo dos resultados experimentais obtidos em SACs de escoamento subsuperficial tratando praguicidas

Tabela 5.3 Resultados obtidos para as variáveis de qualidade monitoradas durante o experimento no tanque a montante e nos pontos a $12 \mathrm{~m}$ e $24 \mathrm{~m}$ da aplicação

Tabela 6.1 Alguns efeitos estudados em Typha spp. devido à exposição a agroquímicos

Tabela 6.2 Concentrações médias $\left(\right.$ dag $\left.\mathrm{kg}^{-1}\right)$ de nutrientes na matéria seca (parte aérea) da taboa

Tabela 6.3 Concentrações médias $\left(\right.$ dag $\left.\mathrm{kg}^{-1}\right)$ de nutrientes na matéria seca (parte subterrânea) da taboa 
xviii

Tabela 6.4 Quantidade $\left(\mathrm{kg} \mathrm{ha}^{-1}\right)$ de nutrientes (parte aérea) da taboa............................ 119

Tabela 6.5 Quantidade $\left(\mathrm{kg} \mathrm{ha}^{-1}\right)$ de nutrientes (parte subterrânea) da taboa................... 119

Tabela 6.6 Comprimento de largura média do limbo foliar de Typha latifolia .............. 120

Tabela 6.7 Características anatômicas da parte aérea da T. latifolia .............................. 120

Tabela 6.8 Valores médios de respiração obtidos nos SACs não vegetados (I, J e K) e nos SACs cultivados com taboa, valores em $\left(\mu \mathrm{mol} \mathrm{h} \mathrm{h}^{-1}\right)$

Tabela 6.9 Crescimento de raízes e brotos ( \pm desvio padrão) e porcentagem de germinação de $T$. latifolia exposta a ametrina durante os 10 dias iniciais do desenvolvimento 


\section{LISTA DE ABREVIATURAS E SIGLAS}

ABIQUIM Associação Brasileira da Indústria Química.

ABNT Associação Brasileira de Normas Técnicas.

AETR Área Experimental de Tratamento de Resíduos.

APHA American Public Health Association.

AT

Alcalinidade Total.

AWWA American Water Works Association.

BIOAGRO Instituto de Biotecnologia Aplicada à Agropecuária.

CAS Chemical Abstract Service Number.

CE Condutividade Elétrica.

CI Color Index Generic Name.

COPPE Instituto Alberto Luiz Coimbra de Pós-graduação e Pesquisa de Engenharia.

$\mathrm{Cu} \quad$ Coeficiente de Uniformidade.

CW Constructed Wetland.

DBV/CCB/UFV Departamento de Biologia Vegetal.

DEA/CCA/UFV Departamento de Engenharia Agrícola.

DEQ/CCE/UFV Departamento de Química.

Di Diafragma.

DPS/CCA/UFV Departamento de Solos.

DQO Demanda Química de Oxigênio.

DTR Distribuição de Tempos de Residência.

EPB Epiderme Abaxial.

ES Estômato.

ET Evapotranspiração.

EUA Estados Unidos da América.

EV Elemento de Vaso. 
EXTOXNET The Extension Toxicology Network.

FAP Floating Aquatic Plant System.

Fi Fibras.

FS Fluorescina Sódica.

FWS Free Water Surface.

GUS Groundwater Ubiquity Score

ID Idioblasto do Diafragma.

IFAS Institute of Food and Agricultural Sciences.

ITRC The Interstate Technology and Regulatory Council.

IUPAC International Union of Pure and Applied Chemistry

IWA International Water Association.

LA Lacuna Aerífera,

LAQUA Laboratório de Química Analítica e Ambiental.

LOEC Lowest Observed Effect Concentration.

LQA Laboratório de Qualidade da Água.

LT Laboratório de Traçadores.

MM Massa Molecular.

MO Matéria Orgânica.

MS Matéria Seca.

NBR Norma Brasileira.

NOEC No Observed Effect Concentration.

NPSP Nonpoint Source Pollution.

PAN Pesticide Action Network.

pH Potencial Hidrogeniônico.

PP Parênquima Paliçádico.

PVC Policloreto de vinila.

RWT Rodamina WT. 
SAC Sistema Alagado Construído.

SAEG Sistema para Análises Estatísticas.

SHS/EESC/USP Departamento de Hidráulica e Saneamento.

SRC Syracuse Research Corporation.

SSF Subsurface Flow.

SST Sólidos Suspensos Totais.

UFCG Universidade Federal de Campina Grande.

UFRGS Universidade Federal do Rio Grande do Sul.

UFRJ Universidade Federal do Rio de Janeiro.

UFSC Universidade Federal de Santa Catarina.

UFV Universidade Federal de Viçosa.

Unicamp Universidade Estadual de Campinas.

US DA United States Department of Agriculture.

US EPA United States Environmental Protection Agency.

USP Universidade de São Paulo.

VFS Vegetative Filter Strip.

WEF Water Environment Federation. 



\section{LISTA DE SÍMBOLOS}

A Área sob a curva concentração-tempo.

B Largura.

c Concentração de soluto.

$\mathrm{Cu}$ Coeficiente de uniformidade.

D Coeficiente de dispersão.

d Número adimensional de dispersão.

$\mathrm{D}_{60} \quad$ Diâmetro efetivo.

E Distribuição da idade de saída.

$\mathrm{K}_{\mathrm{H}} \quad$ Constante de equilíbrio de Henry.

$\mathrm{K}_{\mathrm{OC}} \quad$ Coeficiente de partição.

$\mathrm{K}_{\mathrm{OW}}$ Coeficiente de partição octanol-água.

$\mathrm{K}_{\mathrm{s} 20}$ Condutividade hidráulica saturada.

L Comprimento.

$\mathrm{M}_{0} \quad$ Massa recuperada no teste hidrodinâmico.

P Precipitação.

P Pressão de vapor.

$\mathrm{Q}_{\mathrm{AF}} \quad$ Vazão afluente.

QEF Vazão efluente.

QSIS Vazão média do sistema.

S Solubilidade.

T Temperatura.

t Tempo.

$t_{\mathrm{P}} \quad$ Tempo de pico.

u Velocidade do fluido.

V Volume. 
xxiv

$\mathrm{V}_{\mathrm{EF}} \quad$ Volume de efluente.

$\mathrm{V}_{\mathrm{SIS}} \quad$ Volume médio do sistema.

$\phi \quad$ Tempo de residência ponderado.

$\lambda \quad$ Comprimento de onda.

$\lambda \quad$ Eficiência hidráulica.

$\theta \quad$ Tempo de residência adimensional.

$\sigma^{2} \quad$ Variância.

$\tau \quad$ Tempo de residência hidráulica.

$\tau_{\mathrm{N}} \quad$ Tempo de residência hidráulica nominal.

$\tau_{\mathrm{R}} \quad$ Tempo de residência hidráulica experimental. 


\section{CONTEÚDO}

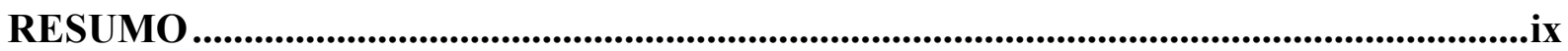

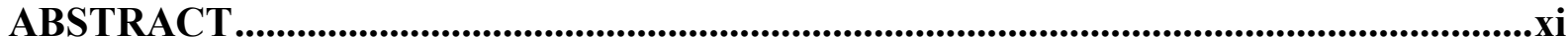

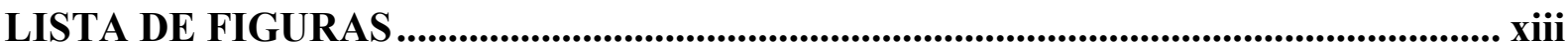

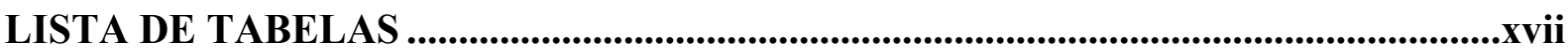

LISTA DE ABREVIATURAS E SIGLAS....................................................................

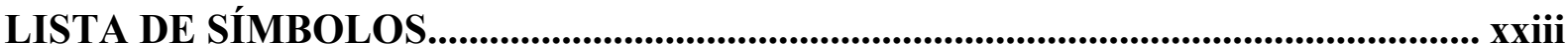

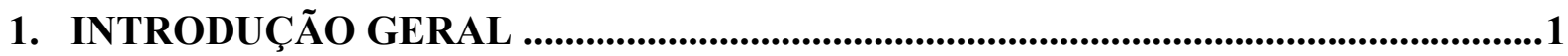

Introdução e justificativa ........................................................................................................2

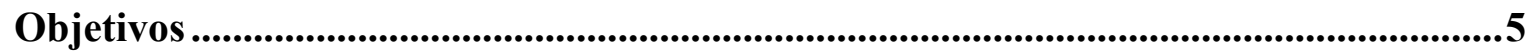

2. ALAGADOS CONSTRUIIDOS PARA REMEDIAÇÃO DE ÁGUAS

CONTAMINADAS COM PRAGUICIDAS: ESTADO DA ARTE ................................7

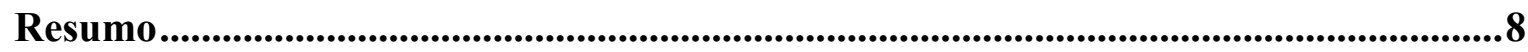

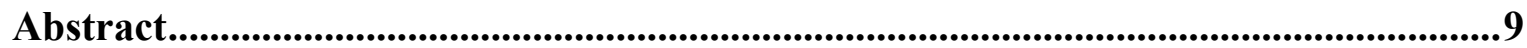

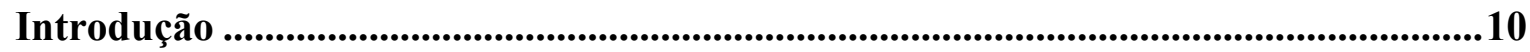

Sistemas alagados construídos ........................................................................................11

Mecanismos de remoção de praguicidas em sistemas alagados construídos................17

Experimentos de aplicação dos SACs no tratamento de praguicidas ............................20

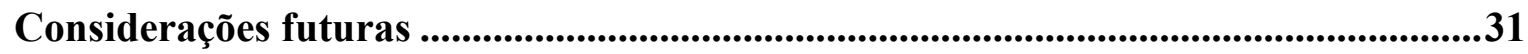

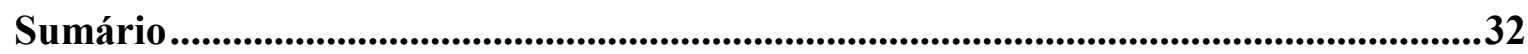

Referências bibliográficas ........................................................................................34 


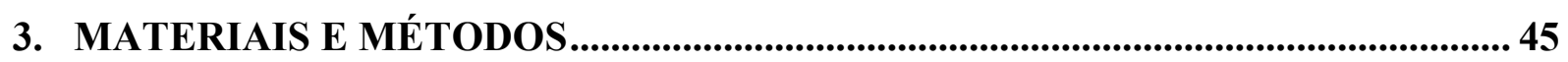

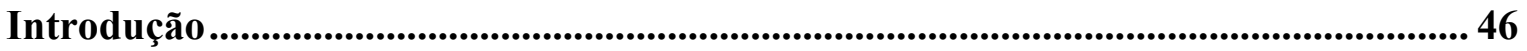

Localização dos experimentos ....................................................................................... 46

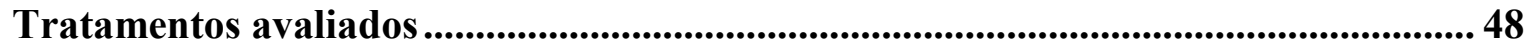

Análises laboratoriais e estatísticas...........................................................................5

Referências bibliográficas........................................................................................ 57

4. USO DE TRAÇADORES PARA AVALIAÇÃO DA HIDRODINÂMICA DE ALAGADOS CONSTRUÍDOS OPERANDO SOB CLIMA TROPICAL .................59

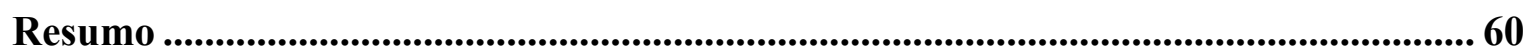

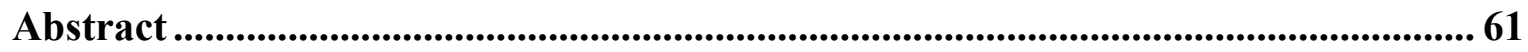

Introduçãa

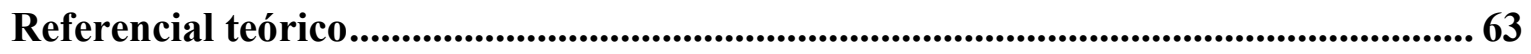

Metodologia..................................................................................................................................... 68

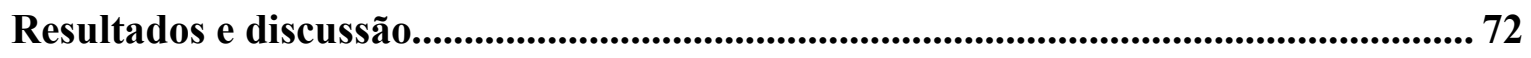

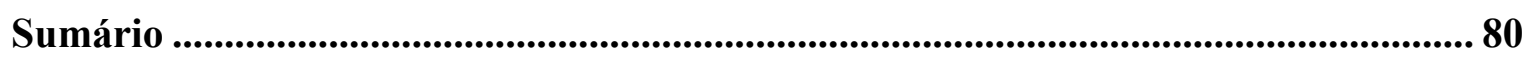

Referências bibliográficas..................................................................................... 81

5. USO DE ALAGADOS CONSTRUIIDOS DE ESCOAMENTO SUBSUPERFICIAL PARA MITIGAÇÃO DA CONTAMINAÇÃO DE ÁGUAS COM AMETRINA...... 85

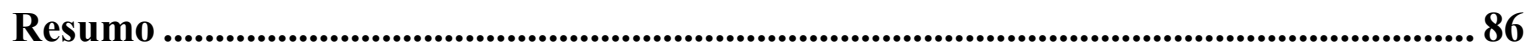

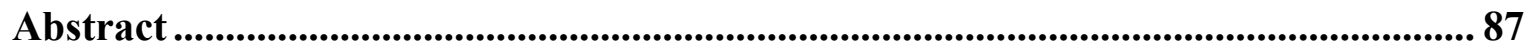

Introdução

Metodologia............................................................................................................................................ 91

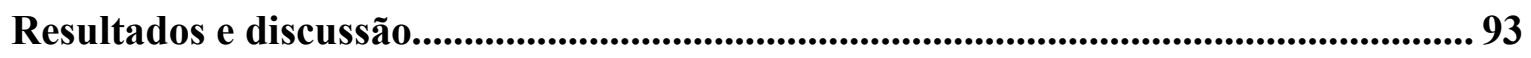

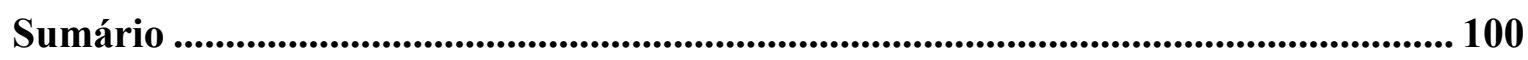

Referências bibliográficas.................................................................................. 101 
6. EFEITOS DO HERBICIDA AMETRINA NO TEOR DE NUTRIENTES, NA MORFO-ANATOMIA E NA GERMINAÇÃO DE TYPHA LATIFOLIA.

Resumo 108

Abstract. 109

Introdução 110

Metodologia 113

Resultados e discussão. 115

Sumário 125

Referências bibliográficas 126

7. CONCLUSÕES E SUGESTÕES 131

Conclusões gerais 132

Sugestões para estudos futuros 133 

CAPÍTULO 1

INTRODUÇÃO GERAL 


\subsection{INTRODUÇÃO E JUSTIFICATIVA}

A emissão não controlada de despejos industriais, agrícolas e domésticos nos cursos de água é considerada a principal causa da poluição hídrica. Sabe-se que o saneamento ambiental é importante ferramenta sócio-econômica no desenvolvimento de uma sociedade e que como apenas $0,78 \%$ da água disponível no planeta pode ser prontamente utilizada para abastecimento público, justificam-se os esforços direcionados à conservação da qualidade dos mananciais existentes, considerando-se não só aspectos sanitários, mas também ambientais.

Atenção especial vem sendo dispensada aos aportes de poluentes feitos de maneira difusa, ou seja, não pontual. Tais fontes são associadas ao escoamento pluvial, à mineração e, principalmente, às atividades agrícolas. Pesquisas recentes têm enfocado a problemática da poluição de mananciais com fertilizantes e praguicidas. Sabe-se que a qualidade ambiental do meio aquático relaciona-se fortemente com a agricultura devido à possibilidade de contribuição difusa de cargas de insumos agrícolas via escoamento (escorrimento) superficial nas bacias hidrográficas.

Estima-se que o uso indiscriminado de praguicidas seja a segunda, em grau de importância, forma de poluição dos rios, córregos e lagos no país. Além do escoamento superficial em áreas agrícolas, devem ser consideradas outras importantes formas de contribuição: contaminação direta de esgotos sanitários, deriva das aplicações por pulverização, atividades como viveiros de mudas e replantio/manutenção de gramados, processamento (lavagem, despolpa) de produtos agropecuários, além dos resíduos da fabricação dos praguicidas.

O uso de agroquímicos no meio rural tem trazido uma série de conseqüências, tanto para o ambiente como para a saúde do homem do campo. O quadro é agravado pelo baixo nível sócio-econômico e cultural da grande maioria desses trabalhadores. O enorme déficit sanitário brasileiro, em meio urbano ou rural, ratifica a necessidade de adoção de sistemas simplificados de mitigação de poluição. Tais processos devem ser sustentáveis, conjugando baixos custos de implantação e simplicidade operacional.

Sistemas de tratamento de efluentes são condicionamentos usados para que o corpo hídrico receptor não sofra alterações nos parâmetros de qualidade fixados para a região afetada pela emissão. Quando a técnica de tratamento proposta está fundamentada no uso de fenômenos e/ou recursos naturais, convenciona-se adotar o conceito de ecotecnologia. Nesse 
sentido, sistemas alagados - wetlands - têm se mostrado promissores para a bioremediação e tratamento de efluentes, uma vez que com a utilização dessa tecnologia há ganho ambiental, com custos de implantação e operação reduzidos, quando comparados com sistemas mais tecnificados. Alagados naturais ou artificiais (construídos) têm sido utilizados, especialmente em países desenvolvidos, com bons resultados no tratamento de águas residuárias domésticas, agrícolas e industriais.

As chamadas terras úmidas construídas foram idealizadas a partir da observação dos processos presentes em alagados naturais. Wetlands construídas agem como filtro biológico de águas superficiais, nas quais ocorrem processos físicos, químicos e biológicos de transformação e retenção de poluentes. Tais sistemas foram criados para controlar sistematicamente o tratamento e otimizar a habilidade do sistema de várzea na mitigação da poluição, além de possuir funções hidrológicas, climáticas e de habitat e biodiversidade.

A expressão constructed wetlands é utilizada internacionalmente para identificação desse tipo de sistema, que no Brasil ainda não tem um único nome. Termos como "zona de raízes", "terras úmidas", "leitos cultivados" "áreas alagadas construídas" e "sistemas alagados construídos" vêm sendo usados, sendo este último a opção preferencial no presente estudo.

Experimentos bem sucedidos sobre tratamento de resíduos via sistemas alagados construídos vêm sendo relatados nas últimas décadas. A International Water Association (IWA) promove a cada dois anos uma conferência sobre sistemas wetlands para controle de poluição. Relata-se o uso de alagados construídos para fins diversos, tanto na melhoria de qualidade de águas como no tratamento de efluentes de fontes pontuais e difusas.

No Brasil, sistemas de alagados construídos (SACs) vêm sendo estudados em várias instituições federais (UFCG, UFRGS, UFSC, UFV) e estaduais (Unesp, Unicamp, USP) de ensino e pesquisa. Entre os trabalhos apresentados nos congressos das associações científicas nacionais, encontram-se temas como remoção de coliformes, recuperação de córregos via wetlands construídas, comparação de espécies de macrófitas na remoção de poluentes, viabilidade de redução de concentração de metais pesados e modelagem dos processos de remoção de material orgânico e nutrientes.

De uma maneira geral, embora se registrem iniciativas de pesquisas sobre a tratabilidade de águas contaminadas por praguicidas em SACs, não se dispõe ainda de conhecimento suficiente sobre o transporte e a degradação de vários desses poluentes, sendo necessários mais estudos enfocando o tema. Como já exposto, o uso intensivo de determinados praguicidas agrícolas ocorre no meio rural, em regiões que demandam sistemas 
simplificados e menos dispendiosos de mitigação de poluição, como é o caso dos SACs. Dessa maneira, a presente proposta de investigação é baseada na hipótese de remoção de um herbicida sistêmico de uso corrente - ametrina - em sistemas alagados construídos e é justificada quando se constatam fatores como a lacuna de estudos desse tipo em regiões de clima tropical e principalmente a necessidade de um melhor entendimento desse processo.

A tese foi redigida na forma de capítulos. Após a apresentação da hipótese central, da justificativa e dos objetivos do estudo (Capítulo 1), expõe-se um artigo de revisão sobre o tema (Capítulo 2) e um compêndio relativo às áreas experimentais, materiais e métodos usados durante a pesquisa (Capítulo 3); a elaboração deste capítulo fez-se necessária para o melhor entendimento do texto como um todo.

Os artigos apresentados nos Capítulos 4, 5 e 6 são referentes aos experimentos realizados em diferentes escalas e datas, durante o estudo. Como se trata de uma tese, esses capítulos possuem continuidade temática; no entanto, nessa opção de apresentação (apresentação em capítulos) é necessária uma certa independência de cada parte, pois cada seção constitui um artigo técnico-científico. Para maior uniformidade e compreensão do texto, estes três capítulos foram divididos nas mesmas seções: Resumo, Abstract, Introdução, Metodologia (para diferenciação do Capítulo 3), Resultados e Discussão, Sumário (para diferenciação com as conclusões gerais da tese) e Referências.

Como ressaltado anteriormente, os artigos abordam experimentos em diferentes escalas: o Capítulo 4 trata dos resultados referentes à hidrodinâmica dos SACs de escoamento subsuperficial utilizados em campo, o Capítulo 5 aborda a retenção da ametrina em mesoescala e no Capítulo 6 estão apresentados os resultados de ensaios de toxicidade do agroquímico na macrófita estudada.

Por fim, é apresentada uma seção intitulada “Conclusões e Sugestões” (Capítulo 7), na qual são relatadas observações gerais elaboradas com base nos dados obtidos na pesquisa. Sugestões sobre aspectos relevantes para a continuidade de estudos no tema também estão apresentadas. O texto e a formatação da tese foram elaborados observando-se as "Diretrizes para apresentação de dissertações e teses da USP", as orientações do "Sistema Internacional de Unidades" e a norma brasileira (NBR) "Informação e documentação - Referências Elaboração", publicada em agosto de 2002 pela Associação Brasileira de Normas Técnicas $(\mathrm{ABNT})$. 


\subsection{OBJETIVOS}

O objetivo geral desta pesquisa foi avaliar a remoção, a retenção e o transporte do herbicida ametrina em sistemas alagados construídos de escoamento subsuperficial. Foram estabelecidos ainda, os seguintes objetivos específicos:

- Verificar a capacidade suporte dos sistemas em depurar ou reter ametrina, quando submetidos a aportes contínuos desta substância;

- Avaliar, por meio de ensaios de estímulo-resposta, as condições hidrodinâmicas dos sistemas;

- Avaliação da contribuição da macrófita aquática Typha latifolia no mecanismo de redução/retenção do poluente, por meio de ensaios em casa de vegetação;

- Aferir, por meio de análise de desempenho nutricional, a influência da adição da ametrina na sanidade da espécie vegetal utilizada;

- Verificar possíveis alterações morfo-anatômicas no vegetal após exposição a doses crescentes de ametrina;

- Predição da sustentabilidade do sistema, por meio de ensaios de toxicidade do herbicida em sementes da macrófita Typha latifolia. 



\section{CAPÍTULO 2}

ALAGADOS CONSTRUÍDOS PARA REMEDIAÇÃO DE ÁGUAS CONTAMINADAS COM PRAGUICIDAS: ESTADO DA ARTE 


\section{ALAGADOS CONSTRUÍDOS PARA REMEDIAÇÃO DE ÁGUAS CONTAMINADAS COM PRAGUICIDAS: ESTADO DA ARTE}

\section{RESUMO}

Sistemas alagados construídos (SACs) têm sido usados para o controle de poluição por cargas pontuais e difusas e o estado da arte sobre os principais fatores de influência no desempenho e operação desse tipo de sistema conta com vários trabalhos de revisão conceitual. Os poluentes agrícolas são importantes fontes de poluição difusa, sendo constituídos de nutrientes, praguicidas e sedimentos. Na literatura estão registrados estudos sobre o uso de SAC na remoção de praguicidas, mas o conhecimento sobre a eficácia desses sistemas e as formas de degradação desses poluentes é ainda limitado. A presente revisão descreve as aproximações usadas para a avaliação da mitigação de praguicidas em SACs, identifica as variáveis que afetam a retenção desses poluentes e avalia a necessidade de estudos futuros para a elucidação de mecanismos de transporte e destino de agroquímicos em unidades de tratamento cultivadas com macrófitas. A compilação de resultados de iniciativas de pesquisas com esse enfoque mostra que a eficácia de sistemas SACs tem sido avaliada com testes de toxicidade em macrófitas aquáticas, estudos com escoamentos simulados ou naturais e com aplicação direta. A magnitude dos processos de transformação e transferência dos praguicidas é função do tempo de residência dos poluentes nos SACs. O destino ambiental dos compostos depende de mecanismos bióticos e abióticos de retenção, das propriedades dos agroquímicos e das variáveis físicas e químicas no sistema de tratamento. A continuidade dos estudos na área contribuirá para o melhor entendimento dos mecanismos de retenção de agroquímicos em SACs. Ademais, experimentos de longo prazo são necessários para a avaliação do real potencial do uso de alagados construídos como faixas tampão na mitigação da contaminação de águas com praguicidas.

PALAVRAS-CHAVE: agroquímicos, alagados construídos, bioremediação, pesticidas sistemas naturais, terras úmidas. 


\section{CONSTRUCTED WETLANDS FOR REMEDIATION OF PESTICIDE-POLLUTED}

WATER: A REVIEW

\section{ABSTRACT}

Constructed wetlands (CW) have been used to control both punctual and diffuse pollution. The present state-of-the-art about the principal influence factors on performance and operation of these systems has several concept-reviews studies. The agricultural contaminants are important nonpoint source pollution (NPSP) being constituted of nutrients, pesticides and sediments. The literature presents studies about retention of pesticides in $\mathrm{CW}$ cells but the transfer and removal processes are not understood quite well. The aims of this article are to describe the approaches used for evaluating pesticide mitigation in CW, identify parameters that affect this pollutants retention in $\mathrm{CW}$, evaluate future research needs with the objective of to elucidate the fate and retention of agrochemicals in vegetated wetland cells. The compilation of the results of current research initiatives with this focus shows that the $\mathrm{CW}$ systems efficacy has been evaluated in macrophyte toxicity tests, simulated or natural runoff and direct application experiments. The magnitude of pesticides transformation and transfer process is function of pesticides' residence time on $\mathrm{CW}$. The compounds' environmental fate depends on biotics and abiotics retention mechanisms, agrochemicals properties and physical-chemicals parameters on treatment cell. The next studies will contribute to understanding the retention mechanisms on $\mathrm{CW}$ quit well. Moreover, long terms studies are necessary for the real potential evaluation of $\mathrm{CW}$ use as buffers strips on mitigation of contamination in pesticide-polluted waters.

KEYWORDS: agrochemicals, constructed wetlands, bioremediation, pesticides, natural systems, wetlands. 


\subsection{INTRODUÇÃO}

A água é um recurso essencial, seja como meio de vida para diferentes espécies, como componente bioquímico para os seres vivos, ou como fator de produção de diversos bens de consumo. Quando comparado aos outros componentes do meio físico, o ambiente aquático apresenta-se extremamente vulnerável a contaminações diversas, que podem ocorrer de forma pontual ou difusa.

Nas últimas décadas, atenção especial vem sendo dispensada às emissões não pontuais de cargas poluentes. Tais fontes, de difícil identificação e modelagem, são consideradas grandes responsáveis pela contaminação de corpos hídricos interiores. Segundo Kao, Wang e $\mathrm{Wu}$ (2001), as fontes difusas podem ser associadas principalmente à agricultura, ao escoamento pluvial urbano e à mineração.

Qualidade de corpos de água e atividades agrícolas são temas relacionados. Via de regra, a proximidade da produção agrícola de lagos, córregos e rios potencializa a contaminação desses sistemas aquáticos (Moore et al., 2001). Os poluentes agrícolas são importantes fontes de poluição difusa, sendo constituídos de nutrientes, sedimentos e praguicidas (Kao, Wang e Wu, 2001). Sabe-se que parte considerável dessas fontes está ligada ao uso intensivo e inapropriado dos praguicidas: substâncias organossintéticas formuladas para prevenir, combater ou controlar agentes indesejáveis ou nocivos, podendo ser, também, genericamente denominados agroquímicos, produtos fitossanitários, defensivos agrícolas, pesticidas ou biocidas e, particularmente, de fungicidas, herbicidas e inseticidas, de acordo com o mecanismo de ação e finalidade específicos. Atualmente, os agroquímicos são os insumos mais utilizados na produção agrícola em larga escala (Lavorenti, Prata e Regitano, 2003).

A principal forma de contaminação de águas superficiais por agroquímicos é o escoamento decorrente de precipitações pluviométricas em áreas agrícolas; no entanto estudos também têm considerado a contribuição direta para águas superficiais decorrentes de deriva (perda de praguicidas aplicados por pulverização) e de atividades especializadas, como lavagem de produtos agrícolas tratados com agroquímicos e viveiros de mudas para cultivo, por exemplo. Segundo Wauchope (1978), a perda de praguicidas via escoamento superficial pode atingir valores entre $0,5 \%$ e $5,0 \%$ do total aplicado. Estima-se que 5 milhões de toneladas de praguicidas sejam aplicados anualmente nas áreas agricultáveis do planeta (Chemical Information Services, 2005), com um potencial de perdas correspondendo a 
centenas de milhares de toneladas de ingredientes ativos. O Brasil aparece como o terceiro maior mercado no mundo, com um movimento previsto de US\$ 3,6 bilhões no ano de 2006, segundo a ABIQUIM (2006).

O uso de praguicidas no meio rural tem trazido uma série de conseqüências tanto para o ambiente como para a saúde do homem do campo. O quadro é agravado em países em desenvolvimento, onde é menor o nível sócio-econômico e cultural da grande maioria desses trabalhadores. Nesse sentido, constata-se a necessidade de adoção de tecnologias simplificadas de bioremediação de águas contaminadas com praguicidas. Sistemas naturais, como sistemas alagados construídos (SACs), apresentam a vantagem de usar energia primária do sistema substrato/planta/microrganismos/radiação, funcionando como reatores para a depuração dos resíduos e proporcionando um ganho ambiental com baixo custo (Shutes, 2001).

No presente capítulo, descreve-se o potencial do uso de SACs para remoção de praguicidas em águas contaminadas, compilando os resultados de iniciativas de pesquisas com enfoque na implementação dessa ecotecnologia, com o objetivo de melhor entender as formas de transporte e degradação desses agroquímicos.

\subsection{SISTEMAS ALAGADOS CONSTRUÍDOS}

O termo wetlands (terras úmidas) é usado para designar áreas de solo hidromórfico inundado ou saturado por águas superficiais/subterrâneas, onde crescem várias espécies vegetais que são diretamente dependentes da hidrologia, do meio suporte e dos nutrientes característicos da região onde se encontram (US EPA, 1988; Reed, 1993; Wood e McAtamney, 1996). As wetlands (pântanos, brejos, banhados, charcos) funcionam como área de retenção e remoção de alguns compostos químicos e como filtros transformadores ou reguladores de outros. Dentre as funções desses ambientes, cita-se a melhoria da qualidade da água, por meio do controle da poluição pontual ou difusa (Geary e Moore, 1999).

Um sistema alagado construído (SAC) age como um filtro biológico onde os responsáveis pela remoção de poluentes são mecanismos físicos e químicos, reações de degradação biológica aeróbia e anaeróbia, evapotranspiração e infiltração (Wood, 1995). Estes sistemas foram criados para controlar o tratamento e otimizar a habilidade dos sistemas 
de várzea (wetlands naturais) em remover ou transformar os poluentes contidos nos efluentes, além de criar ambiente favorável ao desenvolvimento da vida selvagem.

Vários relatos sugerem que chineses, romanos e gregos provavelmente usaram plantas aquáticas no tratamento de águas residuárias; são conhecidas também experiências com uso de SACs no fim do século 19, visando a descontaminação de águas de irrigação e de esgotos domésticos. No entanto, as primeiras tentativas de uso de alagados construídos reconhecidas cientificamente remotam à década de 1950, em investigações realizadas no Instituto Max Planck (Alemanha) por Käthe Seidel e colaboradores (Wood e McAtamney, 1994). Atualmente, são muitos os SACs implantados em escala plena, principalmente na América do Norte e na Europa, com diferenças conceituais quanto ao tipo de crescimento e fixação da vegetação e quanto ao regime de escoamento de água implementado (IWA, 2000; Vymazal, 1998, 2005). No Brasil, várias estações com diferentes concepções foram projetadas pelo grupo de trabalho do Instituto de Ecologia Aplicada de Piracicaba, São Paulo (Salati, 2003). Em relação às iniciativas de pesquisa, registram-se projetos em universidades como a UFSC, a UFV e a Unicamp, por exemplo.

A terminologia usada para as espécies vegetais adaptadas ao ambiente aquático é muito variada, sendo encontrados na literatura especializada termos como helófitas, hidrófilas, hidrófitas, limnófitas e outros. O termo macrófitas aquáticas, contudo, pode ser considerado de uso mais corrente e descreve a comunidade de plantas que crescem na água, em solos saturados ou alagados, independente do aspecto taxonômico. O termo engloba, portanto, macroalgas, angiospermas e até mesmo árvores de ciprestes. Segundo Brasil (2005) as plantas aquáticas vasculares florescentes são as espécies mais representativas nos SACs.

As plantas aquáticas usadas no tratamento de águas residuárias podem ser divididas em três grupos (Figura 2.1): (i) emergentes: sua folhagem principal está em contato com o ar e as suas raízes estão fixadas ao solo (Scirpus spp., Typha spp.); (ii) flutuantes: podem estar fixadas (Nymphaea spp.) ou não (Lemna spp.) ao fundo do leito, mas sua folhagem principal flutua na superfície da água e (iii) submergentes ou submersas: crescem sob a superfície, suspensas na coluna de água, podendo ou não estar fixas por raízes (Elodea spp., Najas spp.). $\mathrm{Na}$ Figura 2.2 podem ser visualizados desenhos esquemáticos referentes aos aspectos morfológicos das macrófitas supracitadas.

O leito (substrato) utilizado serve não só para fixar raízes de algumas espécies vegetais, mas também age como filtro na depuração de poluentes. Os materiais de uso mais recorrente são brita, cascalho, areia, argila, material orgânico e solo in natura. Registra-se 
também o uso de camadas superpostas (brita, pedrisco e solo cultivado com arroz) em um sistema conhecido como Depuração Hídrica com Solos (Salati, 2003) e agregados de argila expandida (Ramalho, Carvalho e Dordio; 2004 e Dordio et al., 2007). Geralmente, a escolha do material está condicionada às finalidades do tratamento proposto, sendo que os fatores a serem analisados são a viabilidade econômica, as condições de fluxo e o potencial reativo (Philippi e Sezerino, 2004).

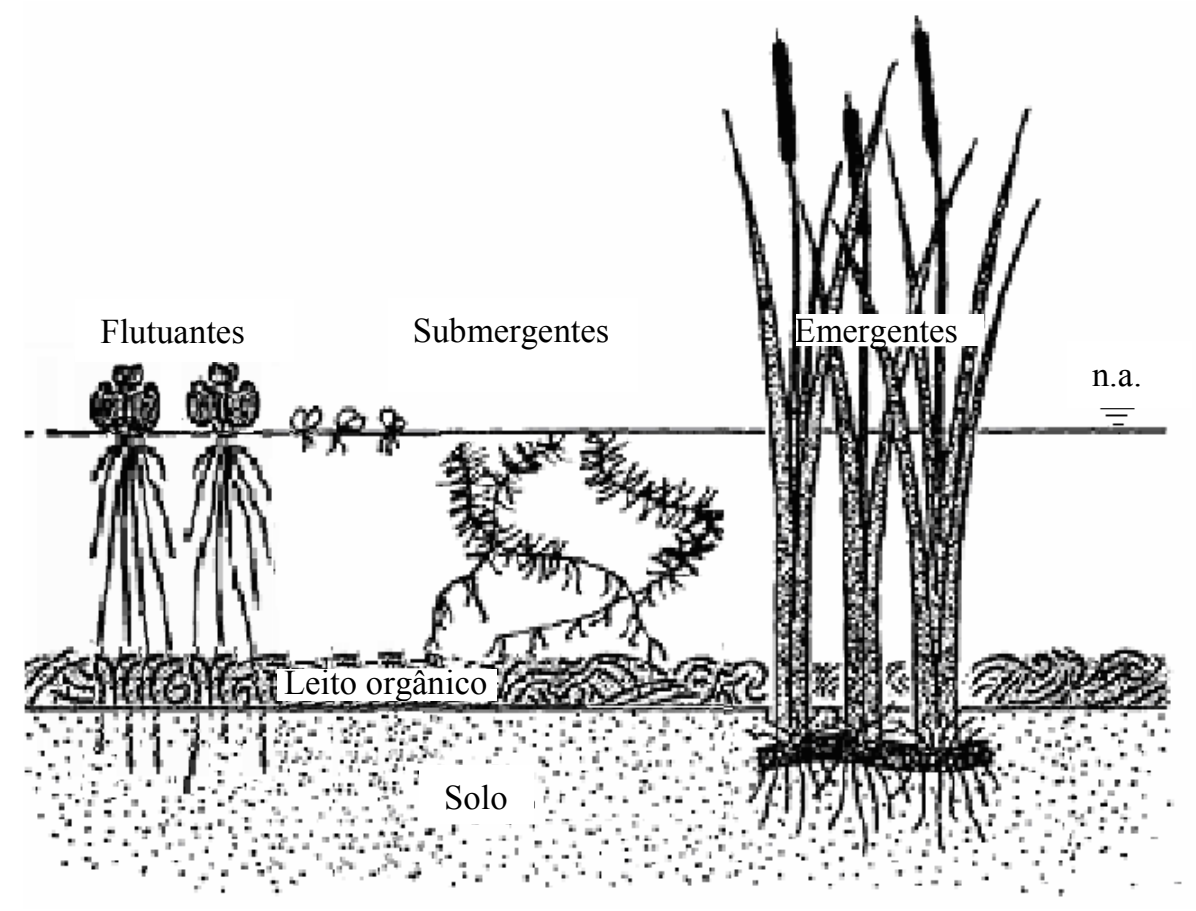

Figura 2.1 - Grupos ecológicos de macrófitas aquáticas (Adaptado de US EPA, 1988)

Não obstante as espécies de macrófitas utilizadas e o tipo de leito utilizados nos SACs, atualmente, considera-se que as principais diferenças entre os SACs se dão em função da forma de escoamento adotada. Assim, os SACs podem ser classificados em dois tipos principais:

(i) sistemas de escoamento sobre a superfície, com lâmina de água livre (free water surface constructed wetlands, FWS), que podem possuir várias espécies vegetais (convencional) ou serem projetados exclusivamente como lagoas de macrófitas flutuantes, as chamadas "lagoas de aguapés" (floating aquatic plants systems, FAP);

(ii) sistemas de escoamento subsuperficial (subsurface flow constructed wetlands, $\mathrm{SSF}$ ), nos quais o líquido residente escoa horizontalmente (mais comum) ou verticalmente (ascensional ou descendente), numa camada de substrato de alta porosidade. 

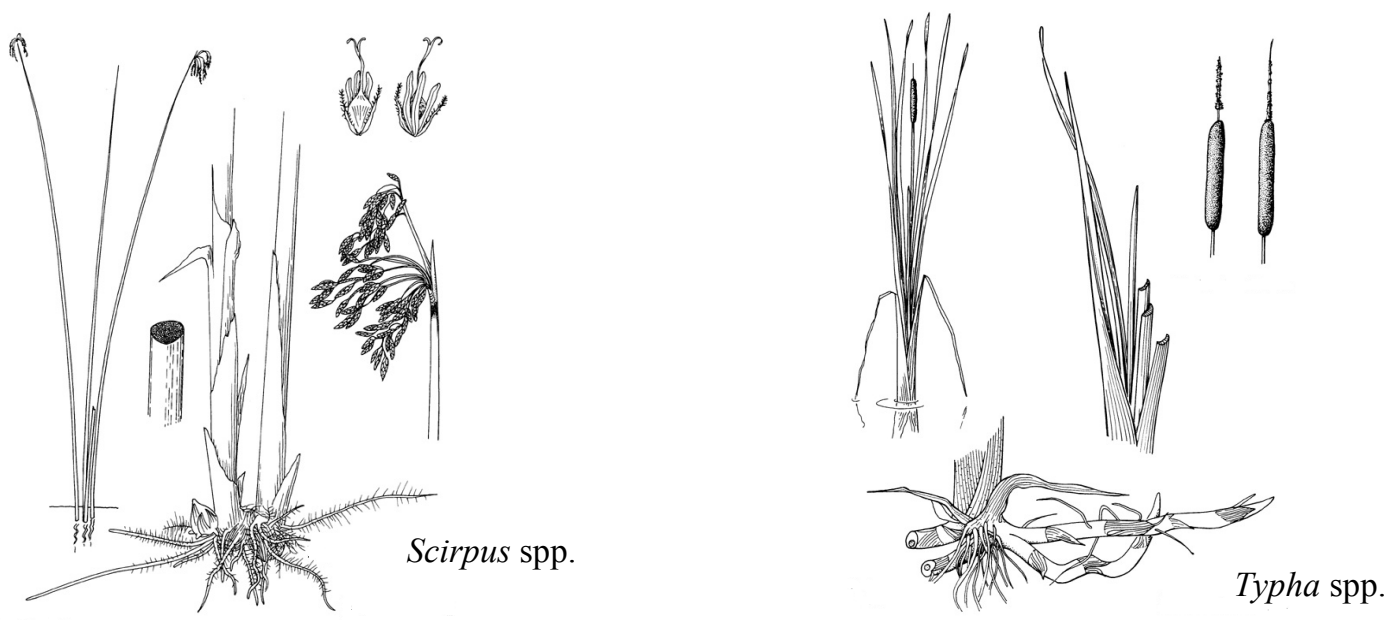

Nymphaea spp.
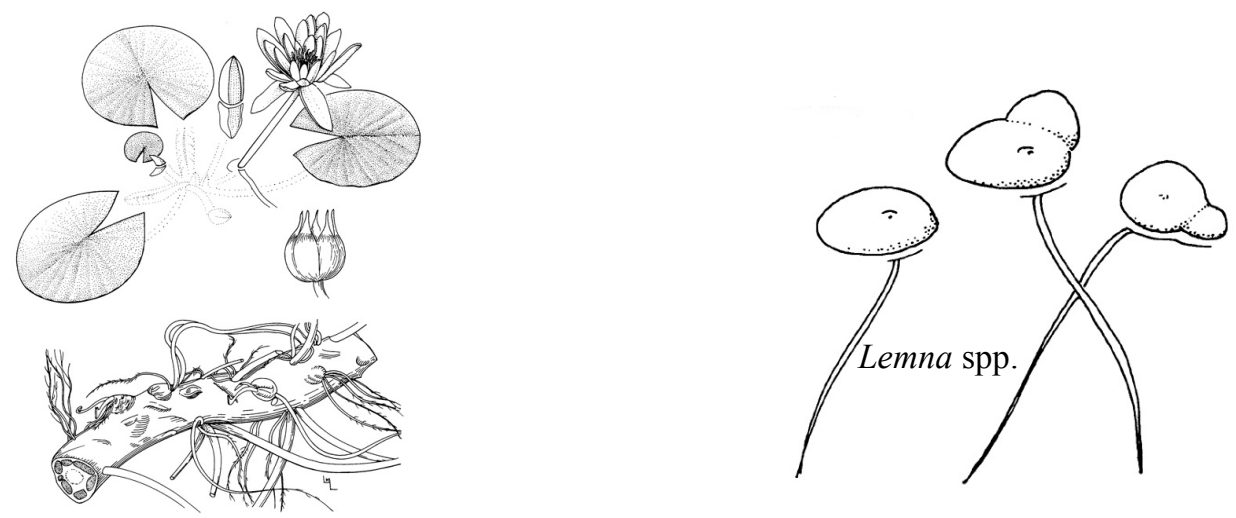

Elodea spp.
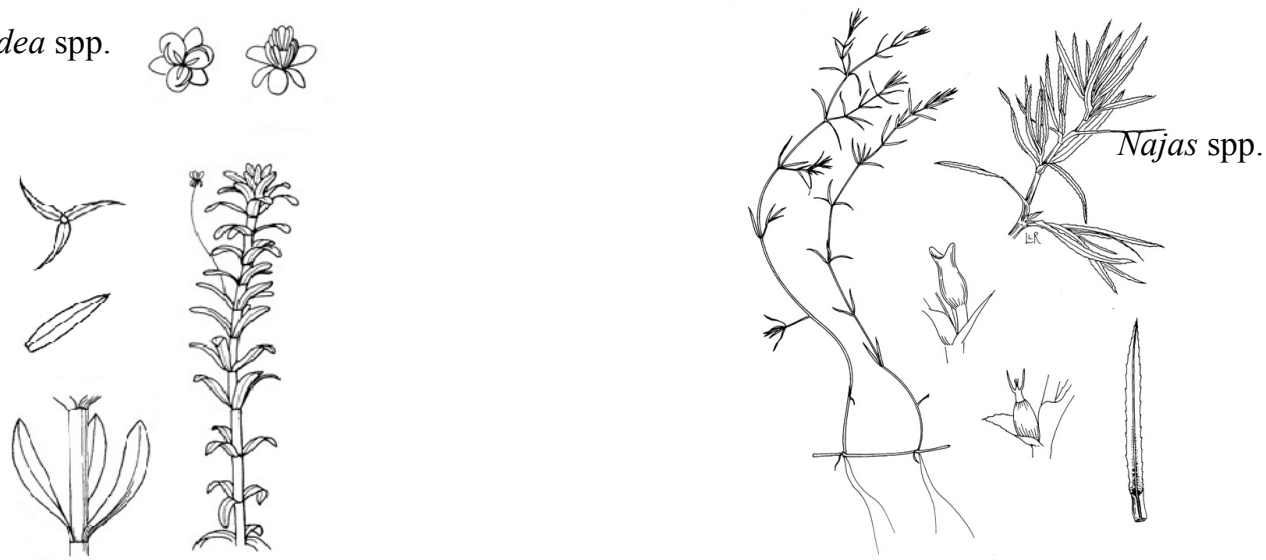

Figura 2.2 - Ilustrações esquemáticas referentes a aspectos morfológicos de macrófitas emergentes, flutuantes e submergentes (Fonte: IFAS, 1990) 
Na Figura 2.3, estão apresentadas ilustrações referentes aos sistemas mais empregados atualmente; em sistemas de escoamento vertical a grande maioria das experiências relatadas se utiliza da aplicação do líquido de forma descendente.

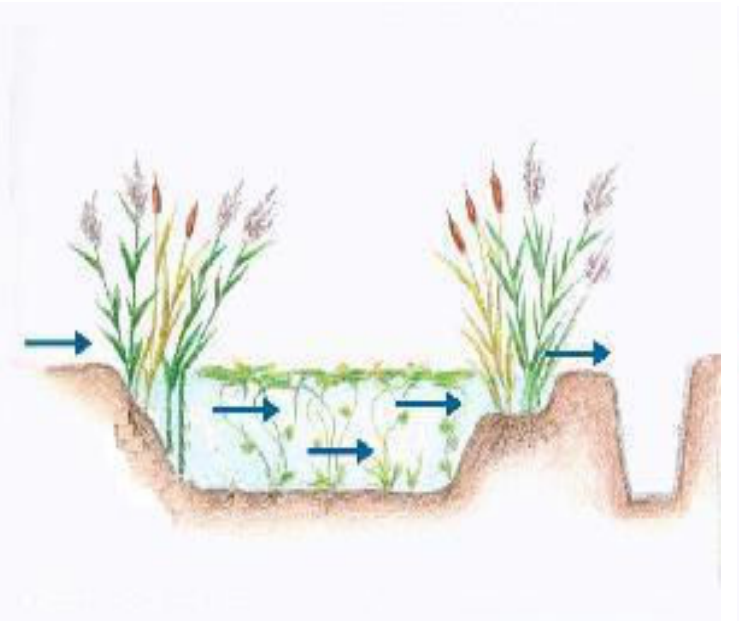

(a)

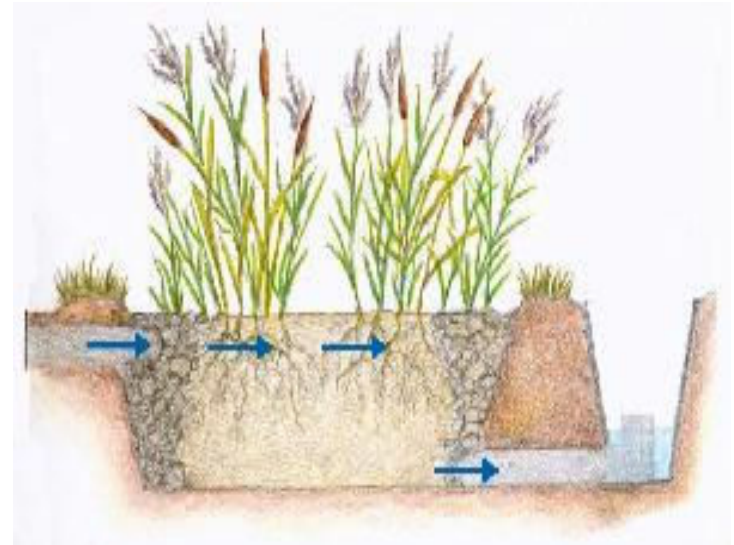

(c)

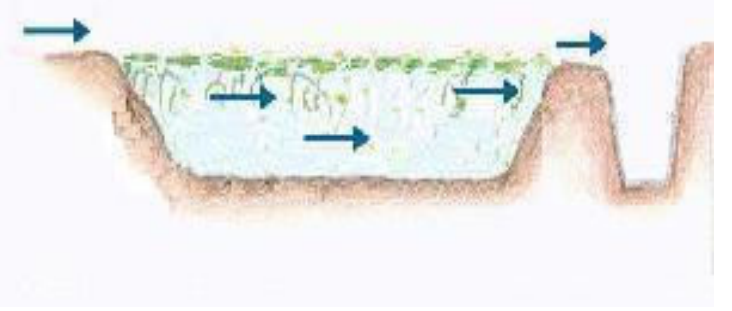

(b)

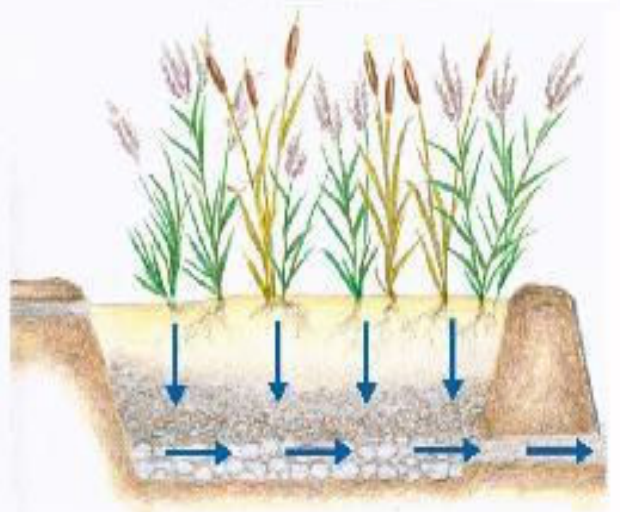

(d)

Figura 2.3 - Diagramas esquemáticos referentes a: (a) SAC de escoamento superficial; (b) lagoa de aguapés; (c) SAC de escoamento horizontal subsuperficial e (d) SAC de escoamento vertical (Adaptado de Kadlec, Wallace e Vymazal, 2004 e Iridra, 2006)

O estado da arte sobre os principais fatores de influência na operação e desempenho de SACs está apresentado em alguns handbooks e artigos de revisão conceitual e.g.: tipos de alagados construídos (Vymazal, 1998, 2001); fundamentos de projeto e operação (Wood, 1995; US EPA, 1988, 2000; ITRC, 2003; IWA, 2000); e revisões sobre a modelagem em 
SACs (Kadlec, 2000; Rousseau et al., 2004; Lautenschlager, 2001, Marshili-Libelli e Checchi, 2005).

Alguns pesquisadores enfocaram, recentemente, o potencial do uso desse sistema de tratamento em países em desenvolvimento dado suas inerentes vantagens de custo e simplicidade operacional (Denny, 1997; Haberl, 1999; Kivaisi, 2001). Já Cronk (1996); Knight et al. (2000), Hunt e Poach (2001) e Healy, Rodgers e Mulqueen (2007) compilaram dados de uso de SACs no tratamento de águas residuárias agroindustriais, como efluentes de processamento de laticínios, criação de gado de corte, suinoculturas, avícolas e tanques de aqüicultura.

Críticas ao tratamento de águas residuárias em SACs também são temas de alguns reviews como, por exemplo, a pesquisa feita por Helfield e Diamond (1997). Segundo os autores, os sistemas alagados construídos não devem ser usados com dupla finalidade melhoria na qualidade da água e recuperação do habitat aquático - uma vez que os riscos de biomagnificação de compostos tóxicos são significantes. Regmi, Thompson e Sievens (2003) e Mara (2005) citam que o componente vegetal (macrófitas) desse tipo de sistema somente desempenha funções significativas de remoção quando há de se estudar a mitigação de nitrogênio e fósforo. No entanto, Brix $(1997,1999)$ ressalta que além da melhoria da qualidade de água, os alagados vegetados apresentam outras funções importantes, como aspectos ecológicos e estéticos. A questão do papel das macrófitas é, portanto, polêmica, e foi também discutida por Guntenspergen, Seams e Kadlec (1988) e Koottatep e Polprasert (1997).

Percebe-se que o uso de SACs na redução de níveis de diversos compostos orgânicos e metálicos é bem difundido, no entanto a efetividade dos alagados construídos na remediação de praguicidas ainda não é suficientemente documentada (Schulz, 2004; Bouldin et al., 2006; Reichenberger et al., 2007). Isso se deve, em parte, ao fato de que esses poluentes e seus subprodutos são considerados tóxicos em níveis de detecção muito baixos. Ademais, existe a dificuldade na análise quantitativa desse tipo de substância (Runes et al., 2003). 


\subsection{MECANISMOS DE REMOÇÃO DE PRAGUICIDAS EM SISTEMAS ALAGADOS CONSTRUÍDOS}

\section{Influência dos componentes básicos dos sistemas alagados construídos}

O destino ambiental de um poluente em SACs é função da ocorrência de processos de remoção biológicos e não biológicos, que dependem das propriedades físico-químicas da molécula e de maneira direta ou indireta, dos componentes básicos de um SAC: (i) o solo; (ii) a hidráulica e (iii) a vegetação.

Os substratos utilizados para o suporte dos vegetais cultivados em um SAC proporcionam a formação de sítios, onde ocorrem as transformações químicas e bioquímicas, além de serem locais para acúmulo de poluentes removidos. Entre os meios suporte mais comumente utilizados em SACs cita-se o cascalho, o solo in natura e material orgânico (refugo de atividades agropecuárias).

O substrato adotado pode contribuir para a maior eficiência no processo. Propriedades como capacidade de troca catiônica, $\mathrm{pH}$, condutividade elétrica e teor de matéria orgânica interferem em mecanismos como precipitação, sorção e degradação biológica (Davis, 1995).

As condições hidrológicas são citadas por Davis (1995), pela IWA (2000) e pelo ITRC (2003) como fator chave no desempenho do processo. São os parâmetros hidráulicos e hidrológicos como carga hidráulica, evapotranspiração, infiltração e precipitação que irão definir os tempos de residência reais dos praguicidas no sistema. O tempo de permanência do poluente no SAC, por sua vez, influencia na ocorrência e magnitude dos mecanismos de transformação e transferência. Nesse sentido, ressalta-se a necessidade da avaliação das eficiências de remoção também em termos de cargas mássicas, pois nos SACs, as concentrações afluentes e efluentes $[\mathrm{M}]\left[\mathrm{L}^{-3}\right]$ variam muito de acordo com o balanço hidrológico.

Sem a vegetação, os SACs seriam variações de lagoas de estabilização (no caso de FWS) ou de filtros com meio suporte (no caso de SSF). Como citado anteriormente, o papel das macrófitas na remoção dos praguicidas vem sendo estudado e debatido nos últimos anos. A parte vegetativa desempenha funções diversas nos SACs, como provimento de sítios para o desenvolvimento de biofilme microbiano, agente facilitador da nitrificação/desnitrificação, fonte de novos sedimentos orgânicos, agente de remoção de nutrientes, de mitigação de 
efeitos de enchentes e de aumento da biodiversidade (aspectos ecológicos), além de promover melhoria na estética do sistema de tratamento (Brix 1997, 1999, Valentim, 2003).

Em virtude dessa configuração ambiental, presente em um ambiente alagado, processos de transporte/transformação/retenção poderão ocorrer de forma única, seqüencial ou simultânea, em cada tipo de contaminante ou espécie presente no SAC. Esses mecanismos podem ser abióticos (físico/químicos) ou bióticos (biológicos). Caso a transformação seja completa, dando origem a gás carbônico, água e íons minerais, emprega-se o termo mineralização; por outro lado, usa-se a expressão metabolização para a transformação parcial dos agroquímicos (Lavorenti, Prata e Regitano, 2003). Hidrocarbonetos em geral são potencialmente suscetíveis aos mecanismos de degradação típicos dos SACs. Todavia, existe pouca informação sobre esses processos em SACs remediando hidrocarbonetos mais estáveis, tais como praguicidas organoclorados (ITRC, 2003).

\section{Processos abióticos}

Uma vez aplicados, processos físicos e químicos de transformação poderão ocorrer com os praguicidas, seja no ambiente como um todo ou em SACs.

Os agroquímicos só sedimentarão ou serão filtrados se aderidos a material particulado, na forma de sólidos suspensos totais (SST). Nesse sentido, faz-se necessário avaliar a capacidade sortiva dos compostos ao material particulado em suspensão e aos substratos usados em SACs. Schulz et al. (2001) e Schulz e Peall (2001) relacionam eficiências de remoção de praguicidas com a diminuição da turbidez de um tributário do rio Lourens (África do Sul), após tratamento em uma wetland experimental.

O termo sorção é geralmente utilizado para descrever a retenção de moléculas de organossintéticos, englobando fenômenos de adsorção, absorção, precipitação e partição hidrofóbica (Lavorenti, Prata e Regitano, 2003). Dessa maneira, a sorção significa a “apreensão de um soluto por um constituinte do solo ou substrato sem indicar precisamente o mecanismo envolvido".

Ainda segundo Lavorenti, Prata e Regitano (2003), depois de sorvida, uma fração das moléculas pode retornar à solução do solo, em um processo conhecido como dessorção. Devido à maior área com sítios de sorção (presença de substrato), agroquímicos podem ser retidos em maior quantidade em SACs do tipo subsuperficial. De acordo com as definições 
acima (sorção/dessorção), fica clara a preocupação com a sustentabilidade do processo em um prazo maior de operação.

Dentre as reações químicas de transformação de praguicidas, cita-se a hidrólise como uma das mais importantes. Essa reação de quebra da molécula original depende da solubilidade do composto, sendo influenciada pelo potencial hidrogeniônico, temperatura e sorção do praguicida. A fotólise ou fotodegradação também é uma reação abiótica que depende de variáveis ambientais. Geralmente a luz atua como agente catalisador de outras reações químicas. Em SACs de escoamento livre, a fotólise deverá ser considerada devido à exposição do líquido residente à radiação solar.

A volatilização é outra rota de destino de algumas substâncias praguicidas. Quanto maior a pressão de vapor $(\mathrm{P})$ do composto, maior será o transporte nessa forma. De forma geral, segundo Lavorenti, Prata e Regitano (2003), praguicidas com valores de P maiores que $13 \mathrm{mPa}$ podem ser considerados voláteis.

\section{Processos bióticos}

Além das transformações físicas e químicas, processos biológicos contribuem para a remoção de praguicidas no meio. Os principais processos bióticos que ocorrem em SACs são a degradação biológica e a fitorremediação.

Grande parte das transformações bioquímicas ocorridas nos alagados é controlada pela população microbiana presente (Kadlec, Wallace e Vymazal, 2004). A degradação biológica de micropoluentes orgânicos pode ser verificada em locais com atividade microbiana intensa, como SACs. Segundo Williams (2002), a rizosfera expansiva das macrófitas proporciona o surgimento de uma zona enriquecida para que os micróbios se envolvam na degradação de compostos orgânicos. A estabilização pode se dar pela via oxidativa, por meio de organismos aeróbios e facultativos aderidos às raízes e rizomas das plantas e presentes no substrato, ou por via fermentativa, realizada por microrganismos anaeróbios presentes nos sítios de potencial de oxi-redução negativos.

Fitorremediação é o termo geral para definir a transformação/retenção de um poluente por plantas. Simplificadamente, os principais mecanismos envolvidos nesse processo são (Cunningham et al., 1996; Denardi et al., 2003; ITRC, 2003): 
(i) a fitoextração, que envolve a absorção dos contaminantes pelas raízes de plantas hiperacumuladoras, tais poluentes são nelas armazenados ou transportados e acumulados para as partes aéreas dos vegetais;

(ii) a fitoestabilização, na qual os poluentes são incorporados à lignina da parede vegetal ou ao húmus, sendo posteriormente incorporados a matriz do solo;

(iii) a fitodegradação, em que os contaminantes orgânicos são degradados ou mineralizados dentro das células vegetais por enzimas específicas, como nitroredutases, lacases e desalogenases, por exemplo;

(iv) a rizofiltração/rizodegradação, na qual há absorção, concentração ou precipitação de contaminantes pelo sistema radicular das plantas e

(v) a fitovolatilização/evapotranspiração, em que compostos orgânicos são absorvidos pelas raízes, convertidos em formas menos complexas e liberados na atmosfera.

\subsection{EXPERIMENTOS DE APLICAÇÃO DOS SACs NO TRATAMENTO DE PRAGUICIDAS}

\section{O estudo da mitigação dos efeitos de praguicidas em SACs}

Segundo Cooper e Moore (2003), para que os efeitos da contaminação por agroquímicos sejam mitigados, há de se prever a ocorrência da transferência (referente, mas não limitada à volatilização, solubilidade, vazão, retenção, sorção e infiltração) e da transformação (referente e também não limitada aos fenômenos de fotólise, oxidação, hidrólise e biotransformação). Faixas vegetadas (vegetative filter strips, VFS) têm sido avaliadas com essa finalidade, mas o uso de SACs vegetados com plantas aquáticas na remoção de praguicidas pode ser considerado recente (Schulz, 2004; Krutz et al., 2005; Bouldin et al., 2006).

Entre as contribuições para a implementação de SACs com a finalidade abordada, citase o trabalho de Rodgers e Dunn (1993). Os pesquisadores discutiram diretrizes para projeto de SACs na mitigação de praguicidas. Questões como seleção dos agroquímicos e de macrófitas, desenho experimental, simulação de escoamento e modelagem do transporte dos poluentes foram definidas como estrategicamente importantes para futuras investigações. 
Após mais de uma década, a literatura registra estudos com diferentes espécies de macrófitas aquáticas (Tabela 2.1) na remediação de praguicidas, cujas principais propriedades podem ser visualizadas na Tabela 2.2.

Tabela 2.1 - Principais plantas usadas em SACs para estudos de remediação de praguicidas

\begin{tabular}{|c|c|c|c|}
\hline \multirow[t]{2}{*}{ Nome científico } & \multicolumn{2}{|c|}{ Nome comum } & \multirow[t]{2}{*}{ Tipo } \\
\hline & Português & Inglês & \\
\hline Canna spp. & Cana do brejo & Canna lily & Emergente \\
\hline Cyperus spp. & Junça, junquinho & Sedge & Emergente \\
\hline Eichhornia spp. & Aguapé & Water hyacinth & Flutuante \\
\hline Eleocharis spp. & Junco manso & Spikerush & Emergente \\
\hline Elodea spp. & Elódea & Waterweed & Submergente \\
\hline Iris spp. & Íris, flor de lis & Flag iris & Emergente \\
\hline Juncus spp. & Junco & Rush & Emergente \\
\hline Leersia spp. & Grama do brejo & Cutgrass & Emergente \\
\hline Lemna spp. & Lentilha d'água & Duckweed & Flutuante \\
\hline Ludwigia spp. & Ludwígia, florzeiro & Water primrose & Emergente \\
\hline Lupinus spp. & Tremoçeiro & Lupine & Emergente \\
\hline Myriophyllum spp. & Pinheirinho & Parrot feather & Submergente \\
\hline Najas spp. & Najas & Naiads & Submergente \\
\hline Nymphaea spp. & Ninféia, Lírio d'água & Water lily & Flutuante \\
\hline Phragmites spp. & Carriço, caniço & Reed & Emergente \\
\hline Scirpus spp. & Navalha de mico & Bulrush & Emergente \\
\hline Typha spp. & Taboa & Cattail & Emergente \\
\hline Vetiveria spp. & Vetiver, patchuli & Vetiver grass & Emergente \\
\hline
\end{tabular}




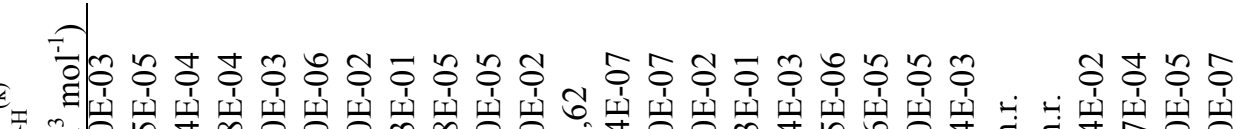
च हृ?

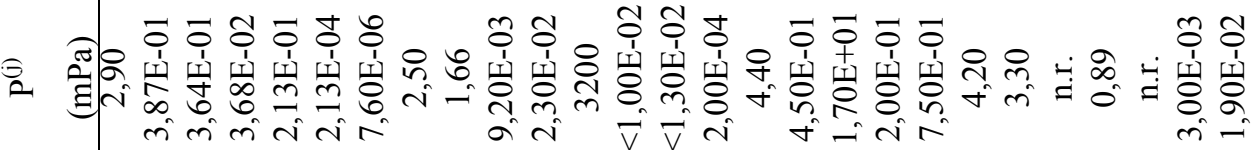

ஓ̊ำ

वंजितर

a $v \vec{v} \vec{v}+\vec{i}-$

(1)

$\Theta$

$\infty$

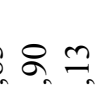

ใ. $\infty 8$

$\therefore$ 요요 8 : $8=$

$\ddot{\circ}$

궁

$\lesssim$

ஓ्ष̊

ن

$\ddot{\infty}$

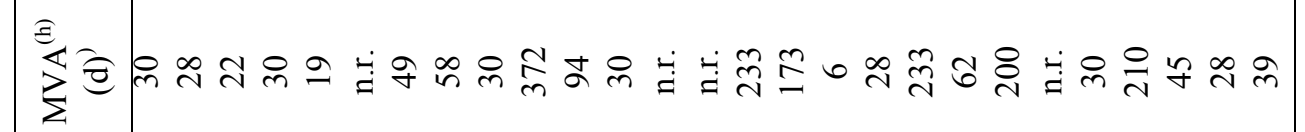

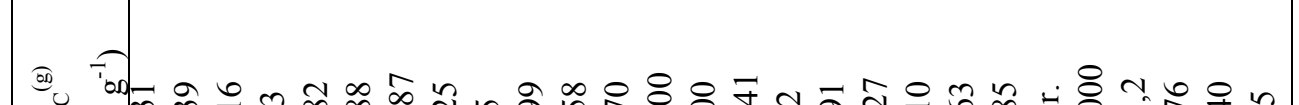

司

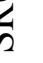

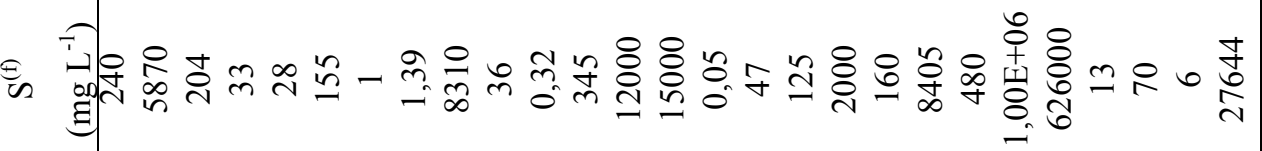

?ִ

胥

远

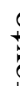

马

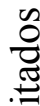

ర

.

êa

Ua Ua

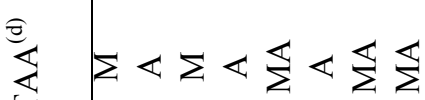

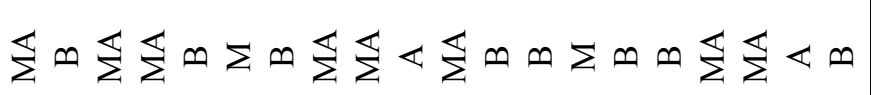

-

¿

.

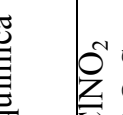

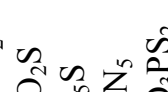

กี

药

$0_{n}^{\infty}$

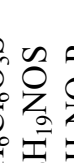

嫽

U

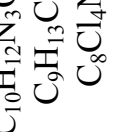

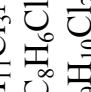


A eficácia de sistemas SACs na mitigação e transporte de agroquímicos pode ser predita por meio de aproximações distintas, tais como testes de toxicidade em macrófitas, estudos relativos a tratamento de águas contaminadas natural ou artificialmente e pesquisas com aplicação direta de praguicidas.

Nos testes de toxicidade, geralmente realizados em pequenos volumes (microcosmos) de águas contaminadas. são analisados os efeitos da aplicação de concentrações crescentes dos contaminantes sobre a sanidade das macrófitas. Nos estudos de campo, culturas são tratadas com praguicidas e a água contaminada, gerada com a lavagem das folhas e da superfície do solo é coletada e aplicada em SACs. Na aplicação direta, os compostos são adicionados aos SACs em cargas e concentrações conhecidas e controladas.

\section{Testes de toxicidade relacionados ao uso de SACs}

Os testes de toxicidade com praguicidas em macrófitas aquáticas são importantes uma vez que o sistema planta-microrganismos constitui o componente biológico dos SACs. Concentrações limitantes a fatores tais como o crescimento, a reprodução vegetativa e a atividade fotossintética, entre outros, são avaliadas nesses experimentos.

Segundo Boutin, Freemark e Keddy (1995), os testes são realizados submetendo-se os organismos a uma faixa de cinco concentrações em progressão geométrica; dessa forma são obtidas curvas de resposta às doses que identificam a concentração sem determinados efeitos observáveis (no observed effect concentration, NOEC), a menor concentração com efeitos observáveis (lowest observed effect concentration, LOEC) e concentrações com determinado efeito a uma fração dos organismos presentes (e.g. effect concentration affecting $50 \%$ of tested individuals, $\mathrm{EC}_{50}$ ). Além do trabalho citado (Boutin, Freemark e Keddy, 1995), são registrados outros importantes reviews sobre o assunto, elaborados por Wang (1991) e Lewis (1995).

É importante salientar que, em um ensaio de toxicidade, a finalidade é avaliar o comportamento do organismo submetido ao teste; no entanto vários são os estudos em que é feito um acompanhamento das mudanças nas concentrações dos princípios ativos com o decorrer do tempo. Dessa maneira, faz-se necessário registrar separadamente os testes no sentido estrito e os chamados ensaios em batelada.

Plantas flutuantes, como as macrófitas da família Lemnaceae, vêm sendo usadas mais intensamente em ensaios de toxicidade, com diferentes aspectos sendo abordados. Fairchild et 
al. (1997) avaliaram a toxicidade de vários herbicidas ao desenvolvimento da espécie Lemna minor, que pode ser usada nos sistemas FAP. Os resultados obtidos pelos pesquisadores, que também avaliaram os efeitos da exposição da alga Selenastrum capricornutum (muito usada em testes de toxicidade) aos compostos, estão sumarizados na Tabela 2.3.

Friesen-Pankratz et al. (2003) sugeriram que SACs com culturas com alta densidade de fitoplâncton podem vir a ser mais eficientes na remediação de praguicidas. Para tal conclusão, os autores monitoraram concentrações de clorofila $a$ em Selenastrum capricornutum, quando submetida aos praguicidas atrazina e lindano.

Quanto aos estudos com espécies emergentes vasculares, relatam-se pesquisas com as principais plantas usadas em SACs com escoamento subsuperficial: Typha spp., Juncus spp., Phragmites spp. e Scirpus spp.

Tabela 2.3 - Toxicidade de herbicidas ao ganho de biomassa para Lemna minor e Selenastrum capricornutum (Adaptado de Fairchild et al., 1997)

\begin{tabular}{|c|c|c|c|c|}
\hline \multirow[t]{2}{*}{ Herbicida } & \multicolumn{2}{|c|}{ Lemna minor } & \multicolumn{2}{|c|}{ Selenastrum capricornutum } \\
\hline & $\mathrm{NOEC}^{(\mathrm{a})}$ & $\mathrm{LOEC}^{(\mathrm{a})}$ & $\mathrm{NOEC}^{(\mathrm{a})}$ & $\mathrm{LOEC}^{(\mathrm{a})}$ \\
\hline Alacloro & 32 & 62 & 4 & 8 \\
\hline Atrazina & 75 & 150 & 75 & 150 \\
\hline Cianazina & 300 & 600 & 9 & 19 \\
\hline Dicamba & n.a. ${ }^{(b)}$ & n.a. (b) & 12500 & 25000 \\
\hline EPTC & 5000 & 10000 & $<6250$ & 6250 \\
\hline Metolacloro & 187 & 375 & 38 & 75 \\
\hline Simazina & 75 & 150 & 600 & 1200 \\
\hline $2,4-\mathrm{D}$ & n.a. ${ }^{(b)}$ & n.a. ${ }^{(b)}$ & 25000 & 50000 \\
\hline
\end{tabular}

Em experimentos aquosos de 7 dias de germinação e desenvolvimento de sementes de Typha latifolia submetidas à presença de atrazina e paraquat, Moore et al. (1999) observaram valores de NOEC de $0,1 \mathrm{mg} \mathrm{L}^{-1}$ (raízes) e $15 \mathrm{mg} \mathrm{L}^{-1}$ (brotos) para atrazina e NOEC's de 
$0,01 \mathrm{mg} \mathrm{L}^{-1}$ (raízes) e $0,1 \mathrm{mg} \mathrm{L}^{-1}$ (brotos) para exposição ao paraquat. Também estudando toxicidade em sementes, Garcinuño, Fernandez-Hernando e Camara (2003) verificaram que a Lupinus sp. pode acumular praguicidas a razões maiores que 5,2 $\mathrm{mg} \mathrm{g}^{-1}$ (massa de praguicida por massa seca de semente).

Langan e Hoagland (1996) expuseram brotos de Typha latifolia e Scirpus acutus à contaminação com atrazina. Os pesquisadores citam a importância da escolha da macrófita a ser usada nesses casos, uma vez que espécies diferentes podem não tolerar igualmente as doses de praguicidas. Nesse estudo, observou-se que após o monitoramento do crescimento das plantas em 16 semanas, a taboa foi a espécie mais robusta; contudo ressalta-se que os efeitos da exposição em campos naturais, mesmo que em curto prazo são desconhecidos.

Wilson, Whitwell e Klaine (2000) estudaram a tolerância da taboa (Typha latifolia) à exposição à simazina e metalaxil. No entanto, exemplares adultos, e não sementes, foram usados na pesquisa. A menor concentração com efeitos observáveis para a simazina foi de $1 \mathrm{mg} \mathrm{L}{ }^{-1}$, valor semelhante ao reportado pelos mesmos autores em testes com Canna sp. (Wilson, Whitwell e Klaine, 2001). Os autores concluíram que o uso da Typha latifolia na fitoremediação de simazina e metalaxil é promissor, no entanto aspectos relacionados a concentrações limitantes para a sanidade da espécie devem ser considerados.

Usando Canna sp. Myriophyllum aquaticum, plantas ornamentais de SACs e o herbicida simazina, Knuteson, Whitwell e Klaine (2002) estudaram a influência da idade e do tamanho das macrófitas na remoção do poluente. Com a realização do estudo se concluiu que as plantas usadas são mais sensíveis à toxicidade da simazina, logo após a emergência.

Lytle e Lytle $(2002,2005)$ observaram que a atrazina (herbicida) pode afetar o crescimento do junco (Juncus effusus) em concentrações típicas de escoamentos em áreas agrícolas e também em misturas com outros praguicidas, tais como o inseticida clorpirifós. Diminuição na contagem e no tamanho dos brotos, precedidas por observações, como ausência de novas raízes, foram alguns dos efeitos negativos relatados.

Registram-se também ensaios realizados em batelada, nos quais concentrações conhecidas e controladas de praguicidas são aplicadas em um pequeno SAC; posteriormente avalia-se tanto o efeito nas macrófitas usadas quanto o destino e transporte das quantidades adicionadas do composto.

Wolverton e Harrison (1973) verificaram, em laboratório, remoção de mevinfós na presença de macrófitas emergentes. Após 2 semanas, as concentrações do inseticida foram 
reduzidas a níveis não tóxicos; por outro lado, os tratamentos testemunha (não vegetados) continuavam apresentando toxicidade à fauna aquática (peixes), mesmo após 5 semanas de observação. Wolverton, trabalhando em um projeto com a agência espacial americana (NASA), introduziu os SACs de escoamento subsuperficial nos Estados Unidos (na América do Norte o sistema de escoamento livre é mais difundido); portanto, o ensaio em batelada citado (Wolverton e Harrison, 1973) pode ser considerado como precursor dos estudos atuais de mitigação de agroquímicos em SACs.

Cull et al. (2000) observaram a potencialidade do uso da gramínea vetiver (Vetiver zizanioides) na tolerância a concentrações de atrazina e diurom em relação a Phragmites australis. No experimento realizado em casa de vegetação, verificou-se que a vetiver mostrou-se resistente a concentrações na ordem de $2 \mathrm{mg} \mathrm{L}^{-1}$, níveis raramente encontrados no meio ambiente.

Enfocando a degradação da atrazina, Runes et al. (2001) usaram pequenas unidades de tratamento de 256 L. Os autores sugeriram que a absorção da atrazina pela macrófita usada ( $T$. latifolia) tenha contribuído para a diminuição dos níveis do produto; no entanto os resultados indicaram que o sedimento é um componente muito importante no sistema. Em outro estudo Runes, Jenkins e Bottomley (2001) verificaram que a adição de sedimento contendo microrganismos adaptados à degradação do composto, chamada de "bioaumento", se mostrou eficiente para melhoria no desempenho das unidades, que não apresentaram quantidades detectáveis de atrazina e seus metabólitos mais comuns em 30 dias.

Kao, Wang e Wu (2001) compararam SACs em microcosmos aeróbios e anaeróbios. Os resultados apontaram que, nas condições anaeróbias, a remoção de atrazina é mais efetiva (99\%) e que via de regra, um substrato primário (no caso do experimento, sacarose) é necessário para maior biodegradação do herbicida.

A remoção de MCPA em unidades cultivadas com taboa foi estudada por Ramalho, Carvalho e Dordio (2004) que, em experimentos em batelada, verificaram aumento na tolerância da planta de $1 \mathrm{mg} \mathrm{L}^{-1}$ para $5 \mathrm{mg} \mathrm{L}^{-1}$ com o uso de uma argila expandida como substrato nos SACs. Sherrard et al. (2004) realizaram ensaios do mesmo tipo em unidades de $250 \mathrm{~L}$ de capacidade, preenchidas com soluções de clorotalonil $\left(296 \mu \mathrm{g} \mathrm{L}{ }^{-1}\right)$ e clorpirifós $\left(19,4 \mu \mathrm{g} \mathrm{L}^{-1}\right)$, cultivadas com Scirpus cyperinus tendo obtido redução de $98 \%$ e 100\%, respectivamente, na toxicidade às espécies sentinelas (Ceriodaphnia dubia e Pimephales promelas). 
Bouldin et al. (2006) investigaram rotas de seqüestro dos praguicidas atrazina e lambda cialotrina por meio de hidroponia, em microcosmos. As plantas usadas foram Juncus effusus e Ludwigia peploides. Observou-se a distribuição da atrazina nas raízes e partes aéreas das plantas; já o piretróide lambda cialotrina ficou retido preponderantemente nas raízes das macrófitas.

Reinhold e Saunders (2006) estudaram a mitigação de agroquímicos fluorados por macrófitas e citaram que mesmo com a dificuldade de predição das velocidades (taxas) de absorção, pode-se afirmar que as plantas aquáticas exercem papel importante na fitoremediação de praguicidas em águas superficiais.

Consultando a literatura disponível, observa-se que a capacidade suporte de um SAC pode ser prevista por meio de testes de toxicidade. Contudo, a opção por SACs com várias espécies de plantas e a possibilidade de adição de misturas de compostos agroquímicos nas unidades de tratamento podem ser citados como fatores a serem ponderados.

A necessidade da comparação dos resultados dos testes nos variados estágios de desenvolvimento das espécies a serem usadas também deve ser ressaltada: a definição de doses tóxicas a germinação de sementes, crescimento de raízes, propagação de mudas ou crescimento de plantas adultas torna-se uma questão importante para a implementação dos alagados construídos na remoção de praguicidas.

\section{Remoção de praguicidas em mesocosmos}

As pesquisas em que a água contaminada com praguicidas é obtida por meio de escoamento superficial são as que mais se aproximam das condições que ocorrem no meio ambiente. Nesse tipo de aproximação, a forma de obtenção da água contaminada pode ser natural (eventos de precipitação na região) ou simulada, por meio da qual doses do praguicida são aplicadas em área conhecida e, por meio de uma chuva artificial, obtém-se o escoamento superficial contendo o praguicidas dissolvido em água e, ou adsorvidos aos sedimentos transportados. Schulz (2004) ressaltou que a contaminação de águas superficiais com a deriva de pulverizações com praguicidas também deve ser considerada e avaliada.

Baseada nas indicações feitas no estudo de Rodgers e Dunn (1992), Darby (1995) avaliou o transporte do inseticida clorpirifós em SACs de escoamento superficial verificando que a maior parte do composto foi adsorvida no início das unidades experimentais. 
Moore et al. (2000, 2001, 2002a), expandindo o estudo de Darby, usaram as mesmas unidades construídas na Universidade do Mississipi para pesquisas com o escoamento simulado de vários praguicidas. Após a aplicação dos produtos no ponto afluente de cada SAC, uma chuva simulada com "intensidade" de $12,6 \mathrm{~L} \mathrm{~s}^{-1}$ foi iniciada. O volume total de água adicionado correspondia a, aproximadamente, 3 vezes o volume de cada unidade. Amostragens espaciais e temporais foram realizadas para possibilitar estimativa do comprimento ótimo de SACs.

Considerando casos extremos de escoamento entre $0,5 \%$ e $5 \%$, observou-se que a contaminação com atrazina a concentrações iniciais de 73 e $147 \mu \mathrm{g} \mathrm{L}^{-1}$ demandariam células de SAC com comprimento entre 100 e 280 metros para a mitigação de seus efeitos. Quando se adicionou metolacloro, um herbicida da classe cloroacetanilida, os valores para as faixastampão variariam entre 100 e 400 metros.

Mesmo com a constatação da possibilidade de remoção de níveis diversos dos praguicidas, os estudos supracitados não previram a instalação de unidades controle, sem a presença de vegetação. Tal limitação foi corrigida por Schulz et al. (2003a, 2003b) e Milam et al.(2004), que verificaram melhor desempenho de unidades vegetadas, quando comparadas com o controle.

Recentemente Moore et al. (2006) também constataram que células cultivadas são comparativamente mais efetivas na mitigação do herbicida paration metílico do que leitos não cultivados. No estudo foram usadas 4 células de $50 \mathrm{~m}$ por $5,5 \mathrm{~m}$ com $0,2 \mathrm{~m}$ de profundidade. $\mathrm{Na}$ presença das macrófitas Juncus effusus e Leersia oryzoides houve maior rapidez na separação da massa adicionada da coluna de água para o sedimento e para as plantas; o que indica a necessidade de uma faixa-tampão menor, o que foi comprovado na estimativa do tempo de meia vida do praguicida nas células, que foi equivalente a 2,84 dias para células vegetadas e 7,80 dias para as células controle. No entanto cabe ressaltar que quando estudado o transporte do praguicida diazinon (Moore et al., 2007), o papel das macrófitas aquáticas não foi bem evidenciado.

A potencialidade de SACs reduzirem concentrações e conseqüentemente toxicidade de praguicidas também foi verificada em escala maior. Moore et al. (2002b) monitoraram, paralelamente, a remoção de clorpirifós nas unidades-controle no Mississipi (EUA) e a toxicidade (usando Chironomus tentans) de concentrações efluentes de um SAC construído na África do Sul. Verificou-se que, se construídas com comprimento suficiente, SACs podem 
proporcionar diminuição na toxicidade aguda aquática em águas contaminadas com praguicidas.

Paralelamente, Ralf Schulz e colaboradores conduzem pesquisas, estudando o transporte e redução dos níveis de inseticidas aplicados em pomares na bacia do Rio Lourens, África do Sul. A aplicação de clorpirifós e azinfós metílico é feita com pulverização e os estudos são realizados em um SAC de escoamento superficial $\left(4400 \mathrm{~m}^{2}\right)$, construído com o objetivo inicial de reduzir o aporte de sólidos suspensos no rio.

A toxicidade dos praguicidas citados foi verificada em estudo prévio, efetuado no local por Liess e Schulz (1999), tendo se concluído que escoamentos agrícolas, devido à ocorrência de eventos extremos de chuva, contribuíram para mudanças na comunidade de macroinvertebrados no rio em estudo. Para melhor avaliação da efetiva mitigação dos poluentes, testes com organismos-sentinela têm sido realizados. Os resultados obtidos indicam maior índice de sobrevivência dos organismos-teste em locais a jusante do SAC, quando comparados aos valores obtidos a montante do sistema (Schulz et al., 2001, 2003a, 2003b, 2003c; Schulz e Peall, 2001).

Em estudos de campo, Braskerud e Haarstad (2003), Haarstad e Braskerud (2005), Blankenberg, Braskerud e Haarstad (2006) e Blankenberg, Haarstad e Braskerud (2007) verificaram a retenção de diversos praguicidas em alagados construídos situados em uma bacia hidrográfica agricultável de $220000 \mathrm{~m}^{2}$, na Noruega. Mesmo com a perda dos compostos na área aplicada, a diminuição das concentrações de pico nas SACs foi observada. Considerações sobre as áreas necessárias de alagados construídos de escoamento superficial e sobre a influência de fatores como condutividade hidráulica, temperatura, potencial redox, índice de polaridade foram levantadas; no entanto, somente o índice de meia vida apresentou significância estatística na predição da retenção dos compostos aplicados.

Rose et al. (2006) monitoraram a redução nas concentrações de quatro praguicidas aplicados em uma fazenda que cultivava algodão, em um sistema lagoa de estabilização/lagoa vegetada, na Austrália. As reduções mais significativas ocorreram na região vegetada com macrófitas. As taxas adsorvidas ao sedimento também foram monitoradas e os autores reiteram as afirmações de Alvord e Kadlec (1996), de que a obtenção de dados relativos à sorção dos produtos nas macrófitas e no biofilme são importantes para o modelagem do processo em SACs.

Pesquisas sobre a remoção de herbicidas usados em viveiros de mudas também são relatadas. Runes et al. (2003) verificaram a remoção da atrazina e seus metabólitos contidos 
nesses escoamentos. Os valores de eficiência alcançados ( $\tau$ de 7 dias) se situaram na ordem de $20 \%$. Foi observada nos SACs de escoamento superficial uma baixa densidade de microrganismos potencialmente mineralizadores da cadeia etílica do agroquímico.

Também estudando a mitigação de escoamentos contaminados de viveiros, George et al. (2003) e Stearman et al. (2003) avaliaram células de alagados construídos de escoamento subsuperficial (dimensões de 1,2 $\mathrm{m}$ por $4,9 \mathrm{~m}$ ou $2,4 \mathrm{~m}$ por $4,9 \mathrm{~m}$ e profundidade $30 \mathrm{~cm}$ ou $45 \mathrm{~cm}$ ) que coletavam o escoamento superficial de uma área de $465 \mathrm{~m}^{2}$ de leito de cascalho para acondicionamento de mudas em Baxter, Estados Unidos. Durante o período de dois anos, as wetlands vegetadas com Scirpus validus removeram $82,4 \%$ de metolacloro e $77,1 \%$ de simazina, enquanto os valores registrados nas células não vegetadas foram de 63,2\% e 64,3\%, respectivamente. Os autores concluíram que a presença de macrófitas e a implementação de tempos de residência hidráulica maiores (cinco dias) influenciaram positivamente na remoção dos herbicidas.

Embora a aplicação de água de escoamento superficial seja mais comum, registra-se a adição controlada de praguicidas em SACs, que é proporcionada pelo armazenamento de águas com concentração conhecida em tanques reservatórios situados à montante dos sistemas. Para que isso seja possível, quantidades conhecidas dos praguicidas devem ser adicionadas aos sistemas em estudo. Como vantagem da adoção dessa metodologia, cita-se o maior controle das variáveis operacionais do sistema, tais como vazão aplicada, concentração afluente e controle sobre a forma (dissolvida ou suspensa) de transporte do praguicida.

McKinlay e Kasperek (1999) observaram a descontaminação de água poluída por atrazina em SACs de escoamento subsuperficial, investigando quatro espécies de macrófitas: Schoenoplectus lacustris, Typha latifolia, Iris pseudacorus e Phragmites australis. Foram adicionadas concentrações do herbicida na ordem de $6 \sim 7 \mathrm{mg} \mathrm{L}^{-1}$ e, como resultado, observou-se decréscimo no tempo limite de detecção de 32 para 7 dias. A tolerância das plantas às aplicações foi variável, entretanto, os pesquisadores concluíram que, de uma forma geral, a remoção de herbicidas por macrófitas é uma técnica simples, não onerosa e viável para promover a descontaminação da água.

Cheng et al. (2002) verificaram redução nas concentrações aplicadas dos inseticidas paration e ometoato ( $2 \mu \mathrm{g} \mathrm{L}^{-1}$ e $60 \mu \mathrm{g} \mathrm{L}^{-1}$, respectivamente) até valores menores que os limites de detecção dessas substâncias. Em contrapartida, as reduções nos níveis dos herbicidas MCPA e de dicamba não foram satisfatórias no tipo de sistema estudado (SACs com escoamento vertical usado em tratamento de aplicações seqüenciais de agroquímicos). 
Matadoros et al. (2007) verificaram que os principais grupos químicos de praguicidas apresentam comportamento diferente, quando tratados em SACs de escoamento subsuperficial. Observaram-se remoções maiores que 90\% para o inseticida organoclorado lindano e, por outro lado, constatou-se que o herbicida diurom (à base de uréia) comportou-se como recalcitrante. Levando-se em conta que houve reduzido acúmulo dos contaminantes no substrato (leito de brita), a biodegradação e a absorção pela planta (Phragmites australis) foram, segundo os autores, os mecanismos mais importantes na redução dos compostos estudados na água contaminada.

A aplicação de praguicidas em SACs, feita de forma controlada, deve ser melhor estudada, pois com o maior domínio sobre as variáveis intervenientes, os mecanismos de transporte e o destino desses produtos no sistema terão de ser melhor entendidos. Ademais, segundo Krutz et al. (2005), essa rotina operacional pode ser útil no desenvolvimento de modelos matemáticos desenvolvidos para predizer o comportamento de praguicidas presentes em águas de escoamento em áreas agrícolas.

\subsection{CONSIDERAÇÕES FUTURAS}

Rodgers e Dunn (1993) sugeriram que algumas hipóteses fossem testadas para a verificação da possibilidade do uso de SACs na mitigação de efeitos da contaminação com praguicidas. Mesmo com os avanços nesse campo de estudo, algumas recomendações permanecem atuais:

(i) O papel da vegetação usada nos SACs deve ser ressaltado. O uso de sistemas multi-espécies e recomendações sobre o controle das macrófitas e da sucessão ecológica nos sistemas são temas a serem estudados.

(ii) A sorção e dessorção dos praguicidas nos substratos ou sedimentos é questão crucial. Os compostos permanecem biodisponíveis ou bioativos? Quais procedimentos devem ser adotados em longo prazo?

(iii) Atenção especial deve ser dispensada nos estudos aos parâmetros de projeto, com vistas à definição de valores como carga de aporte máxima e velocidade de degradação de praguicidas. 
(iv) Pouco se sabe sobre os custos de manutenção dos sistemas. A rotina de operação dos sistemas deve ser compatível com as práticas rotineiras na agricultura.

(v) As investigações devem continuar no sentido de se verificar a sustentabilidade dessa prática. A implantação de programas de monitoramento contínuo e de longo prazo e a comparação do desempenho de SACs recentes e antigos são alguns dos tópicos a serem abordados.

Williams (2002) e Schulz (2004) enfatizaram o pequeno número de estudos de campo realizados. Os resultados promissores obtidos em microcosmos devem ser validados com pesquisas realizadas em maior escala. Schulz (2004) também citou a necessidade de se quantificar aporte de praguicidas proporcionados por deriva, e não somente aqueles associados ao escoamento superficial.

Mais investigações são necessárias para que melhor se entenda os mecanismos relevantes no destino de praguicidas em SACs. Dados como comprimentos de faixa-tampão e possível reutilização da vegetação e da água poderão ser obtidos caso haja continuidade nos estudos relativos à essa área do conhecimento.

\subsection{SUMÁRIO}

Com a revisão da literatura apresentada verifica-se o potencial do uso de SACs para a remoção de praguicidas em águas contaminadas. Necessidades de investigações futuras foram abordadas e algumas observações podem ser ratificadas.

O destino dos praguicidas aplicados em SACs depende de mecanismos bióticos e abióticos de retenção, das propriedades físico-químicas dos compostos e das variáveis ambientais (solo e água) nesses sistemas. Do tempo de residência do poluente (função da hidrodinâmica e do tamanho do SAC), depende a magnitude dos processos de transformação e transferência.

A mitigação dos efeitos da contaminação de corpos hídricos com agroquímicos tem sido avaliada por meio de testes de toxicidade, escoamento natural ou simulado e aplicação direta dos compostos. Tais estratégias se diferenciam em relação a aspectos como tamanho (escala), controle das variáveis experimentais no sistema e reprodutibilidade dos fenômenos 
que acontecem no meio ambiente. Todas as aproximações usadas são necessárias para o avanço das pesquisas sobre o tema. Os resultados obtidos se complementam no objetivo de melhor compreensão dos mecanismos de retenção de praguicidas que ocorrem em SACs. Todavia, generalizações dentro e entre os sistemas devem ser evitadas devido à heterogeneidade observada entre os tipos de SACs.

O substrato utilizado e as condições hidrodinâmicas são componentes básicos desse tipo de sistema e influenciam sobremaneira os mecanismos de retenção. O tipo de vegetação estabelecida poderá afetar a retenção de praguicidas, espécies diferentes têm habilidades distintas em promover extração, estabilização, degradação, filtração ou volatilização dos poluentes. A melhor distinção entre esses diferentes processos próprios da parte vegetativa pode ser feita nos ensaios em batelada.

A atividade microbiana é mais intensa em células vegetadas, devido à maior presença de microrganismos. A atividade enzimática no substrato também se mostra mais elevada e de maneira geral, os SACs colonizados com macrófitas são mais eficientes que as unidadescontrole. Ressalta-se que se deve avaliar a retenção de praguicidas em termos de massa, devido à influência do regime hidrológico (chuvas e evapotranspiração, principalmente) nos valores de concentração dos compostos na água em tratamento.

Embora os dados obtidos até o momento indiquem o potencial dos SACs em reduzir o transporte de praguicidas para corpos receptores, dois fatores devem ser considerados para a melhor aceitação desses sistemas de fitorremediação: (i) a necessidade de obtenção de remoções contínuas dos contaminantes em escalas maiores e (ii) a observação do comportamento dos SACs em maiores períodos de tempo, com o objetivo de melhor compreensão de todos os processos, avaliação das condições operacionais e de manutenção e, principalmente verificação da sustentabilidade das propostas em longo prazo. 


\subsection{REFERÊNCIAS BIBLIOGRÁFICAS}

\section{ABIQUIM [ASSOCIAÇÃO BRASILEIRA DA INDÚSTRIA QUÍMICA]. A indústria} química: estatísticas. 2006. Disponível em: $<\mathrm{http}$ ://www.abiquim.org.br $>$. Acesso em 15 ago. 2007.

ALVORD, H. H.; KADLEC, R. H. Atrazine fate and transport in the Des Plaines wetlands. Ecological Modelling, Amsterdam, v.90, n.1, p.1465-1475, 1996.

BLANKENBERG, A. G. B.; BRASKERUD, B. C.; HAARSTAD, K. Pesticide retention in two small constructed wetlands: treating non-point source pollution from agriculture runoff. International Journal of Environmental Analytical Chemistry, Abingdon, v.86, n.3-4, p.225-231, 2006.

BLANKENBERG, A. G. B.; HAARSTAD, K.; BRASKERUD, B. C. Pesticide retention in an experimental wetland treating non-point source pollution from agriculture runoff. Water Science and Technology, Londres, v.55, n.3, p.37-44, 2007.

BOULDIN, J. L. et al. Hydroponic uptake of atrazine and lambda-cyhalothrin in Juncus effusus and Ludwigia peploides. Chemosphere, Oxford, v.65, n.6, p.1049-1057, 2006.

BOUTIN, C.; FREEMARK, K. E.; KEDDY, C. J. Overview and rationale for developing regulatory guidelines for nontarget plant testing with chemical pesticides. Environmental Toxicology and Chemistry, Pensacola, v.14, n.9, p.1465-1475, 1995.

BRASKERUD, B. C.; HAARSTAD, K. Screening the retention of thirteen pesticides in a small constructed wetland. Water Science and Technology, Londres, v.48, n.5, p.267-274, 2003.

BRASIL, M. S. Desempenho de sistema alagado construído para tratamento de esgoto doméstico. 2005. 160f. Tese (Doutorado em Engenharia Agrícola) - Universidade Federal de Viçosa, Viçosa.

BRIX, H. Do macrophytes play a role in constructed treatment wetlands? Water Science and Technology, Londres, v.35, n.5, p.11-17, 1997. 
BRIX, H. How "green" are aquaculture, constructed wetlands and conventional wastewater treatment systems? Water Science and Technology, Londres, v.40, n.3, p.45-50, 1999.

CHEMICAL INFORMATION SERVICES. Chemical Informer. Ago. 2005. Dallas. Disponível em: $<$ http://www.chemicalinfo.com/informer/archives/2005/aug2005.htm>. Acesso em 15 ago. 2007.

CHENG, S. et al. Xenobiotics removal from polluted water by a multifunctional constructed wetland. Chemosphere, Oxford, v.48, n.4, p.415-418, 2002.

COOPER, C. M.; MOORE, M. T. Wetlands and agriculture. In: HOLLAND, M. M.; BLOOD, E. R.; SHAFFER, L. R. (eds.). Achieving sustainable freshwater systems: a web of connections. Washington: Island Press, 2003. p.221-235.

CRONK, J. K. Constructed wetlands to treat wastewater from dairy and swine operations: a review. Agriculture, Ecosystems and Environment, Amsterdam, v.58, n.2-3, p.97-114, 1996.

CULL, R. et al. Application of vetiver grass technology in off-site pollution control II. Tolerance to herbicides under selected wetland conditions. In: INTERNATIONAL VETIVER CONFERENCE, 2, 2000, Phetchaburi. Proceedings... Bangkok: Office of The Royal Development Projects Board, 2000. p.1-9.

CUNNINGHAM, S. D. et al. Phytoremediation of soils contaminated with organic coumponds. Advances in Agronomy, San Diego, v.56, p.55-114, 1996.

DARBY, M. A. Modeling the fate of chlorpyrifos in constructed wetlands. 1995. 113f. Dissertação (Mestrado em Engenharia Ambiental) - Universidade do Mississippi, Mississipi.

DAVIS, L. (ed.) A handbook of constructed wetlands, a guide to creating wetlands for: agricultural wastewater, domestic wastewater, coal mine drainage and stormwater in the Mid-Atlantic region, v.1: general considerations, Washington: US DA, 1995. 54p.

DINARDI, A. L. et al. Fitorremediação. In: FÓRUM DE ESTUDOS CONTÁBEIS, 3, 2003, Rio Claro. Anais... Rio Claro: Faculdades Integradas Claretianas, 2003. CD-Rom. 
DENNY, P. Implementation of constructed wetlands in developing countries. Water Science and Technology, Londres, v. 35, n. 5, p.27-34, 1997.

DORDIO, A. V. et al. Selection of a support matrix for the removal of some phenoxyacetic compounds in constructed wetlands systems. Science of the Total Environment, Amsterdam, v.380, n.1-3, p.237-246, 2007.

EXTOXNET [THE EXTENSION TOXICOLOGY NETWORK]. The EXTOXNET

InfoBase, 1998. Disponível em <http://extoxnet.orst.edu>. Acesso em 15 ago. 2007.

FAIRCHILD, J. F. et al. Comparative sensitivity of Selenastrum capricornutum and Lemna minor to sixteen herbicides. Archives of Environmental Contamination and Toxicology, Nova Iorque, v.32, n.4, p.353-357, 1997.

FOOTPRINT. The FOOTPRINT pesticides properties database, 2007. Disponível em $<$ http://www.eu-footprint.org/ppdb.html $>$. Acesso em 15 ago. 2007.

FRIESEN-PANKRATZ, B. B. et al. Interactions between algae (Selenastrum capricornutum) and pesticides: implications for managing constructed wetlands for pesticides removal. Journal of Environmental Science and Health, Part B - Pesticides, Food, and Agricultural Wastes, Nova Iorque, v.38, n.2, p.147-155, 2003.

GARCINUÑO, R. M.; FERNANDEZ-HERNANDO, P.; CAMARA, C. Evaluation of pesticide uptake by Lupinus seeds. Water Research, Oxford, v.37, n.14, p.3481-3489, 2003.

GEARY, P. M.; MOORE, J. A. Suitability of a treatment wetland for dairy wastewaters. Water Science and Technology, Londres, v.40, n.3, p.179-185, 1999.

GEORGE, D. B. et al. Simazine and metolachlor removal by subsurface flow constructed wetlands. Water Environmental Research, Alexandria, v.75, n.2, p.101-112, 2003.

GUNTENSPERGEN, G. R.; STEAMS, F.; KADLEC, J. A. Wetland vegetation. In: HAMMER, D. A. (ed.). Constructed wetlands for wastewater treatment: municipal, industrial and agricultural. Chelsea: CRC-Lewis, 1989. p.73-78. 
HAARSTAD, K.; BRASKERUD, B. C.; Pesticide retention in the watershed and in a small constructed wetland treating diffuse pollution. Water Science and Technology, Londres, v.51, n.3-4, p.143-150, 2005.

HARBEL, R. Constructed wetlands: a chance to solve wastewater problems in developing countries. Water Science and Technology, Londres, v.40, n.3, p.11-17, 1999.

HEALY, M. G.; RODGERS, M.; MULQUEEN, J. Treatment of dairy wastewater using constructed wetlands and intermittent sand filters. Bioresource Technology, Oxford, v.98, n.12, p.2268-2281, 2007.

HELFIELD, J. M.; DIAMOND, M. L. Use of constructed wetlands for urban stream restoration: a critical analysis. Environmental Management, Nova Iorque, v.21, n.3, p.329$341,1997$.

HUNT, P. G.; POACH, M. E. State of the art for animal wastewater treatment in constructed wetlands. Water Science and Technology, Londres, v.44, n.11-12, p.19-25, 2001.

IFAS [INSTITUTE OF FOOD AND AGRICULTURAL SCIENCES] University of Florida. Aquatic, Wetland and Invasive Plants - Line Drawings. 1990. Disponível em: $<$ http://plants.ifas.ufl.edu>. Acesso em 15 ago. 2007.

IRIDRA. Constructed wetlands. 2006. Disponível em: $<$ http://www.iridra.com>. Acesso em 15 ago. 2007.

ITRC [THE INTERSTATE TECHNOLOGY AND REGULATORY COUNCIL]. Technical and regulatory guidance document for constructed treatment wetlands. Nova Jersey: ITRC, 2003. 199p.

IWA [INTERNATIONAL WATER ASSOCIATION]. Constructed wetlands for pollution control: process, performance, design and operation. Londres: IWA, 2000. 156p.

KADLEC, R. H.; WALLACE, S.; VYMAZAL, J. Treatment wetlands. 2 ed. Boca Raton: CRC-Lewis, 2004. 800p. 
KADLEC, R. H. The inadequacy of first-order treatment models. Ecological Engineering, Amsterdam, v.15, n.1, p.105-119, 2000.

KAO, C. M.; WANG, J. Y.; WU, M. J. Evaluation of atrazine removal processes in a wetland. Water Science and Technology, Londres, v.44, n.11-12, p.539-544, 2001.

KIVAISI, A. K. The potential for constructed wetlands for wastewater treatment and reuse in developing countries: a review. Ecological Engineering, Amsterdam, v.16, n.4, p.545-560, 2001.

KNIGHT, R. L. et al. Constructed wetlands for livestock wastewater management. Ecological Engineering, Amsterdam, v.15, n.1-2, p.41-55, 2000.

KNUTESON, S. L.; WHITWELL, T.; KLAINE, S. J. Influence of plant age and size on simazine toxicity and uptake. Journal of Environmental Quality, Madison, v.31, n.6, p.2096-2103, 2002.

KOOTTATEP, T.; POLPRASERT, C. Role of plant uptake on nitrogen removal in constructed wetlands located in the tropics. Water Science and Technology, Londres, v.36, n.12, p.1-8, 1997.

KRUTZ, L. J. et al. Reducing herbicide runoff from agricultural fields with vegetative filter strips: a review. Weed Science, Lawrence, v.53, n.3, p.353-367, 2005.

LANGAN, M. M.; HOAGLAND, K. D. Growth responses of Typha latifolia and Scirpus acutus to atrazine contamination. Bulletin of Environmental Contamination and Toxicology, Nova Iorque, v.57, n.2, p.2096-2103, 1996.

LAUTENSCHLAGER, S. R. Modelagem do desempenho de Wetlands construídas. 2001. 90f. Dissertação (Mestrado em Engenharia Civil) - Universidade de São Paulo, São Paulo.

LAVORENTI, A.; PRATA, F.; REGITANO, J. B. Comportamento de pesticidas em solos fundamentos. In: CURI, N. et al. Tópicos em ciência do solo, v.3, Viçosa: SBCS, 2003. p.291-334. 
LEWIS, M. A. Use of freshwater plants for phytotoxicity testing: a review. Environmental Pollution, Oxford, v.87, n.3, p.319-336, 1995.

LIESS, M.; SHULZ, R. Linking insecticide contamination and population response in an agricultural stream. Environmental Toxicology and Chemistry, Pensacola, v.18, n.9, p.1848-1955, 1999.

LYTLE, T. F.; LYTLE, J. S. Uptake and loss of chlorpyrifos and atrazine by Juncus effusus L. in a mesocosm study with a mixture of pesticides. Environmental Toxicology and Chemistry, Pensacola, v.21, n.9, p.1817-1825, 2002.

LYTLE, T. F.; LYTLE, J. S. Growth inhibition as indicator of stress because of atrazina following multiple toxicant exposure of the freshwater macrophyte, Juncus effuses L., Environmental Toxicology and Chemistry, Pensacola, v.24, n.5, p.1198-1203, 2005.

MATADOROS, V. et al. Behavior of selected priority organic pollutants in horizontal subsurface flow constructed wetlands: a preliminary screening. Chemosphere, Oxford, no prelo, 2007.

MARA, D. D. To plant or not to plant? Questions on the role of plants in constructed wetlands. In: IWA INTERNATIONAL CONFERENCE ON WASTE STABILISATION PONDS, 6; IWA INTERNATIONAL CONFERENCE ON WETLAND SYSTEMS, 9, 2004, Avignon. Communications of common interest. Avignon: IWA, 2004. p. 7-12.

MARSHILI-LIBELLI, S.; CHECCHI, N. Identification of dynamic models for horizontal subsurface constructed wetlands. Ecological Modelling, Amsterdam, v.187, n.2-3, p.201-218, 2005.

McKINLAY, R. G.; KASPEREK, K. Observations on decontamination of herbicide-polluted water by marsh plant systems. Water Research, Oxford, v.33, n.2, p.505-511, 1999.

MILAM, C. D. et al. Evaluating acute toxicity of methyl parathion application in constructed wetland mesocosms. Environmental Toxicology, Hoboken, v.19, n.5, p.471-479, 2004. 
MOORE, M. T. et al. Herbicide effects on Typha latifolia (Linneaus) germination and root and shoot development. Chemosphere, Oxford, v.38, n.15, p.3637-3647, 1999.

MOORE, M. T. et al. Constructed wetlands for mitigation of atrazine-associated agricultural runoff. Environmental Pollution, Oxford, v.110, n.3, p.393-399, 2000.

MOORE, M. T. et al. Mitigation of metolachlor-associated agricultural runoff using constructed wetlands in Mississippi, USA. Agriculture, Ecosystems and Environment, Amsterdam, v.84, n.2, p.169-176, 2001.

MOORE, M. T. et al. Pesticide mitigation capacities of constructed wetlands. In: CONFERENCE ON SUSTAINABILITY OF WETLANDS AND WATER RESOURCES: HOW WELL CAN RIVERINE WETLANDS CONTINUE TO SUPPORT SOCIETY IN TO THE $21^{\text {ST }}$ CENTURY?, 1, 2000, Oxford. Proceedings ... Asheville: US DA, 2002a, p.133134.

MOORE, M. T. et al. Mitigation of chlorpyrifos runoff using constructed wetlands.

Chemosphere, Oxford, v.46, n.6, p.827-835, 2002 b.

MOORE, M. T. et al. Influence of vegetation in mitigation of methyl parathion runoff.

Environmental Pollution, Oxford, v.142, n.2, p.288-294, 2006.

MOORE, M. T. et al. Diazinon mitigation in constructed wetlands: influence of vegetation.

Water, Air and Soil Pollution, Dordrecht, v.184, n.1-4, p.313-321, 2007.

PAN [PESTICIDE ACTION NETWORK]. PAN Pesticides Database, v.7.1, 2006.

Disponível em: <http://www.pesticideinfo.org>. Acesso em 15 ago. 2007.

PHILIPPI, L. S.; SEZERINO, P. H. Aplicação de sistemas tipo wetlands no tratamento de águas residuárias: utilização de filtros plantados com macrófitas. Florianópolis: Ed. do Autor, 2004. 144p. 
RAMALHO, I.; CARVALHO, A.; DORDIO, A. MCPA pesticide removal in constructed wetlands with light expanded clay aggregates. In: IWA INTERNATIONAL CONFERENCE ON WETLAND SYSTEMS, 9, 2004, Avignon. Proceedings... Avignon: IWA, 2004. CDRom.

REED, S. C. Subsurface flow constructed wetlands for wastewater treatment: a technology assessment. Washington: US EPA, 1993. 87p. EPA 832-R-93-008.

REGMI, T. P., THOMPSON, A. L.; SIEVENS, D. M. Comparative studies of vegetated and non-vegetated submerged-flow wetlands treating primary lagoon effluent. Transactions of the ASAE, St. Joseph, v.46, n.1, p.17-27, 2003.

REICHENBERGER, S. et al. Mitigation strategies to reduce pesticide inputs into ground- and surface water and their effectiveness; A review. Science of the Total Environment, Amsterdam, no prelo, 2007.

REINHOLD, D. M.; SAUNDERS, F. M. Phytoremediation of fluorinated agrochemicals by duckweed. Transactions of the ASABE, St. Joseph, v.49, n.6, p.2077-2083, 2006.

RODGERS, J. H., Jr.; DUNN, A. Developing design guidelines for constructed wetlands to remove pesticides from agricultural runoff. Ecological Engineering, Amsterdam, v.1, n.1-2, p.83-95, 1992.

ROSE, M. T. et al. Pesticide removal from cotton farm tailwater by a pilot-scale ponded wetland. Chemosphere, Oxford, v.63, n.11, p.1849-1858, 2006.

ROUSSEAU, D. P. L. et al. Model-based design of horizontal subsurface flow constructed treatment wetlands: a review. Water Research, Oxford, v.38, n.6, p.1484-1493, 2004.

RUNES, H. B.; JENKINS, J. J.; BOTTOMLEY, P. J. Atrazine degradation by bioaugmented sediment from constructed wetlands. Applied Microbiology Biotechnology, Nova Iorque, v.57, n.3, p.427-423, 2001.

RUNES, H. B. et al. Atrazine remediation in wetland microcosms. Environmental Toxicology and Chemistry, Pensacola, v.20, n.5, p.1059-1066, 2001. 
RUNES, H. B. et al. Treatment of atrazine in nursery irrigation runoff by a constructed wetland. Water Research, Oxford, v.37, n.3, p.539-550, 2003.

SALATI, E. Utilização de sistemas de wetlands construídas para tratamento de águas.

Biológico, São Paulo, v.65, n.1-2, p.113-116, 2003.

SCHULZ, R. et al. Concentration, load and toxicity of spraydrift-borne azinphos-mephyl at the inlet and outlet of a constructed wetland. Ecological Engineering, Amsterdam, v.18, n.2, p.239-245, 2001.

SCHULZ, R. et al. Acute toxicity of methyl-parathion in wetland mesocosms: assessing the influence of aquatic plants using laboratory testing with Hyalella azteca. Arquives of Environmental Contamination and Toxicology, Nova Iorque, v.45, n.3, p.331-336, 2003a.

SCHULZ, R. et al. Methyl parathion toxicity in vegetated and nonvegetated wetland mesocosms. Environmental Toxicology and Chemistry, Pensacola, v.22, n.6, p.1262-1268, $2003 b$.

SCHULZ, R. et al. Fate and effects of azinphos-methyl in a flow-through wetland in South Africa. Environmental Science and Technology, Washington, v.37, n.10, p.2139-2144, $2003 c$.

SCHULZ, R. Field studies on exposure, effects, and risk mitigation of aquatic nonpointsource insecticide pollution: a review. Journal of Environmental Quality, Madison, v.33, n.2, p.419-448, 2004.

SCHULZ, R.; PEALL, S. K. C. Effectiveness of a constructed wetland for retention of nonpoint-source pesticide pollution in the Lourens river catchment, South Africa.

Environmental Science and Technology, Washington, v.35, n.2, p.422-426, 2001.

SHERRARD, R. M. et al. Feasibility of constructed wetlands for removing chlorothalonil and chlorpyrifos from aqueous mixtures. Environmental Pollution, Oxford, v.127, n.3, p.385394, 2004. 
SHUTES, R. B. E. Artificial wetlands and water quality improvement, Environment International, Oxford, v.26, n.5-6, p.441-447, 2001.

SRC [SYRACUSE RESEARCH CORPORATION]. SRC PhisProp Database. 2004.

Disponível em: <http://www.syrres.com/esc/physdemo.htm>. Acesso em 15 ago. 2007.

STEARMAN, G. K. et al. Pesticide removal from container nursery runoff in constructed wetland cells. Journal of Environmental Quality, Madison, v.32, n.4, p.1548-1556, 2003.

US DA [US DePARTMENT OF AGRICUlTURE]. ARS Pesticide Properties Database, 2006 Disponível em: $<$ http://www.ars.usda.gov/services/docs.htm?docid=14199>. Acesso em 15 ago. 2007.

US EPA [US ENVIRONMENTAL PROTECTION AGENCY]. Guiding principles for constructed treatment wetlands: providing for water quality and wildlife habitat, Washington: US EPA, 2000. 42p. EPA 843-B-00-003.

US EPA [US ENVIRONMENTAL PROTECTION AGENCY]. Design manual: constructed wetlands and aquatic plant systems for municipal wastewater treatment. Cincinnati: US EPA, 1988. 83p. EPA/625/I-88/022.

VALENTIM, M. A. A. Desempenho de leitos cultivados ("constructed wetland") para tratamento de esgoto: contribuições para concepção e operação. 2003. 210f. Tese (Doutorado em Engenharia Agrícola) - Universidade Estadual de Campinas, Campinas.

VYMAZAL, J. et al. Removal mechanisms and types of constructed wetlands. In: VYMAZAL, J. et al. (eds.) Constructed wetlands for wastewater treatment in Europe. Leiden: Backhuys Publishers, 1988. p.1-15.

VYMAZAL, J. Constructed wetlands for wastewater treatment. Ecological Engineering, Amsterdam, v.25, n.5, p.475-477, 2005.

WANG, W. Literature review on higher plants for toxicity testing. Water, Air and Soil Pollution, Dordrecht, v.59, n.3-4, p.381-400, 1991. 
WAUCHOPE, R. D. The pesticide content of surface water draining from agricultural fields a review. Journal of Environmental Quality, Madison, v.7, n.4, p.459-472, 1978.

WILLIAMS, J. B. Phytoremediation in wetland ecosystems: progress, problems, and potential. Critical Reviews in Plant Sciences, Philadelphia, v.21, n.6, p.607-635, 2002.

WILSON, P. C.; WHITWELL, T.; KLAINE, S. J. Metalaxyl and simazine toxicity to and uptake by Typha latifolia. Archives of Environmental Contamination and Toxicology, Nova Iorque, v.39, n.3, p.282-288, 2000.

WILSON, P. C.; WHITWELL, T.; KLAINE, S. J. Metalaxyl toxicity, uptake, and distribution in several ornamental plant species. Journal of Environmental Quality, Madison, v.30, n.2, p.411-417, 2001.

WOLVERTON, B. C.; HARRISON, D. D. Aquatic plants for removal of mevinphos from the aquatic environment. Journal of the Mississippi Academy of Sciences, Jackson, v.19, p.84$88,1973$.

WOOD, A. Constructed wetlands in water pollution control: Fundamentals to their understanding. Water Science and Technology, Londres, v.32, n.3, p.21-29, 1995.

WOOD, R. B.; McTAMNEY, C. F. The use of macrophytes in bioremediation.

Biotechnology Advances, Oxford v.12, n.4, p.653-662, 1994.

WOOD, R. B.; McTAMNEY, C. F. Constructed wetlands for waste water treatment: the use of laterite in the bed medium in phosphorus and heavy metal removal, Hydrobiologia, Dordrecht v.340, n.1-3, p.323,331, 1996. 


\section{CAPÍTULO 3}

MATERIAIS E MÉTODOS 


\subsection{INTRODUÇÃO}

Conforme abordado no Capítulo 1, a equipe de pesquisa optou pela apresentação da tese em capítulos inter-relacionados, redigidos como artigos técnico-científicos separados. Entretanto, observou-se durante a redação do documento, a necessidade de um compêndio sobre quais os materiais, equipamentos e metodologia utilizados, além de informações mais detalhadas sobre a localização dos experimentos.

O Capítulo 3 foi redigido e acrescentado ao texto com o objetivo de proporcionar uma melhor compreensão geral do trabalho e apresenta, com mais detalhamento, as informações contidas nos itens "Metodologia" contidos nos artigos dos capítulos subseqüentes (Capítulos $4,5$ e 6$)$.

\subsection{LOCALIZAÇÃO DOS EXPERIMENTOS}

Os experimentos foram conduzidos em áreas pertencentes ao Departamento de Engenharia Agrícola do Centro de Ciências Agrárias da Universidade Federal de Viçosa (DEA/CCA/UFV), localizadas na cidade de Viçosa, Minas Gerais (latitude 20 45' 14" S, longitude $42^{\circ} 52^{\prime} 53^{\prime}$ W, altitude média de $650 \mathrm{~m}$ e clima Cwa, segundo a classificação de Köeppen).

Os estudos feitos nos SACs sob escoamento subsuperficial foram realizados na Área Experimental de Tratamento de Resíduos (AETR) e os ensaios de toxicidade às macrófitas foram conduzidos em casa de vegetação situada nas dependências do Laboratório de Hidráulica do DEA. Na Figura 3.1 visualiza-se a planta da AETR, onde se situam os SACs e, na Figura 3.2, visualizam-se fotografias das áreas experimentais citadas.

As análises físicas, químicas e biológicas de amostras da água e do tecido vegetal das plantas foram realizadas em diferentes laboratórios, devido à característica interdisciplinar das pesquisas na área ambiental. Foram utilizados equipamentos e técnicas dos seguintes laboratórios: 
(i) Laboratório de Qualidade da Água (LQA), Laboratório de Química dos Resíduos, Laboratório de Solos e Resíduos Sólidos e Laboratório de Microbiologia, situados no edifíciosede do DEA/CCA/UFV;

(ii) Laboratório de Mecanização Agrícola e Laboratório de Hidráulica, situados no campus da UFV e pertencentes ao DEA;

(iii) Laboratório de Química Analítica e Ambiental (LAQUA), do Departamento de Química da UFV (DEQ/CCE/UFV);

(iv) Laboratório de Biotecnologia Ambiental e Biodiversidade, do Instituto de Biotecnologia Aplicada à Agropecuária (BIOAGRO) da UFV;

(v) Laboratório de Anatomia Vegetal, do Departamento de Biologia Vegetal da UFV (DBV/CCB/UFV);

(vi) Laboratório de Espectrometria Molecular e Atômica do Departamento de Solos da UFV (DPS/CCA/UFV) e

(vii)Laboratório de Traçadores do Instituto Alberto Luiz Coimbra de Pós-graduação e Pesquisa de Engenharia (COPPE) da Universidade Federal do Rio de Janeiro (UFRJ).

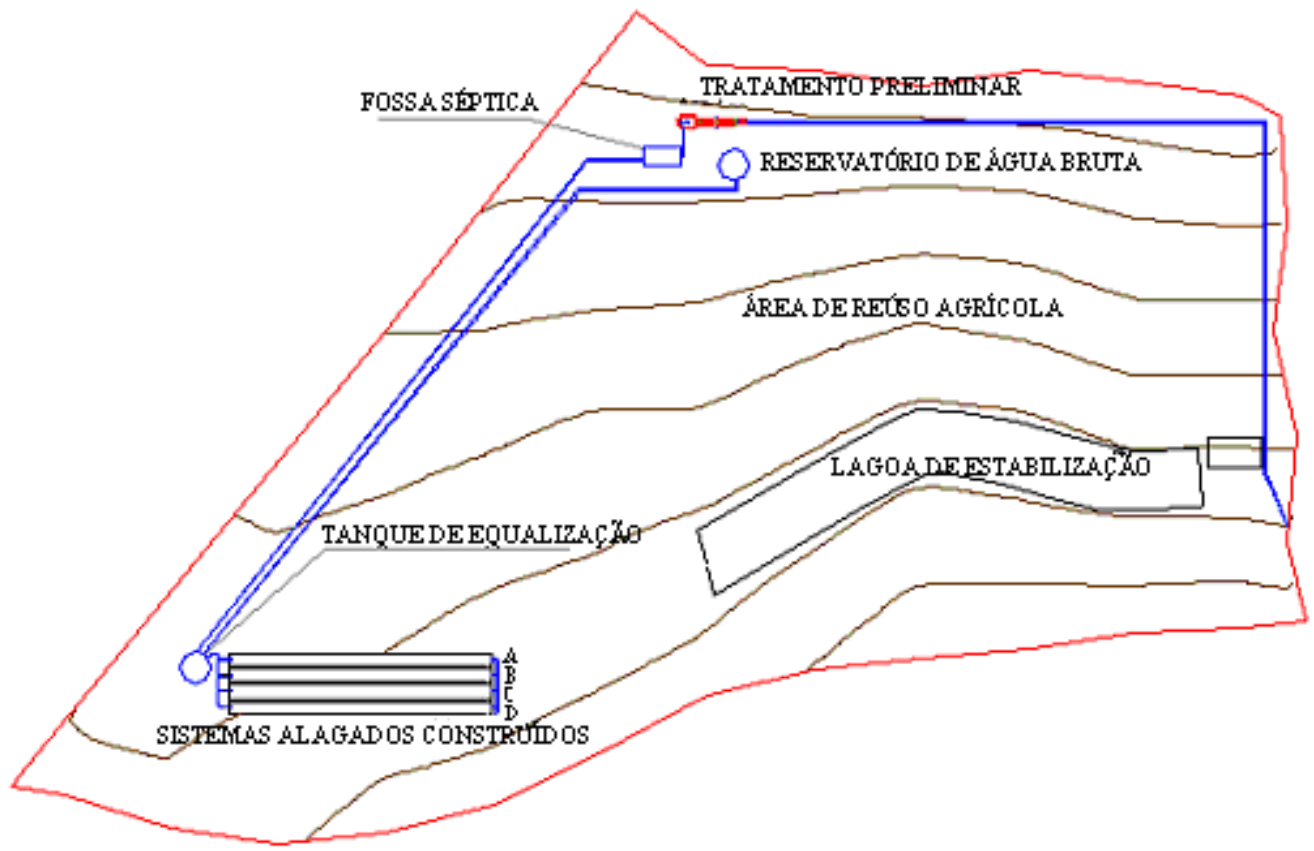

Figura 3.1 - Planta de situação da AETR (Adaptado de Brasil, 2005) 


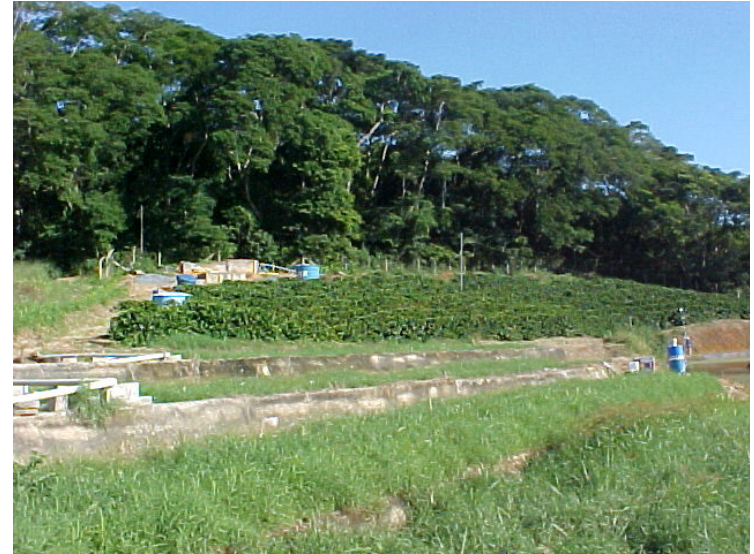

(a)

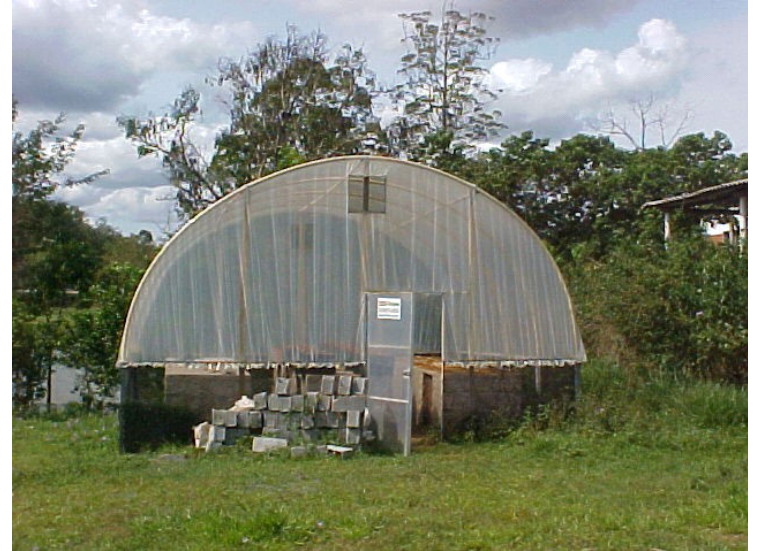

(b)

Figura 3.2 - Fotografias das áreas experimentais utilizadas: (a) vista da Área Experimental de

Tratamento de Resíduos e (b) casa de vegetação localizada nos fundos do Laboratório de Hidráulica

\subsection{TRATAMENTOS AVALIADOS}

\section{SACs sob escoamento subsuperficial horizontal}

Os experimentos de hidrodinâmica e de estudo da retenção do agroquímico em mesoescala foram realizados em SACs com escoamento subsuperficial horizontal, projetados e estudados por Brasil (2005). Os SACs foram utilizados para tratamento secundário de esgotos domésticos no período de julho de 2004 a janeiro de 2005. A partir de então, as unidades foram alimentadas continuamente com água bombeada de uma das represas do ribeirão São Bartolomeu, situada no campus da UFV.

Os leitos constituíam-se de paredes laterais construídas em alvenaria e de uma manta de geomembrana de policloreto de vinila (PVC) com 0,50 $\mathrm{mm}$ de espessura, posicionada sobre o solo. Cada unidade possuía $0,35 \mathrm{~m}$ de altura; $1,0 \mathrm{~m}$ de largura e 24,0 $\mathrm{m}$ de comprimento. Como substrato utilizou-se brita "número 0" $\left(\mathrm{D}_{60}=7,0 \mathrm{~mm}, \mathrm{Cu}=1,6\right.$, volume de vazios de $48,4 \%$, condutividade hidráulica saturada $\mathrm{K}_{\mathrm{s} 20}=7.970 \mathrm{~m} \mathrm{~d}^{-1}$ ). As regiões de entrada de cada SAC foram preenchidas com brita "número 2" para a minimização de possíveis entupimentos. Os valores referentes ao volume de vazios e à condutividade hidráulica foram determinados na implantação dos sistemas (Brasil, 2005). O meio suporte preencheu as unidades até a altura de $0,30 \mathrm{~m}$, restando uma borda livre de 0,05 $\mathrm{m}$, conforme 
representado no diagrama esquemático apresentado na Figura 3.3 e na fotografia visualizada na Figura 3.4.
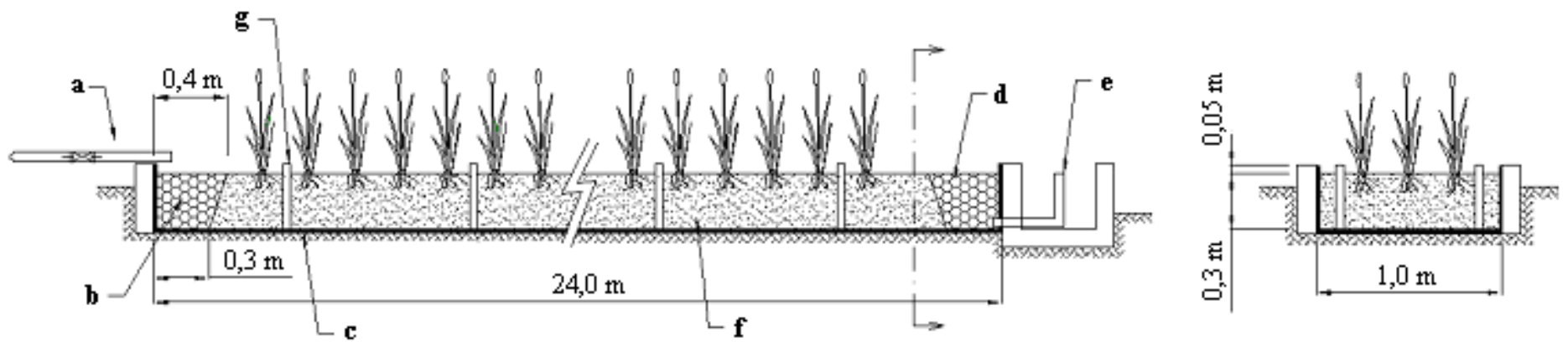

Figura 3.3 - Diagrama esquemático de uma unidade do SAC: (a) dispositivo de distribuição do afluente; (b) zona de entrada; (c) geomembrana impermeável; (d) zona de saída; (e) dispositivo de extravazão para os reservatórios efluentes; (f) meio suporte e (g) pontos de coleta de amostras do líquido residente (Adaptado de Brasil et al., 2007)

O dispositivo para alimentação e distribuição do afluente em cada leito constituiu-se de um tubo de PVC com $32 \mathrm{~mm}$ de diâmetro perfurado longitudinalmente conectado a um registro de gaveta e a um reservatório de polietileno (com capacidade de $1000 \mathrm{~L}$ ). A montante dessas unidades, alocou-se um reservatório de fibra de vidro (com capacidade de 5000 L), que garantia a alimentação contínua e constante de cada leito.

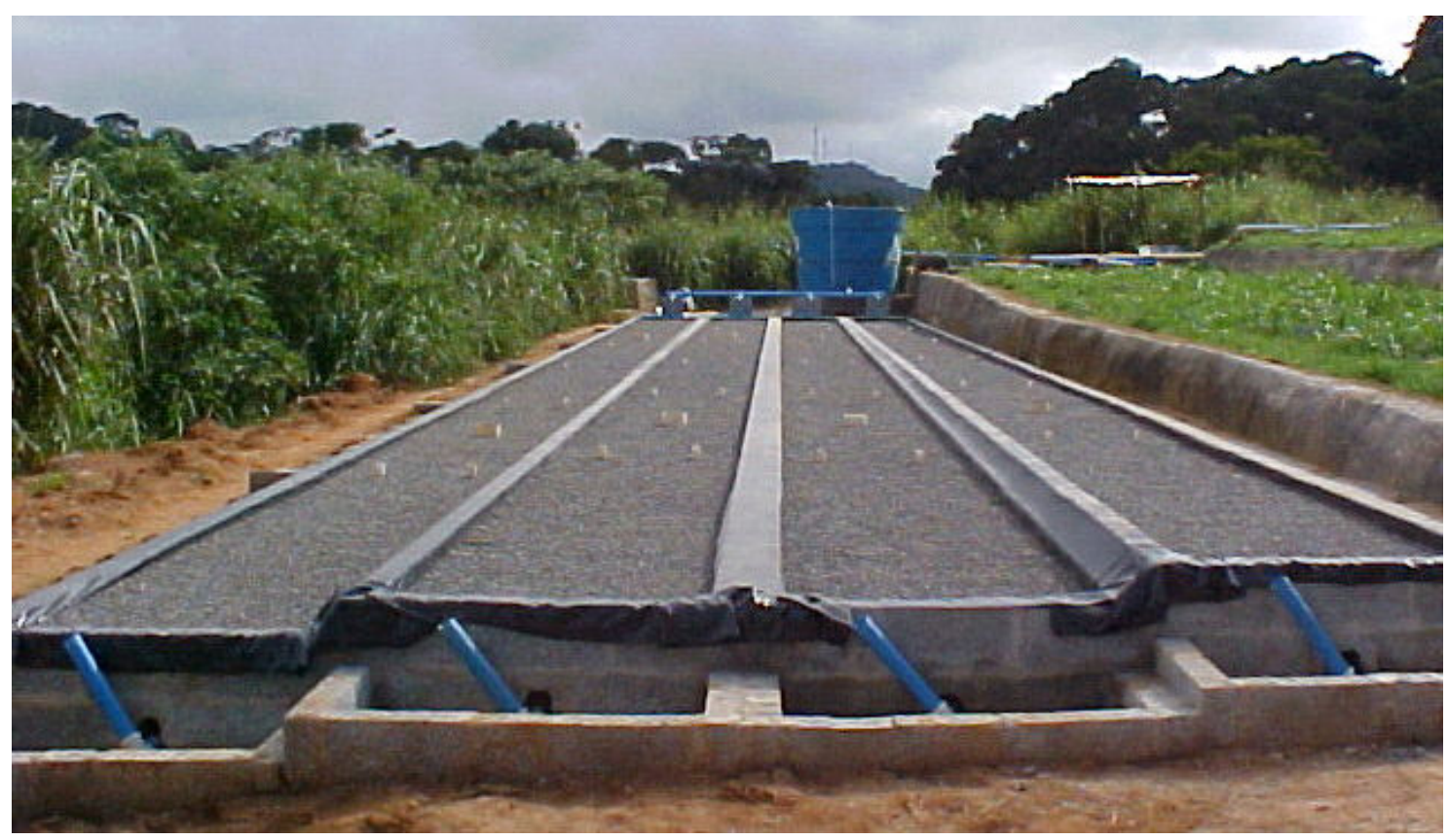

Figura 3.4 - Leitos preenchidos com brita antes do plantio da taboa (Fonte: Brasil, 2005) 
Na saída de cada leito, instalou-se um sistema de drenagem, feito com tubo de PVC de $50 \mathrm{~mm}$ e frestas de $2 \mathrm{~mm}$ de largura, ocupando toda a largura da unidade. Os tubos de descarga e controle de nível ficavam conectados a esses sistemas de drenagem e conduziam o efluente a reservatórios (construídos em amianto) que foram graduados para que fosse possível o cálculo diário do balanço hídrico nas unidades. Após o armazenamento nessas unidades, o líquido era direcionado à rede coletora. Ressalta-se que a unidade $\mathrm{B}$, usada como controle em um dos experimentos, não contava com reservatório coletor de efluentes.

Ao longo das unidades foram instalados, verticalmente, tubos de PVC com frestas transversais. Esses dispositivos, distanciados de 4 em $4 \mathrm{~m}$ no sentido longitudinal e dispostos 2 a 2 transversalmente, permitiam a realização de coletas intermediárias de amostras do líquido residente, quando necessário.

A taboa (Typha latifolia) foi a macrófita plantada nos SACs. Durante o experimento, os SACs apresentavam, em média, 20 plantas $\mathrm{m}^{-2}$. Observou-se a presença de espécies invasoras, como o tiriricão (Cyperus esculentus) e a grama seda (Cynodon dactylon). As espécies invasoras (tiriricão, grama seda e outras, em menores quantidades) ocupavam cerca de 15\% da área dos SACs. Nas Figuras 3.5, e 3.6 visualizam-se fotografias das unidades utilizadas, bem como dos sistemas de distribuição e coleta do líquido.
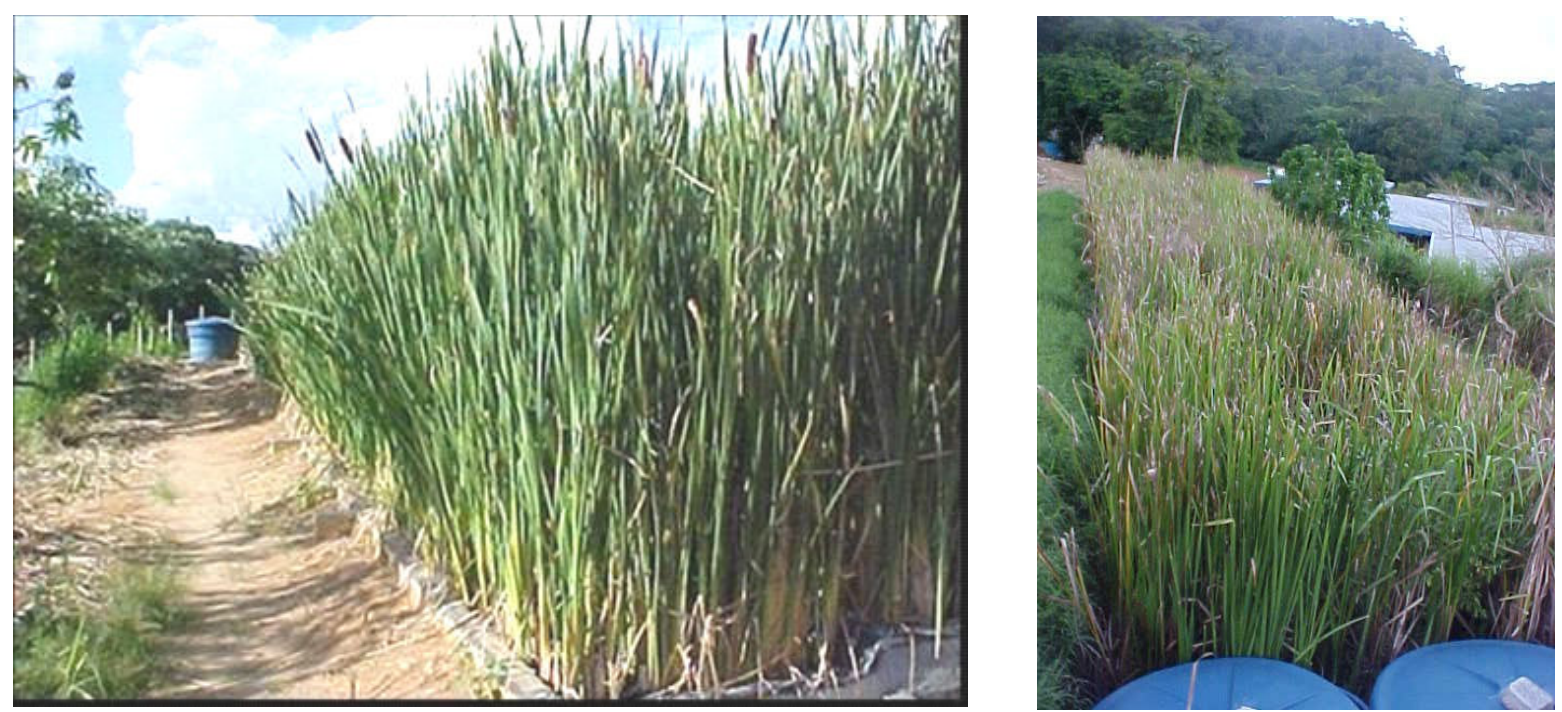

Figura 3.5 - Fotografias de vistas parciais dos sistemas alagados construídos

Os leitos, que foram projetados em um estudo anterior (Brasil, 2005), foram construídos com inclinações de fundo correspondentes a 0,5\% (SAC A); 1,0\% (SACs B e C) e 
1,5\% (SAC D). Como as unidades não possuíam inclinações iguais, o perfil da altura das lâminas de água e os volumes variavam de unidade para unidade (Figura 3.7).

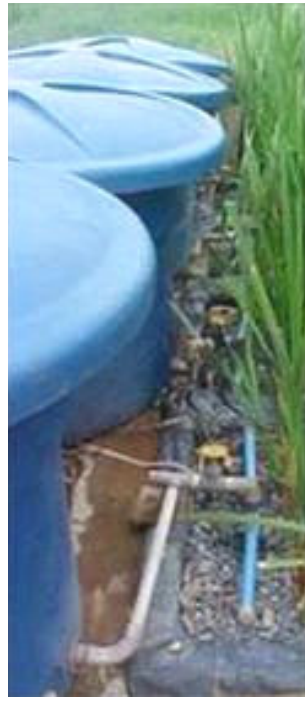

(a)

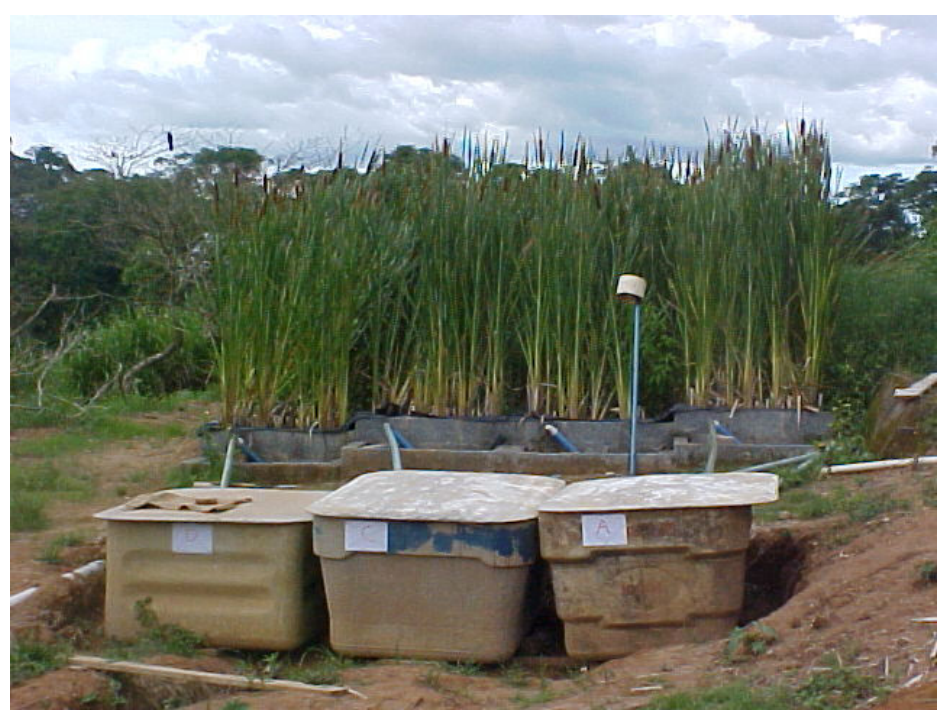

(b)

Figura 3.6 - Detalhes: (a) do sistema de distribuição dos afluentes nas unidades e (b) reservatórios de coletas posicionados a jusante

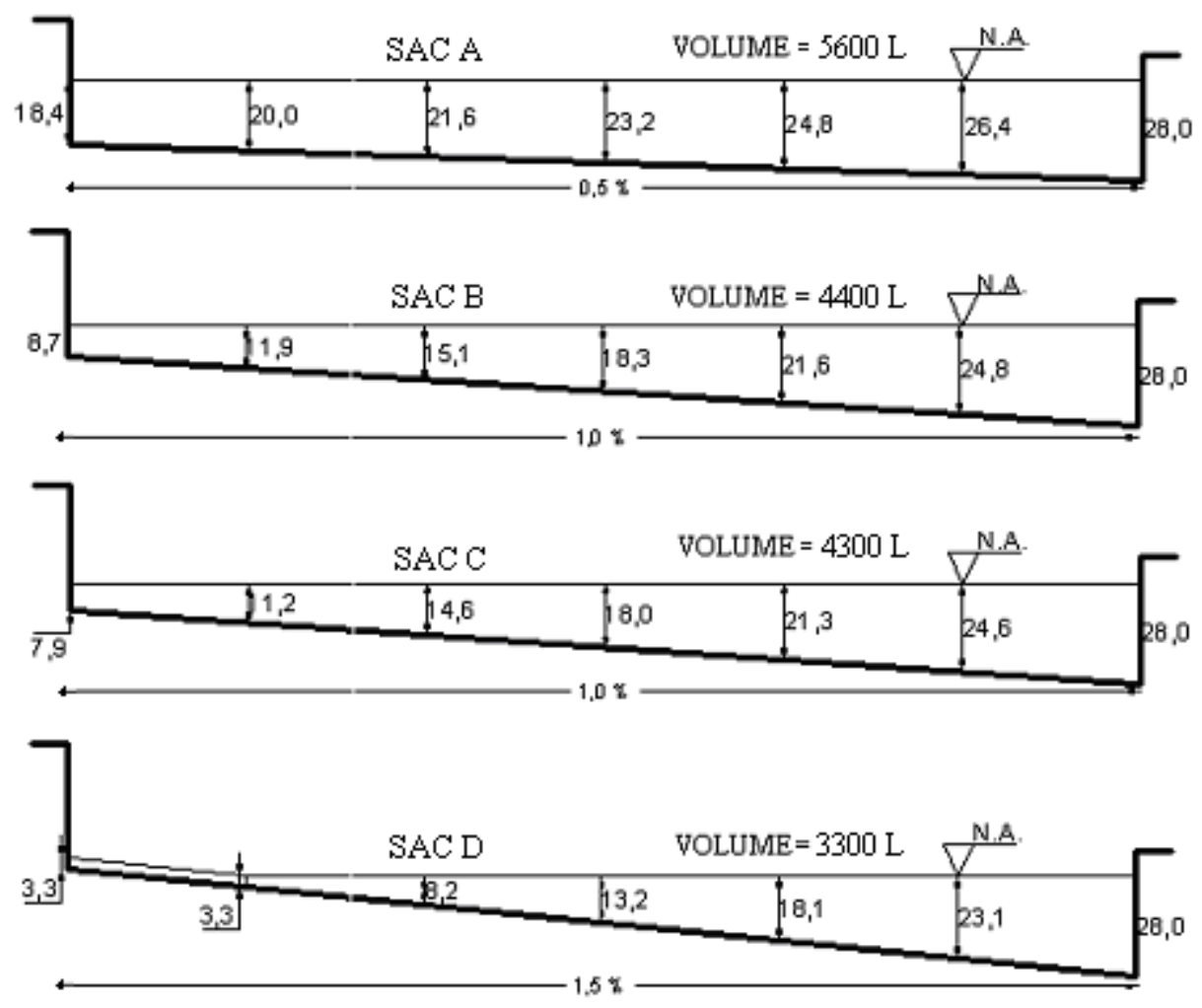

Figura 3.7 - Volume dos alagados construídos em função das diferenças de declividade de fundo (cotas em centímetros; adaptado de Brasil, 2005) 


\section{Estudos da toxicidade de agroquímico à macrófita estudada}

Devido ao fato de se tratar de uma unidade de tratamento de efluentes projetada anteriormente, não foi possível usar, no estudo de campo, o expediente de se aplicar ametrina em unidades não vegetadas. Dessa maneira, optou-se pela realização de novos experimentos em condições controladas. Experimentos de toxicidade (com pequenos SACs operando em batelada em casa de vegetação) e testes com sementes da macrófita (efeitos na germinação e no crescimento de raízes e brotos) foram realizados visando a análise da sustentabilidade da prática de uso de macrófitas na remediação de praguicidas.

Foram utilizados 11 recipientes cilíndricos, cada um com dimensões aproximadas de $28 \mathrm{~cm}$ de altura e $58 \mathrm{~cm}$ de diâmetro. Os SACs foram alimentados com água contaminada com concentrações progressivas de ametrina, de forma a se poder avaliar a influência da presença/ausência das macrófitas e a sustentabilidade do processo fossem avaliadas. Na Figura 3.8 visualizam-se fotografias dos tanques utilizados.

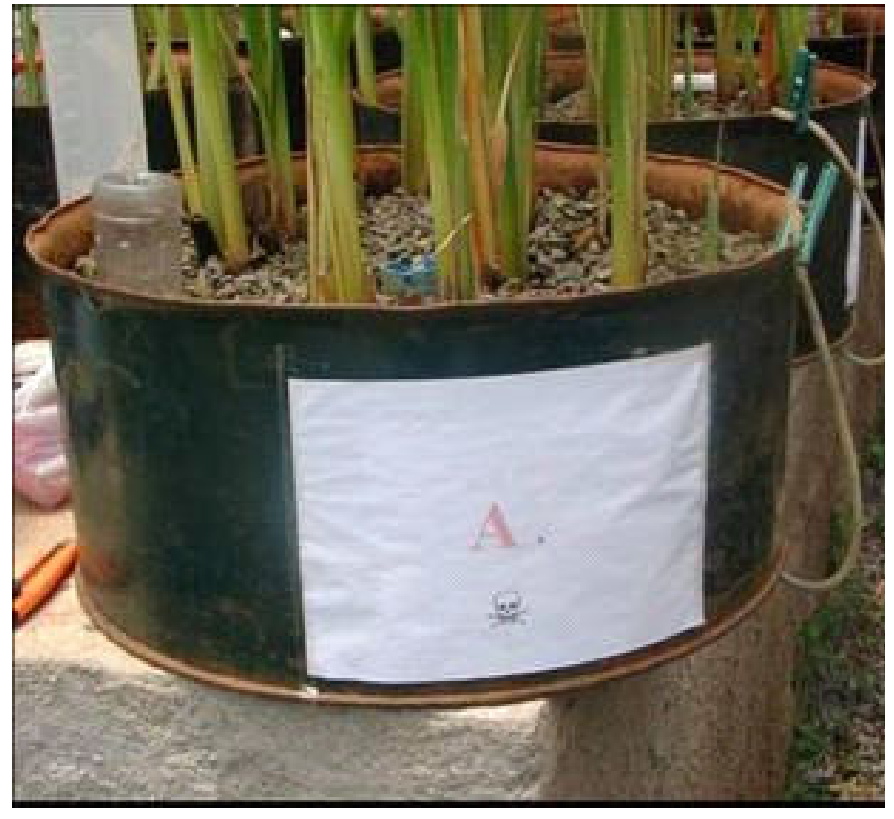

(a)

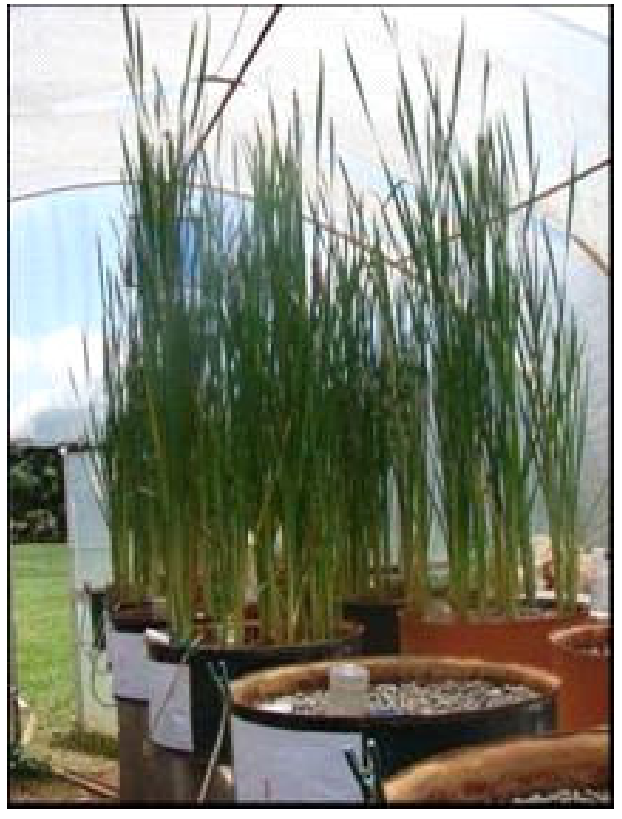

(b)

Figura 3.8 - Fotografias correspondentes a: (a) detalhe do tanque cilíndrico utilizado como SAC; (b) vista parcial do experimento

Faz-se necessário ressaltar que a implantação da $T$. latifolia foi feita por meio de propágulos vegetativos (rizomas), com aproximadamente $15 \mathrm{~cm}$ de comprimento, efetuada em meio sob condições de saturação. Em uma primeira tentativa, todas as macrófitas 
plantadas pereceram (apresentaram sintoma típico de queima de folhas) devido a uma aplicação inapropriada (excessiva) de fertilizantes na água de saturação do meio suporte. Após novo plantio, a espécie se desenvolveu lentamente (utilizou-se água bruta da represa da universidade) e a continuidade dos estudos se deu com a observação da maturidade das plantas (10 meses após o plantio). Na Figura 3.9 observam-se fotografias referentes à fase inicial do estudo.

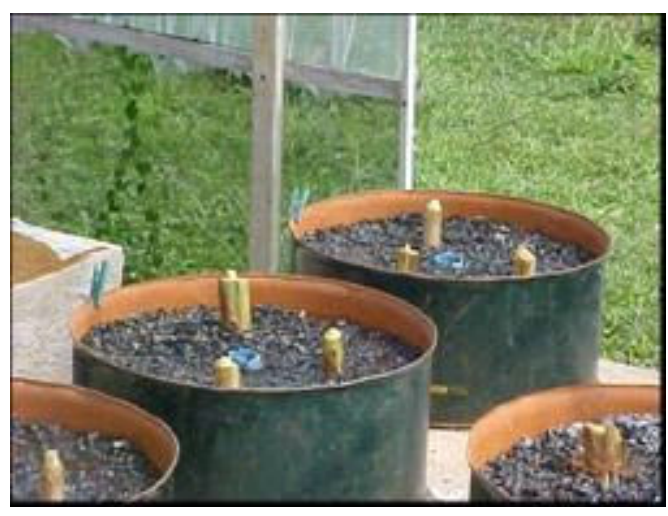

(a)

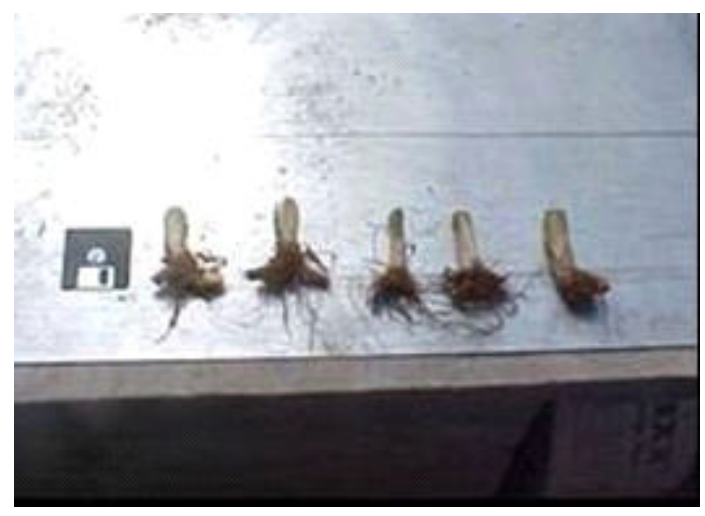

(b)

Figura 3.9 - Fotografias referentes a: (a) plantio dos rizomas; (b) comparação do comprimento dos rizomas implantados

Os testes de germinação de sementes, também necessários para a verificação da sustentabilidade no uso da macrófita, foram realizados em estrutura (armário) adaptada para tal. Nas Figuras 3.10 e 3.11 visualizam-se fotografias referentes à montagem do teste e a estrutura montada para servir como câmara de germinação.

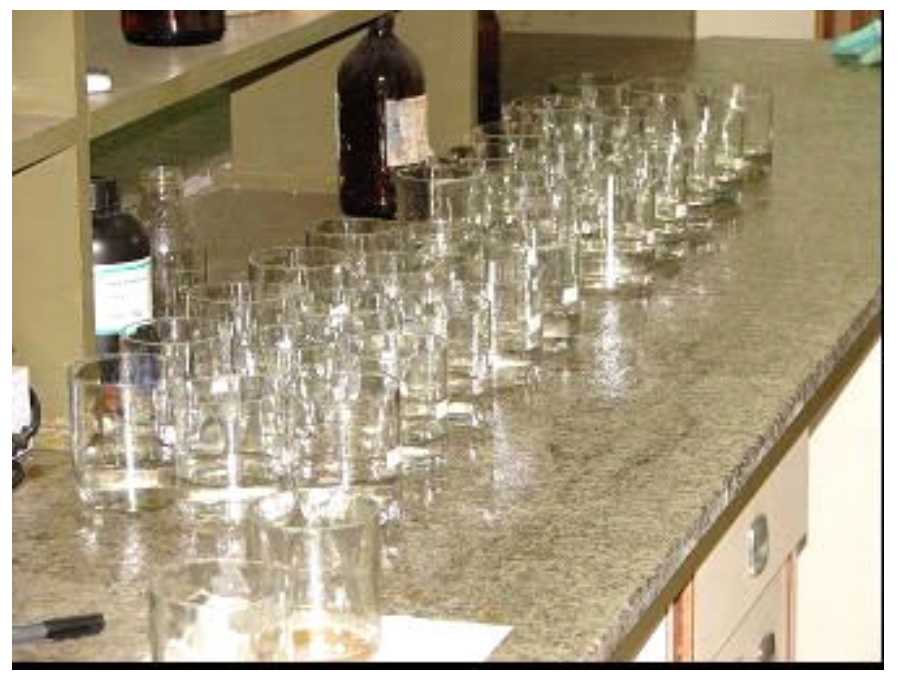

Figura 3.10 - Fotografia referente à montagem do teste de germinação da taboa 


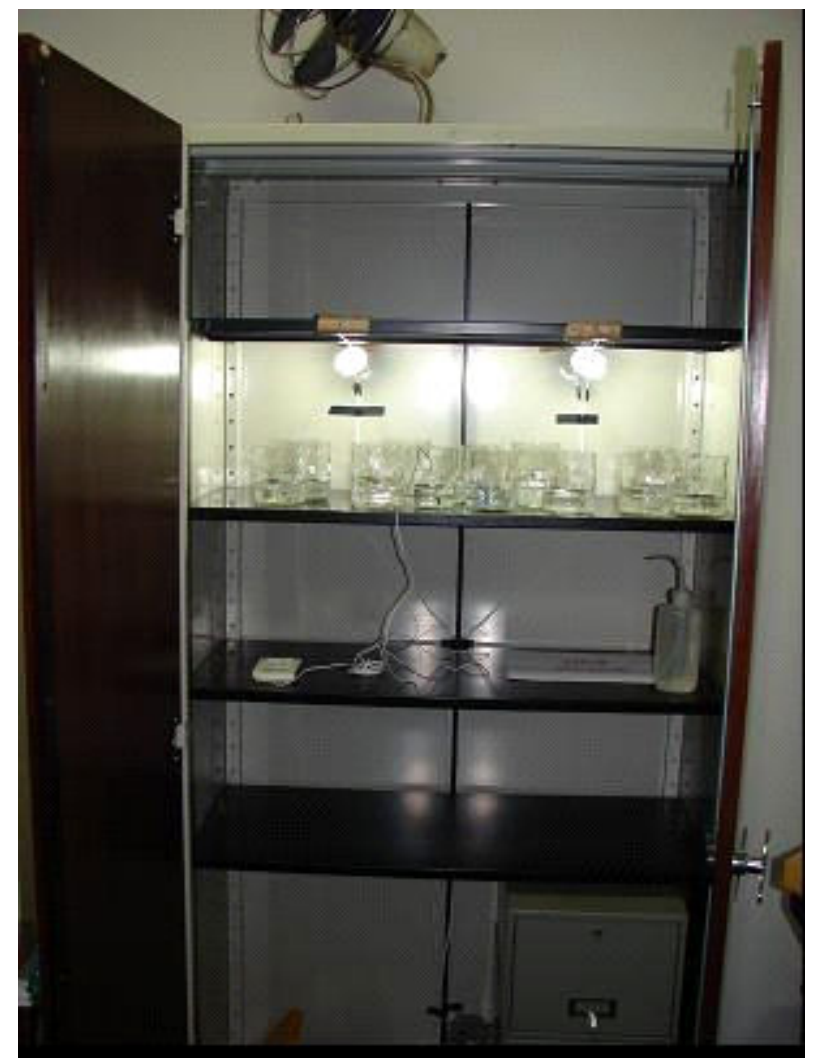

Figura 3.11 - Estrutura (armário) usada para a germinação das sementes (controle de temperatura da água entre $20{ }^{\circ} \mathrm{C}$ e $24{ }^{\circ} \mathrm{C}$ )

\subsection{ANÁLISES LABORATORIAIS E ESTATÍSTICAS}

\section{Análises físicas e químicas da água}

As leituras das variáveis rotineiras foram realizadas no LQA/DEA. A avaliação de qualidade da água foi feita de acordo com o preconizado em Standard Methods for the Examination Water and Wastewater (APHA, AWWA e WEF, 2005), os métodos e/ou equipamentos utilizados para essas variáveis estão sumarizados na Tabela 3.1.

A extração, recuperação e leitura das concentrações de ametrina foram realizadas no LAQUA/DEQ, a partir da seguinte metodologia, adaptada da proposta de Vieira (2005):

(i) a extração do composto com o uso dos solventes acetonitrila (Tedia Brazil) e acetato de etila (Carlo Erba Reagenti), na proporção 2/1 (solventes/amostra). No presente estudo, adicionou-se, a 5,0 mL de amostra, um volume de 8,5 $\mathrm{mL}$ de acetonitrila e 1,5 $\mathrm{mL}$ de acetato de etila; 
(ii) a mistura descrita anteriormente foi agitada (200 rpm, em mesa agitadora) durante $20 \mathrm{~min}$;

(iii) o material foi resfriado a $0^{\circ} \mathrm{C}$ por, no mínimo, $12 \mathrm{~h}$;

(iv) procedeu-se a extração e filtração do solvente, com um volume recuperado de $10,0 \mathrm{~mL}$;

(v) o herbicida foi quantificado por cromatografia gasosa, para tanto utilizou-se um cromatógrafo Shimadzu 17A com o software Class-CR10 acoplado, detector por ionização de chama FID RANGE $\varnothing-300{ }^{\circ} \mathrm{C}$ e coluna cromatográfica BP-5 J\&W, o padrão analítico utilizado foi fornecido pela Sipcam Agro S.A. $(95,9 \% \mathrm{~m} / \mathrm{m})$;

(vi) em caso de não detecção do composto, realizava-se a concentração da amostra por meio de ventilação forçada, o concentrado era novamente injetado no cromatógrafo para a leitura.

Tabela 3.1 - Métodos e/ou equipamentos usados no monitoramento de variáveis rotineiras no LQA/DEA

\begin{tabular}{cc}
\hline Variável & Método/equipamento \\
Série de sólidos & Oxidação química em refluxo aberto \\
Nitrogênio total & $\begin{array}{c}\text { Método gravimétrico, com uso de estufa, forno tipo } \\
\text { mufla e filtração em membrana de fibra de vidro } \\
\text { Fósforo total } \\
\text { Prómica de Oxigênio }\end{array}$ \\
Turbide e potássio & Digestão nítrico-perclórico e espectrofotometria \\
Potencial hidrogeniônico & Turbidímetro de bancada \\
Potencial de oxi-redução & Peagâmetro de bancada \\
Condutividade elétrica & Potenciômetro de bancada \\
Temperatura & Condutivímetro de bancada \\
Alcalinidade & Termômetro de mercúrio \\
& Método potenciométrico e titulométrico proposto por \\
& Ripley, Boyle e Converse (1986) \\
\hline
\end{tabular}


Nos ensaios com traçadores, referentes ao Capítulo 4 (Hidrodinâmica dos SACs) foram determinadas concentrações destes solutos por fluorescência. Para tanto, utilizou-se um espectrofluorímetro marca Turner Designs, modelo TD-700 do Laboratório de Traçadores da COPPE.

\section{Análises nutricionais e morfo-anatômicas na planta}

As análises nutricionais em tecido vegetal foram feitas após secagem do material em estufa, sob temperatura de $65{ }^{\circ} \mathrm{C}$ e posterior trituração em moinho tipo Wiley, de acordo com as recomendações de Kiehl (1985). A quantificação de metais e outros compostos não mensurados anteriormente foram feitas com uso de espectrofotometria de emissão de plasma (Espectrômetro Perkin Elmer, modelo Optima 3300 N), após digestão nítrico-perclórico da amostra, no Laboratório de Espectofotometria Atômica do DPS.

No estudo em casa de vegetação, foram realizadas, também, análises morfoanatômicas do tecido vegetal da taboa. Como realizado em um estudo anterior (Barros, 2005), o material botânico foi fixado em $\mathrm{FAA}_{50}$ e armazenado em álcool etílico. O material incluído em historresina foi seccionado a $8 \mu \mathrm{m}$ de espessura em micrótomo rotativo (Leica RM 2155); a coloração usada foi o azul de toluidina (Kraus e Arduim, 1997). As lâminas permanentes foram montadas em permount.

A captura das imagens para a realização das análises anatômicas foi realizada com uso do microscópio Leica DM IB e dos aplicativos Leica IM50 e Easy Grab. Para obtenção das medidas lineares, foi utilizado o programa Image Pro-Plus.

\section{Análise do substrato}

Ao fim da aplicação contínua de ametrina nos SACs da AETR, foi realizada a medição de teor de matéria orgânica no substrato (com ignição em forno tipo mufla, no LQA/DEA). Nos estudos em estufa, foram feitas análises de respirometria em amostras do meio suporte (respirômetro CA 2A - U12, Sable System do Laboratório de Biotecnologia Ambiental e Biodiversidade do BIOAGRO). 


\section{Análises estatísticas}

Os resultados foram discutidos com uso de estatística descritiva e, quando possível, de inferência estatística.

Para análises de caráter qualitativo, as possíveis diferenças significativas entre os dados $(\alpha=0,05)$ foram observadas com o uso dos testes de Lillierfors e Bartlett (para verificação da normalidade e homogeneidade) seguidos da aplicação do teste de Tukey ou do teste não paramétrico de Kruskal-Wallis, quando pertinentes. Quando se estudaram tratamentos de caráter quantitativo, utilizou-se análise de regressão e/ou teste de médias (Tukey) para comparação do tratamento com o controle. Essas análises também foram efetuadas em nível de significância de 5\%.

As análises estatísticas foram efetuadas utilizando-se os aplicativos Microsoft Excel, Microcal Origin e SAEG.

\subsection{REFERÊNCIAS BIBLIOGRÁFICAS}

APHA [AMERICAN PUBLIC HEALTH ASSOCIATION]; AWWA [AMERICAN WATER WORKS ASSOCIATION]; WEF [WATER ENVIRONMENT FEDERATION]. Standard methods for the examination of water and wastewater. $21 \mathrm{ed}$. Washington: APHA/ AWWA/ WEF, 2005. 1268p.

BARROS, A. L. Morfo-anatomia e teor de nutrientes em três espécies vegetais cultivadas em sistema "wetland construído". 2005. 70f. Dissertação (Mestrado em Botânica) Universidade Federal de Viçosa, Viçosa.

BRASIL, M. S. Desempenho de sistema alagado construído para tratamento de esgoto doméstico. 2005. 160f. Tese (Doutorado em Engenharia Agrícola) - Universidade Federal de Viçosa, Viçosa.

BRASIL, M. S. et al. Modelling of pollution removal in constructed wetlands with horizontal subsurface flow. Agrartechnische Forschung, Potsdam, v.13, n.2, p.48-56, 2007. 
KRAUS, J. E.; ARDUIN, M. Manual básico de métodos em morfologia vegetal. Seropédica: Editora Universidade Rural, 1997. 198p.

KIEHL, E. J. Fertilizantes orgânicos. Piracicaba: Agronômica Ceres, 1985. 492p.

RIPLEY, L.E.; BOYLE, W.C.; CONVERSE, J.C. Improved alkalimetric monitoring for anaerobic digestion of high-strengh wastes. Journal of Water Pollution Control Federation, Washington, v.58, n.5, p.406-411, 1986.

VIEIRA, H. P. Otimização e validação da extração simultânea de piretróides em água e solo e análise por cromatografia gasosa. 2005. 65f. Dissertação (Mestrado em Agroquímica) - Universidade Federal de Viçosa, Viçosa. 


\section{CAPÍTULO 4}

USO DE TRAÇADORES PARA AVALIAÇÃO DA HIDRODINÂMICA DE ALAGADOS CONSTRUÍDOS OPERANDO SOB CLIMA TROPICAL 


\section{USO DE TRAÇADORES PARA AVALIAÇÃO DA HIDRODINÂMICA DE ALAGADOS CONSTRUIIDOS OPERANDO SOB CLIMA TROPICAL}

\section{RESUMO}

Sistemas alagados construídos (SACs) são, atualmente, importante opção para o tratamento de resíduos e controle da poluição pontual e difusa. O uso de SACs com escoamento subsuperficial horizontal tem aumentado ano a ano, mas o nível de entendimento da hidrodinâmica do processo não tem crescido na mesma proporção. Traçadores fluorescentes apresentam-se como opção na determinação de curvas de distribuição de tempos de residência (DTR) e de parâmetros hidráulicos, como número de dispersão e eficiência hidráulica. A pesquisa foi realizada com o objetivo de se avaliar dois corantes (fluorescina sódica e rodamina WT) na determinação das características hidrodinâmicas de SACs com escoamento subsuperficial, operando sob estação chuvosa, em região tropical. Três unidades de escoamento subsuperficial horizontal $(0,5 \% ; 1,0 \%$ e $1,5 \%$ de declive) cultivadas com $T$. latifolia em brita $\left(\mathrm{D}_{60}=7,0 \mathrm{~mm}\right)$ foram usadas nessa avaliação. Os tempos de residência experimentais $\left(\tau_{R}\right)$ para os SACs variaram entre 4,5 d e 5,0 d e os parâmetros de modelos teóricos foram obtidos para cada sistema, indicando dispersões muito pequenas. Os SACs, que apresentavam relação geométrica de 24/1, se comportaram como sistemas de escoamento próximo ao pistonado. Embora a massa total adicionada não tenha sido recuperada (a adsorção é um dos mecanismos de perda), a pesquisa indicou que a rodamina WT pode ser utilizada com resultados satisfatórios na avaliação do comportamento hidrodinâmico de SACs de escoamento subsuperficial.

PALAVRAS-CHAVE: comportamento hidrodinâmico, DTR, fluorescina sódica, número de dispersão, rodamina WT, wetlands construídas. 


\title{
FLUORESCENT DYES FOR HYDRODYNAMIC EVALUATION OF CONSTRUCTED WETLANDS UNDER TROPICAL CONDITIONS CLIMATE
}

\begin{abstract}
Constructed wetlands $(\mathrm{CW})$ systems are an important wastewater treatment option at nowadays. Subsurface flow (SSF) constructed wetlands are one of the main types on use and in researches on these systems dyes tracer experiments are an appropriate tool to determine residence time distribution (RDT) curves and parameters of hydrodynamic models, as a wetland dispersion numbers and hydraulic efficiency. The goals of this paper are to evaluate and compare the performance of two fluorescent tracers (sodium fluorescein and rhodamine WT) on SSF-CW hydraulic characteristics determination. Three horizontal flow cells $(0.5 \%$; $1.0 \%$ and $1.5 \%$ of slope) with a porous gravel $(7 \mathrm{~mm}$ diameter) and cultivated with T. latifolia macrophytes were used for this evaluation. The cells were operated at actual hydraulic residence time $\left(\tau_{\mathrm{R}}\right)$ of a $4.5 \mathrm{~d} \sim 5.0 \mathrm{~d}$ range and the parameters of theoretical models were obtained for each system, indicating very low dispersion. The CWs with length/widths ratio equal to 24 presented as plug flow near systems. Although the recovery of total amount were small (high sorption is one of loss mechanisms during these type of studies), rhodamine WT is a suitable tracer in mesocosms SSF constructed wetland systems study.
\end{abstract}

KEYWORDS: hydrodynamic behavior, RTD, sodium fluorescein, wetland dispersion number, rhodamine WT, constructed wetlands. 


\subsection{INTRODUÇÃO}

Devido a vantagens inerentes a um processo natural, a adoção de alagados construídos (SACs) de escoamento subsuperficial, como sistemas controle de poluição pontual e difusa, vêm crescendo ano a ano (Shutes, 2001). Contudo o nível de entendimento dos fatores envolvidos no processo não tem aumentado na mesma proporção (Vymazal, 2005).

Variáveis hidrológicas (como evapotranspiração na área cultivada) e hidráulicas (como condições de escoamento) têm importância fundamental no projeto e na operação satisfatória de SACs. Hodgson, Perkins e Labadz (2004), por exemplo, lembram que todos os parâmetros usados no monitoramento da eficiência de SACs são função do tempo de residência hidráulico no sistema. De acordo com King, Mitchell e Howes (1997), como dados sobre o comportamento hidrodinâmico de SACs operando em escoamento subsuperficial ainda são escassos, as estimativas para alguns parâmetros de projeto são feitas assumindo-se o modelo idealizado de escoamento tubular pistonado.

O desvio dessa condição ideal pode ser relacionado aos processos dispersivos na unidade, mensurados pelo parâmetro adimensional números de dispersão (d). Segundo a US EPA (2000), quando os valores de d superam 0,200, considera-se que haja grande dispersão no SACs; por outro lado, se d for inferior a 0,025 , sugere-se condição próxima ao escoamento pistonado ideal. Metcalf e Eddy (2003) citaram valores semelhantes, mas não idênticos para os graus de dispersão em sistemas de tratamento de efluentes (Tabela 4.1). King, Mitchell e Howes (1997) e Simi e Mitchell (1999) citaram que o valor de d em SACs de escoamento subsuperficial varia entre 0,070 a 0,350 .

Tabela 4.1 - Números de dispersão em reatores, segundo Metcalf e Eddy (2003)

\begin{tabular}{cc}
\hline Grau de dispersão & Número de dispersão \\
\hline Pistonado ideal & $\mathrm{d}=0$ \\
Baixa dispersão & $\mathrm{d}<0,050$ \\
Dispersão moderada & $0,050 \leq \mathrm{d} \leq 0,250$ \\
Alta dispersão & $\mathrm{d}>0,250$ \\
Mistura completa & $\mathrm{d} \rightarrow \infty$ \\
\hline
\end{tabular}


A avaliação da dispersão em um SAC pode ser feita com a sua distribuição de tempos de residência (DTR), curva que descreve a probabilidade de uma fração do fluido permanecer no volume de controle estudado, por um determinado tempo. As curvas DTR podem ser obtidas a partir da técnica de estímulo e resposta com o uso de traçadores conservativos. No entanto, o ajuste dos modelos de escoamento e a obtenção dos parâmetros hidráulicos podem ser dificultados pelas condições ambientais locais e processos biológicos que ocorrem em SACs de escoamento sub-superficial. Portanto, na escolha dos traçadores a serem usados, fatores como toxicidade, reatividade, solubilidade e limite de detecção devem ser considerados (Dierberg e DeBusk, 2005).

Corantes fluorescentes são substâncias orgânicas que possuem a propriedade de emitir luz visível em um comprimento de onda característico, quando excitados por uma onda específica (Fonseca, 2005). Segundo Zaluski (2001) e Flury e Wai (2003), o uso de corantes fluorescentes como traçadores possui, reconhecidamente, as seguintes vantagens em relação à outras substâncias: (i) são de fácil quantificação em água, (ii) são detectáveis mesmo em baixas concentrações e (iii) não apresentam toxicidade.

Werner e Kadlec (1996) propuseram modificações na maneira de se obter as distribuições de tempos de residência, aplicando a teoria da DTR a situações com variação na taxa de escoamento volumétrico. A proposta se mostrou aplicável em situações como sistemas receptores de escoamentos pluviais intensos, ocasionados em decorrência de tempestades, por exemplo.

A presente investigação foi realizada com os objetivos de (i) avaliar o uso dos corantes fluorescentes rodamina WT e fluorescina sódica como traçadores em SACs vegetados de escoamento subsuperficial e (ii) determinar, segundo a metodologia de Werner e Kadlec (1996), os parâmetros hidráulicos que definem o comportamento hidrodinâmico de SACs com diferentes inclinações, operando sob estação chuvosa, em região tropical.

\subsection{REFERENCIAL TEÓRICO}

Nessa seção são abordados tópicos relativos a aspectos fundamentais no estudo da hidrodinâmica de sistemas de tratamento. As informações teóricas aqui contidas são apresentadas e discutidas com profundidade nos textos de Fogler (2001) e Levenspiel (1999) e 
no trabalho de Werner e Kadlec (1996), que aplicaram a teoria de distribuição de tempos de residências a alagados construídos operando com vazões variáveis.

Devido às contribuições pluviométricas e à evapotranspiração da cultura - que sob clima tropical atinge valores significativos - a vazão efluente em um SAC não é sempre equivalente à vazão aplicada. A vazão média do sistema $\left(\mathrm{Q}_{\mathrm{SIS}}\right)$ pode ser calculada pela média dos valores das vazões afluente $\left(\mathrm{Q}_{\mathrm{AF}}\right)$ e de saída $\left(\mathrm{Q}_{\mathrm{EF}}\right)$ :

$$
\mathrm{Q}_{\mathrm{SIS}}=\frac{\mathrm{Q}_{\mathrm{AF}}+\mathrm{Q}_{\mathrm{EF}}}{2}
$$

O tempo de residência nominal $\left(\tau_{\mathrm{N}}\right)$ em um SAC de escoamento subsuperficial horizontal é dado pela razão entre o volume $\left(\mathrm{V}_{\mathrm{SIS}}\right)$ e a vazão média no sistema $\left(\mathrm{Q}_{\mathrm{SIS}}\right)$ :

$$
\tau_{\mathrm{N}}=\frac{\mathrm{V}_{\mathrm{SIS}}}{\mathrm{Q}_{\mathrm{SIS}}}
$$

Segundo García et al. (2004), a qualidade de um teste hidrodinâmico depende da razão de recuperação do traçador. A massa recuperada no teste $\left(\mathrm{M}_{0}\right)$ é dada pelo soma das massas quantificadas nas iésimas observações (Dierberg e DeBusk, 2005):

$$
\mathrm{M}_{0}=\sum_{\mathrm{i}=1}^{\mathrm{n}}\left(\mathrm{Q}_{\mathrm{EF}_{\mathrm{i}}} \mathrm{c}_{\mathrm{i}} \Delta \mathrm{t}_{\mathrm{i}}\right)
$$

O traçador ideal deve ser um material que, possuindo características o mais próximas possível do fluido em estudo, apresente alguma propriedade que o diferencie para que possa ser detectado analiticamente, ainda que em concentrações reduzidas.

Quando um sinal de traçador tipo pulso ideal é adicionado na entrada de um sistema, a resposta normalizada é chamada curva $\mathrm{C}$, obtida a partir da divisão das concentrações de traçador medidas na corrente de saída (c) pela área sob a curva concentração-tempo (A):

$$
\mathrm{A}=\frac{\mathrm{M}_{0}}{\mathrm{Q}_{\mathrm{SIS}}}
$$

A curva C é então, definida por:

$$
\mathrm{C}_{\mathrm{i}}=\frac{\mathrm{c}_{\mathrm{i}}}{\mathrm{A}}
$$


A distribuição do tempo de residência (DTR) do fluido, ou curva E, obtida a partir da técnica de estímulo e resposta, é uma função estatística que descreve a probabilidade de uma fração de partículas do fluido permanecer no volume de controle por um determinado tempo. O conceito foi introduzido por P. V. Danckverts, em 1953 e desde então tem sido utilizado intensamente em uma gama variada de processos.

Segundo de Nardi (1997), esta técnica experimental consiste em verificar a resposta do sistema estudado a um estímulo qualquer; via de regra, adiciona-se uma quantidade conhecida do traçador na corrente que entra no recipiente, registrando-se sua saída com o tempo no exutório do sistema. Pela maior simplicidade, os sinais do tipo pulso e degrau são mais utilizados nesses experimentos e quando se dispõe de poucos dados numéricos, as funções são descritas na forma discretizada.

A curva de DTR é obtida pela expressão (4.6) e seu primeiro momento $\left(\mathrm{M}_{1}\right)$ equivale ao tempo de residência experimental $\left(\tau_{R}\right)$ (equação 4.7$)$ :

$$
\begin{gathered}
E_{i}=\frac{Q_{E F_{i}} c_{i}}{M_{0}} \\
\tau_{R}=M_{1}=\frac{\sum_{i=i}^{n} t_{i} E_{i} \Delta t_{i}}{\sum_{i=i}^{n} E_{i} \Delta t_{i}}
\end{gathered}
$$

Com o uso das funções nas formas adimensionais, torna-se possível a comparação entre sistemas de operando sob diferentes condições. Define-se então o tempo de residência adimensional $(\theta)$, obtido com a divisão do tempo decorrido da adição do traçador $(\mathrm{t})$ pelo tempo de residência experimental $\left(\tau_{\mathrm{R}}\right)$ :

$$
\theta_{\mathrm{i}}=\frac{\mathrm{t}_{\mathrm{i}}}{\tau_{\mathrm{R}}}
$$

Dessa maneira tem-se a curvas C e E na forma adimensional:

$$
\begin{aligned}
& \mathrm{C}_{\theta_{\mathrm{i}}}=\mathrm{C}_{\mathrm{i}} \tau_{\mathrm{R}}=\frac{\mathrm{c}_{\mathrm{i}} \mathrm{Q}_{\mathrm{SIS}}}{\mathrm{M}_{0}} \tau_{\mathrm{R}} \\
& \mathrm{E}_{\theta_{\mathrm{i}}}=\mathrm{E}_{\mathrm{i}} \tau_{\mathrm{R}}=\frac{\mathrm{Q}_{\mathrm{EF}_{\mathrm{i}}} \mathrm{c}_{\mathrm{i}}}{\mathrm{M}_{0}} \tau_{\mathrm{R}}
\end{aligned}
$$


Em situações onde a vazão seja constante e não ocorram variações de velocidades, difusões ou turbilhões no fluido, as curvas C equivalem a DTR ou distribuição de idade de saída (de Nardi, 1997; Sassaki, 2005).

A avaliação das curvas-resposta abordadas pode ser feita por meio de funções estatísticas. A locação do centróide da distribuição, por exemplo, equivale ao tempo de residência experimental $\left(\tau_{\mathrm{R}}\right)$ e variância da função pode ser associada à magnitude da dispersão da distribuição.

Werner e Kadlec (1996) atentaram para falhas no uso de funções estatísticas citadas em situações com vazão variável, como ocorre em SACs operando sob condições climáticas tropicais, na estação chuvosa, por exemplo. Os pesquisadores propuseram, então, um método para estender a teoria da DTR a esses sistemas. A proposta consiste em normalizar ambos os eixos (abscissas e ordenadas), eliminando a influência devido às variações nas vazões. Aproximações semelhantes já haviam sido sugeridas na engenharia química e de processos por Niemi (1977) e Fernández-Sempere, Font-Montesinos e Espejo-Alcaraz (1995).

Em um sistema com vazões variáveis são verificados tempos menores para o transporte de um volume fixo quando a vazão é grande. Já quando a taxa de escoamento é pequena, mais tempo é demandado para a condução do mesmo volume. O volume de líquido que deixou o sistema em determinado tempo após a adição do traçador é dado por:

$$
\mathrm{V}_{\mathrm{EF}_{\mathrm{i}}}=\sum_{\mathrm{i}=1}^{\mathrm{n}}\left(\mathrm{Q}_{\mathrm{EF}_{\mathrm{i}}} \Delta \mathrm{t}_{\mathrm{i}}\right)
$$

A forma normalizada desse volume é definida como vazão volumétrica ponderada $(\phi)$ :

$$
\phi_{\mathrm{i}}=\frac{\mathrm{V}_{\mathrm{EF}_{\mathrm{i}}}}{\mathrm{V}_{\mathrm{SIS}}}
$$

A abscissa (tempo) é convertida, dessa maneira, em um "tempo ponderado pelas vazões", ou seja, o parâmetro $\phi$. A curva adimensional $\mathrm{C}_{\theta}$, agora denotada como $\mathrm{C}_{\phi}$, deve então ser usada na ordenada, pois ao contrário da curva $E_{\theta}$, ela não depende das vazões parciais, como pode ser observado nas equações (4.9) e (4.10).

Com a rotina apresentada, as funções correspondentes aos momentos da curva $\mathrm{C} \phi$ são então obtidas: 


$$
\begin{gathered}
\mathrm{M}_{0^{*}}=\sum_{\mathrm{i}=1}^{\mathrm{n}} \mathrm{C}_{\phi_{\mathrm{i}}} \Delta \phi_{\mathrm{i}}=1 \\
\mathrm{M}_{1^{*}}=\frac{\sum_{\mathrm{i}=1}^{\mathrm{n}} \phi_{\mathrm{i}} \mathrm{C}_{\phi_{\mathrm{i}}} \Delta \phi_{\mathrm{i}}}{\mathrm{M}_{0^{*}}}=1 \\
\mathrm{M}_{2^{*}}=\frac{\sum_{\mathrm{i}=1}^{\mathrm{n}} \phi_{\mathrm{i}}{ }^{2} \mathrm{C}_{\phi_{\mathrm{i}}} \Delta \phi_{\mathrm{i}}}{\mathrm{M}_{0^{*}}}-\mathrm{M}_{1^{*}}{ }^{2}=\sigma_{\phi}^{2}
\end{gathered}
$$

De acordo com Werner e Kadlec (1996), o valor de $\mathrm{M}_{1 *}$ só será igual à unidade caso um valor "correto" de $V_{\text {SIS }}$ seja obtido. Nesse experimento, os volumes ocupados pelos SACs foram calculados da forma como sugerida pelos autores, sendo que $\mathrm{V}_{\mathrm{AC}}$ corresponde à soma dos volumes efluentes coletados em cada observação (equação 4.16).

$$
\mathrm{V}_{\mathrm{SIS}}=\frac{\sum_{\mathrm{i}=1}^{\mathrm{n}}\left(\mathrm{V}_{\mathrm{AC}_{\mathrm{i}}} \mathrm{Q}_{\mathrm{EF}_{\mathrm{i}}} \mathrm{c}_{\mathrm{i}} \Delta \mathrm{t}_{\mathrm{i}}\right)}{\mathrm{M}_{0}}
$$

A partir dos valores de variância adimensional (equação 4.15) são obtidos os valores de número adimensional de dispersão (d), que indicam o grau de mistura do sistema. $\mathrm{Na}$ equação 4.17, u representa a velocidade do fluido, L o comprimento característico e D o coeficiente de dispersão. Assim, para d nulo tem-se uma dispersão muito pequena, representando o escoamento tubular. Já para d tendendo ao infinito, tem-se um sistema perfeitamente misturado.

$$
\mathrm{d}=\frac{\mathrm{D}}{\mathrm{uL}}
$$

$\mathrm{Na}$ presente pesquisa, foram obtidos os valores de números $\mathrm{d}$ de modelos hidrodinâmicos de dispersão (pequena intensidade e grande intensidade), a fim de se avaliar o grau de dispersão nos SACs implantados sob condições climáticas tropicais, operando em estação chuvosa. As expressões que descrevem como o parâmetro d é obtido em cada modelo estão visualizadas na Tabela 4.2. No final do estudo, também se avaliou a viabilidade do uso de equações empíricas da literatura para a predição da dispersão em SACs. 
Tabela 4.2 - Equações de modelos matemáticos usadas para obtenção do número adimensional de dispersão

Modelo hidrodinâmico Equação para obtenção de d

$$
\mathrm{d}=\frac{\sigma_{\phi}^{2}}{2}
$$

Dispersão de grande intensidade

(reator fechado)

$$
\sigma_{\phi}^{2}=2 d-2 d^{2}\left[1-\exp \left(-\frac{1}{d}\right)\right]
$$

Dispersão de grande intensidade

(reator aberto)

$$
\sigma_{\phi}^{2}=2 d+8 d^{2}
$$

Dispersão de grande intensidade

(reator aberto-fechado)

$$
\sigma_{\phi}^{2}=2 d+3 d^{2}
$$

A variância normalizada e o número de dispersão determinam as condições hidrodinâmicas a partir da curva do traçador mas não consideram qualquer perda no volume útil. Alguns autores têm usado então o conceito de "eficiência hidráulica" $(\lambda)$, que avalia tanto a curva quanto o volume efetivo utilizado. Este parâmetro pode ser calculado a partir do tempo no qual é detectado o pico de concentração do traçador e do tempo de residência nominal (Persson, Somes e Wong, 1999):

$$
\lambda=\frac{\mathrm{t}_{\mathrm{P}}}{\tau_{\mathrm{N}}}
$$

Com a obtenção dos parâmetros citados, a comparação de diferentes unidades de tratamentos torna-se viável até mesmo para SACs operando sob cargas hidráulicas distintas.

\subsection{METODOLOGIA}

\section{Localização e caracterização do experimento}

O experimento foi conduzido durante o mês de dezembro de 2006, na Área Experimental de Tratamento de Resíduos (AETR) do DEA/CCA/UFV, em Viçosa, MG. 
Os ensaios foram realizados em SACs com escoamento subsuperficial horizontal, projetados e estudados por Brasil (2005). Os SACs foram utilizados para tratamento secundário de esgotos domésticos no período de julho de 2004 a janeiro de 2005. A partir de então, as unidades foram alimentadas continuamente com água bombeada de uma das represas do ribeirão São Bartolomeu, situada no campus da UFV.

As características construtivas dos leitos $\left(24 \mathrm{~m}^{2}\right.$ cada) foram descritas no Capítulo 3. Os SACs foram construídos com inclinações de fundo correspondentes a 0,5\% (unidade A); 1,0\% (unidades B e C) e 1,5\% (unidade D). Na presente investigação, foram usadas as unidades A, C e D; como aquelas que não possuíam inclinações iguais, o perfil da altura das lâminas de água variava de unidade para unidade.

\section{Substâncias traçadoras}

No experimento, foram utilizados corantes fluorescentes xantílicos que, devido a suas propriedades, podem ser utilizados como substâncias traçadoras: a rodamina WT e a fluorescina sódica (também conhecida como uranina).

A rodamina WT (Pylam, Inc.) foi adquirida na forma líquida concentrada (20\%) do Laboratório de Saneamento do SHS/EESC/USP. A fluorescina sódica em pó provinha do Laboratório de Traçadores (LT/COPPE/CT/UFRJ).

A Tabela 4.3 contém as principais características dos corantes utilizados e na Figura 4.1 estão visualizadas suas estruturas químicas correspondentes.

Tabela 4.3 - Traçadores usados nos ensaios (Adaptado de Flury e Wai, 2003)

\begin{tabular}{|c|c|c|c|c|}
\hline Traçador & $\mathrm{CI}^{(\mathrm{a})}$ & $\# \mathrm{CAS}^{(\mathrm{b})}$ & $\begin{array}{c}\mathrm{MM}^{(\mathrm{c})} \\
\left(\mathrm{g} \mathrm{mol}^{-1}\right)\end{array}$ & $\begin{array}{l}\lambda^{(\mathrm{d})} \\
(\mathrm{nm})\end{array}$ \\
\hline Fluorescina sódica (FS) & Acid Yelow 73 & $518-47-8$ & 376,3 & 513 \\
\hline Rodamina WT (RWT) & Acid Red 388 & $37299-86-8$ & 567,0 & 555 \\
\hline (a) Color Index Generic Nam & & & & \\
\hline (b) Chemical Abstract Servic & nber, CAS; & & & \\
\hline (c) Massa molecular; & & & & \\
\hline (d) Excitação máxima. & & & & \\
\hline
\end{tabular}




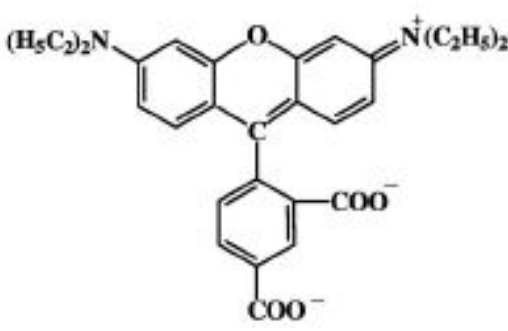

(a)

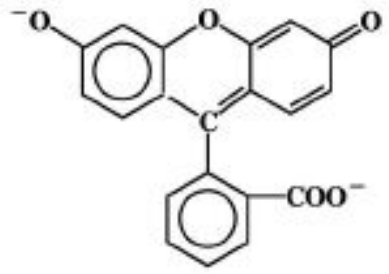

(b)

Figura 4.1 - Estrutura química dos corantes fluorescentes utilizados no estudo (a) rodamina WT e (b) fluorescina sódica

\section{Procedimento experimental}

Os sistemas foram abastecidos com água bruta bombeada de um dos reservatórios da universidade e as vazões aplicadas eram equivalentes a $770 \mathrm{~L} \mathrm{~d}^{-1}$ para a unidade $\mathrm{A}, 600 \mathrm{~L} \mathrm{~d}^{-1}$ para a unidade C e $450 \mathrm{~L} \mathrm{~d}^{-1}$ para a unidade D. Dessa maneira, embora com volumes úteis e cargas hidráulicas distintas, todos os sistemas possuíam o mesmo tempo de residência hidráulico nominal teórico. Cabe ressaltar que essa previsão de $t_{N}$ foi feita sem considerar as precipitações e a perda por evapotranspiração nos SACs.

As soluções dos traçadores fluorescentes, com densidade igual à da fase líquida, foram injetadas na forma de pulso na zona de entrada de cada SAC. Foram tomadas precauções para assegurar que a injeção dos corantes fosse a mais próxima possível de um sinal de entrada na forma de pulso ideal: a injeção foi feita em um curto intervalo de tempo (1,5 min) e o volume utilizado $(50 \mathrm{~L})$ foi pequeno se comparado ao volume de líquido residente nas unidades.

Para o preparo das soluções de injeção, foram adicionados $100 \mathrm{mg}$ de cada traçador em recipientes contendo $50 \mathrm{~L}$ de água bruta. Portanto, em cada SAC foram adicionados 100 mg de rodamina WT e $100 \mathrm{mg}$ de fluorescina sódica em concentrações equivalentes a $2 \mathrm{mg} \mathrm{L}^{-1}$.

Após a adição dos corantes, foram realizadas coletas manuais de amostras simples nos pontos de saída dos SACs, para a obtenção dos valores de concentrações dos traçadores. A amostragem foi feita durante um tempo equivalente ao dobro do $t_{N}$ previsto inicialmente. No decorrer do experimento, também foram monitoradas as variáveis $\mathrm{pH}$ e temperatura no líquido efluente.

As amostras foram acondicionadas em frascos plásticos opacos com capacidade para $20 \mathrm{~mL}$, protegidos da luminosidade. Em cada frasco foi adicionada uma gota de clorofórmio, 
para a preservação biológica das amostras. As 73 coletas efetuadas em cada SAC foram feitas em intervalos de tempo irregulares (mínimos de 1 hora e máximos de 4 horas), considerandose a residência teórica estimada.

Entre duas amostragens consecutivas, mediu-se, nos reservatórios de saída, o volume de efluente gerado em cada unidade. Com este procedimento, os valores de evapotranspiração (ET) foram estimados. Os dados obtidos por esta aproximação foram validados quando comparados aos dados climatológicos (precipitação e evaporação no tanque classe A e evapotranspiração de referência) da estação climatológica da Universidade Federal de Viçosa.

\section{Monitoramento das variáveis estudadas}

A temperatura do líquido efluente foi medida com um termômetro de mercúrio. $\mathrm{O} \mathrm{pH}$ foi monitorado por meio de um peagâmetro de bancada (Digimed DM-20).

Os volumes efluentes nos intervalos entre as coletas foram mensurados de maneira direta, com a calibração volumétrica dos reservatórios de saída. A vazão de alimentação era mantida constante, por meio de aferição nas válvulas de afluência. Foram obtidos, na estação climatológica do DEA/CCA/UFV, os valores de evapotranspiração do tanque classe $\mathrm{A}$, precipitação e temperatura média do ar.

As concentrações efluentes dos corantes foram quantificadas por fluorescência, com auxílio de curvas de calibração, obtidas a partir de diluições das soluções adicionadas aos SACs $\left(2 \mathrm{mg} \mathrm{L}^{-1}\right)$. A fluorescência das amostras foi determinada em espectrofluorímetro marca Turner Designs, modelo TD-700. Conforme especificado pelo fabricante, para a leitura de fluorescina sódica, o equipamento usa uma lâmpada de mercúrio azul, um filtro de excitação (486 nm) e um filtro de emissão $(510 \mathrm{~nm} \sim 700 \mathrm{~nm})$. Já para as análises da rodamina, foi usada uma lâmpada de quartzo claro, um filtro de excitação $(550 \mathrm{~nm})$ e um filtro de emissão $(570 \mathrm{~nm})$. Na Figura 4.2, podem ser visualizadas as curvas (retas) de calibração utilizadas. 


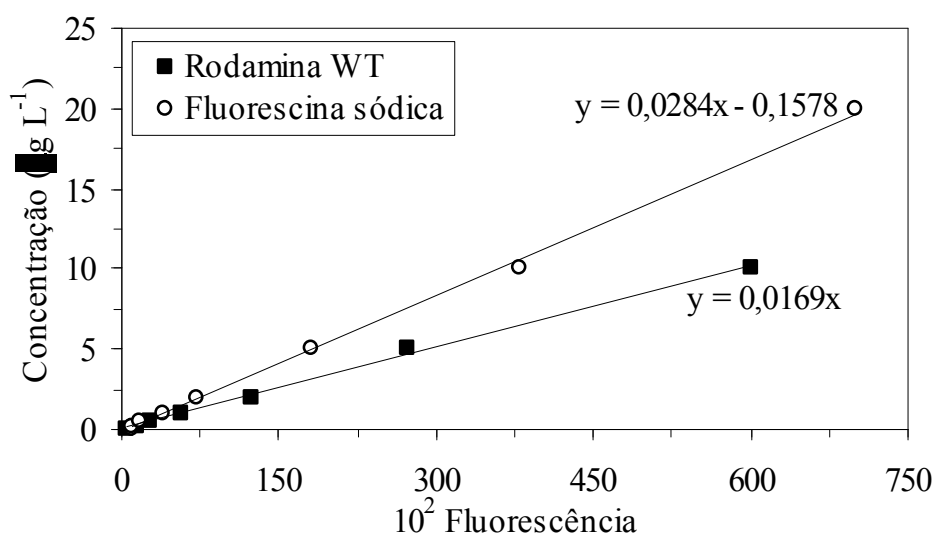

Figura 4.2 - Curvas de calibração utilizadas para quantificação da concentração dos traçadores fluorescentes

\subsection{RESULTADOS E DISCUSSÃO}

A partir da medição de fluorescência nas amostras, foram obtidas as concentrações dos corantes ao longo do tempo do ensaio. Nas Figuras 4.3, 4.4 e 4.5 estão apresentadas as curvas de concentração versus tempo para os SACs A, C e D, respectivamente.

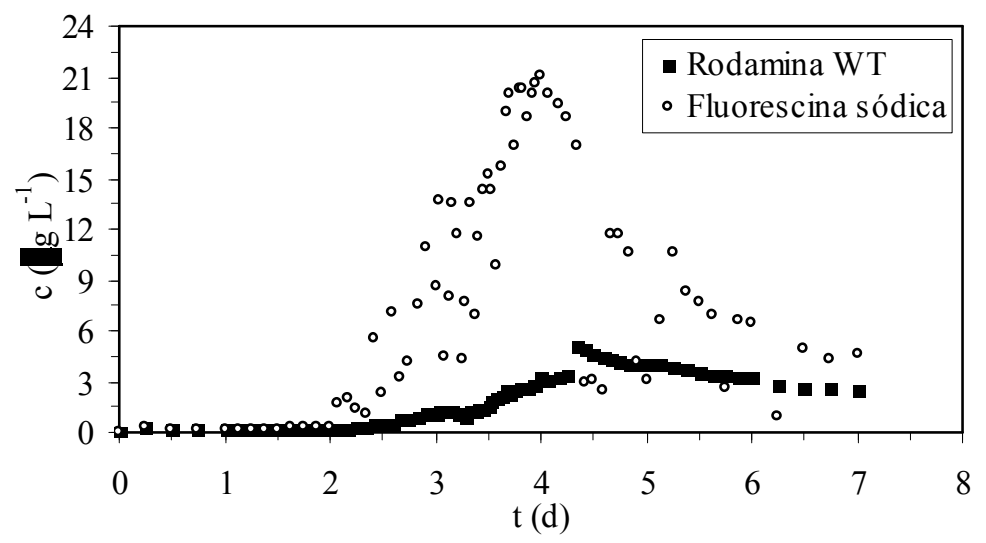

Figura 4.3 - Concentrações dos traçadores florescentes na saída do SAC A 


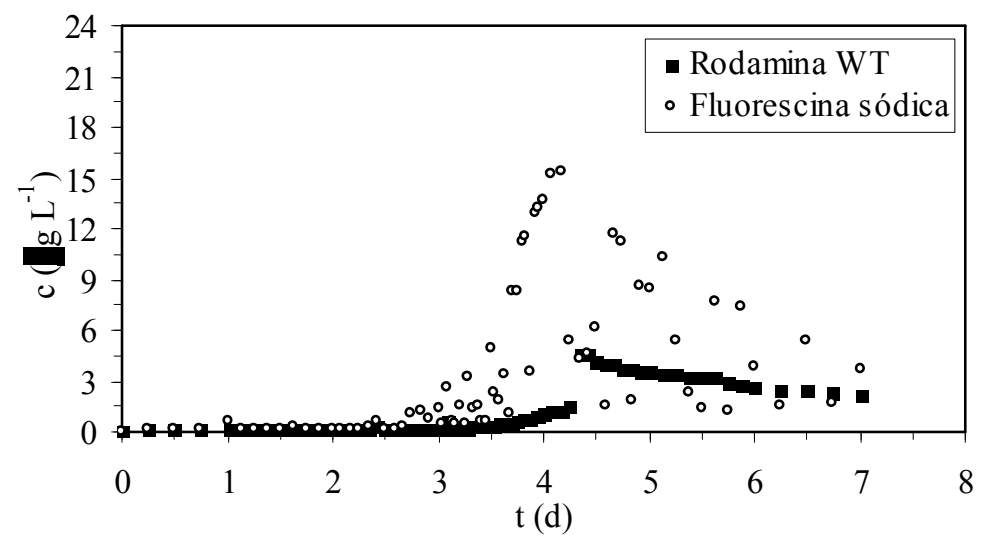

Figura 4.4 - Concentrações dos traçadores florescentes na saída do SAC C

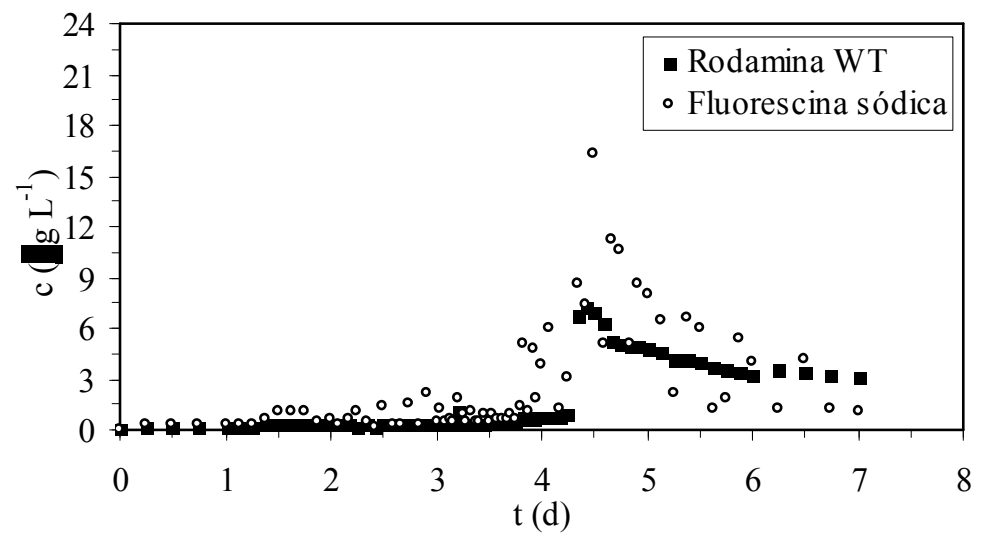

Figura 4.5 - Concentrações dos traçadores florescentes na saída do SAC D

Como pode ser observado nas figuras acima, a detecção de uranina foi maior em todos os sistemas. De maneira preliminar, também podem ser citadas as longas caudas apresentadas no formato das curvas, principalmente no que se refere ao corante rodamina WT. Tal fenômeno reflete o lento sinal do traçador na saída dos sistemas.

Não se observou tempo de retardo para que valores mínimos fossem detectados na saída dos sistemas, fato que poderia ser associado às fortes chuvas que ocorreram durante o ensaio ou a condições de grande mistura. No entanto, verifica-se que os picos de passagem dos traçadores se deram após o tempo inicial estimado de 3,5 d, o que indica que mesmo na estação chuvosa deve-se considerar a evapotranspiração da cultura. O rebatimento dos pontos à montante do pico, tal como feito por Lima, Silveira e Zaiat (2004), proporcionaria melhor visualização da passagem do traçador pelo sistema, mas possivelmente subestimaria a massa 
total recuperada. Os valores de massa recuperada (média de 15\%) estão próximos aos verificados por Hodgson, Perkins e Labadz (2004) e podem ser considerados reduzidos, se comparados aos obtidos em experimentos de bancada. A recuperação observada seria maior se as amostras fossem coletadas por mais extenso período de tempo.

Dierberg e DeBusk (2005) compararam o desempenho dos traçadores rodamina WT e cloreto de lítio em pequenas unidades de escoamento livre, com $1,74 \mathrm{~m}^{2}$ de área superficial. Os pesquisadores que reportaram grandes eficiências de recuperação no ensaio principal analisaram, paralelamente, a adsorção/dessorção e a fotólise dos compostos em um sistema em batelada. A principal conclusão da pesquisa é que reduções na recuperação dos traçadores não afetaram a acurácia de obtenção dos parâmetros hidráulicos derivados da análise do método dos momentos da RTD, desde que uma resposta concentração-tempo seja discernível na curva. Tal afirmação baseia-se no fato de que as perdas (da rodamina) obedecem a reações de ordem zero e são irreversíveis.

Lin et al. (2003) reafirmam tais proposições, indicando a rodamina WT como uma substância de desempenho satisfatório no uso como traçador. Investigando um SAC de escoamento livre, em condições de campo, os pesquisadores relataram uma recuperação de 29\% de rodamina WT e também atribuíram as perdas da substância ao mecanismo de sorção irreversível.

Embora o escoamento adotado fosse subsuperficial, há de se prever também uma possível ocorrência de fotodegradação dos corantes. Smith e Pretorius (2002) ressaltaram que a fluorescina é degradada rapidamente, quando exposta a alta luminosidade. Outro fator importante é a perda de fluorescência devido a variações no $\mathrm{pH}$. Na faixa de valores monitorados ( $\mathrm{pH}$ equivalente a 6,3 $\pm 0,2$ ) não há influência na fluorescência da rodamina WT, entretanto, na fluorescina pode provocar mudanças em suas propriedade espectrais (Flury e Way, 2003).

O monitoramento dos volumes acumulados nos reservatórios de saída durante os intervalos das amostragens permitiu que fossem quantificados in loco os valores do conjunto das componentes hidrológicas (evapotranspiração e precipitação) nos SACs. Quanto à evapotranspiração, no caso específico da Typha latifolia, Brasil (2005) obteve, nos mesmos SACs utilizados neste experimento, valores médios de $9,3 \mathrm{~mm} \mathrm{~d}^{-1}$. Os valores obtidos para a parcela [P-ET] no presente experimento foram validados quando comparados aos dados da estação climatológica local e indicam evapotranspiração nessa ordem de valores (descontados 
os volumes precipitados). Na Figura 4.6 visualiza-se a média de contribuições e perdas de água registradas nos SACs.

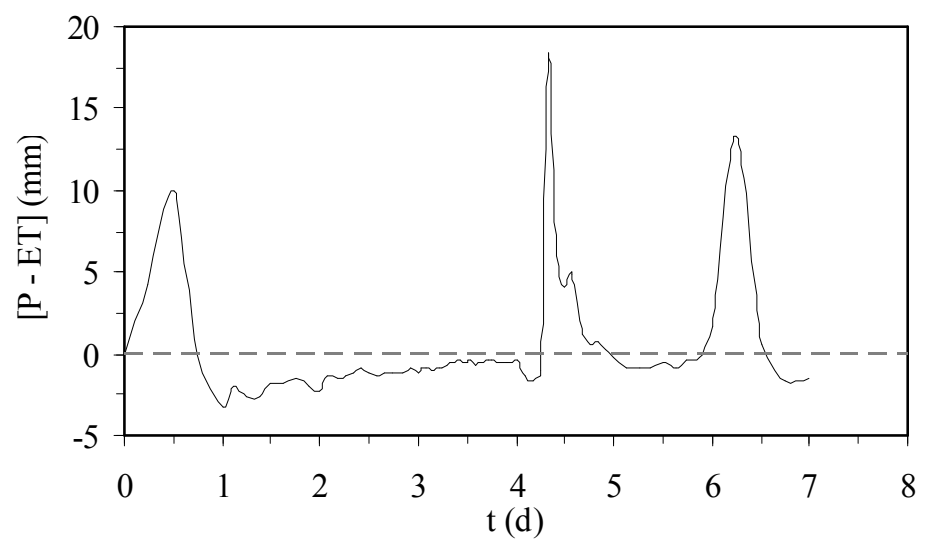

Figura 4.6 - Balanço hídrico obtido pelo monitoramento dos volumes efluentes

Com base no balanço hídrico de cada SAC, foi possível quantificar a vazão média (equação 4.1) e o tempo de residência teórico (equação 4.2). Devido à diferença entre a vazão aplicada na zona de entrada e as vazões médias (obtidas somente após o cômputo do balanço hídrico), os tempos de residências teóricos nas unidades foram maiores que o tempo estimado inicialmente $(3,5 \mathrm{~d})$.

Com a obtenção das hidrógrafas das vazões médias durante as amostragens, foi possível a obtenção da curva de DTR, segundo a proposta de Werner e Kadlec (1996). Como exemplo para visualização, estão plotadas na Figura 4.7 as curvas adimensionais $C_{\theta}$ e as corrigidas $\mathrm{C}_{\phi}$ para o $\mathrm{SAC} \mathrm{A}$, com uso de rodamina $\mathrm{WT}$ como traçador.

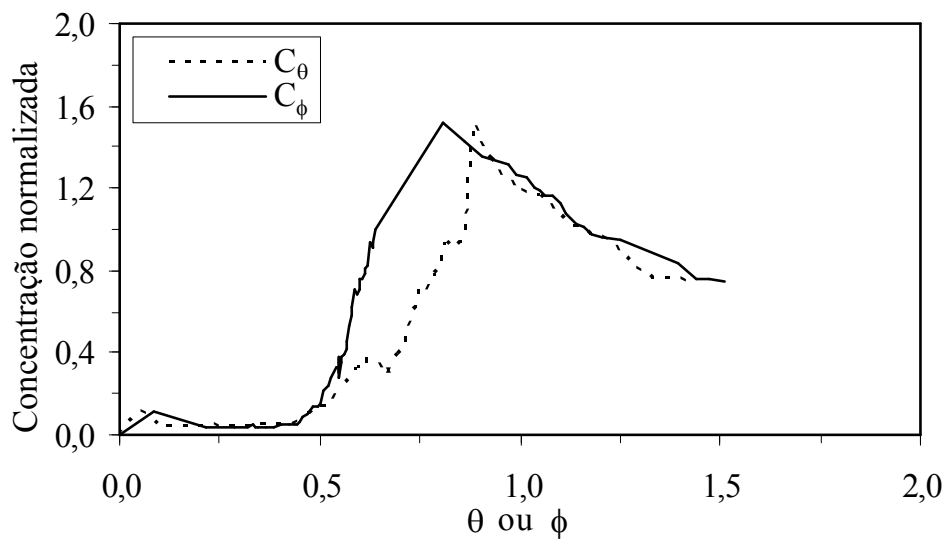

Figura 4.7 - Comparação entre os perfis de saída para as funções $C_{\theta}$ e $C_{\phi}$ versus o tempo normalizado ou volume ponderado normalizado 
Nota-se que, trabalhando com o volume ponderado normalizado $\phi$, há um deslocamento da curva para a esquerda; as contribuições ou perdas extremas também são minimizadas nessa aproximação. $\mathrm{O}$ uso da função $\mathrm{C}_{\phi}$ permitiu a obtenção das medidas estatísticas que descrevem o comportamento hidrodinâmico e as condições de mistura. Como ressaltam Werner e Kadlec (1996), devido às possíveis diferenças entre as cargas hidráulicas em cada sistema, a comparação de similaridades ou discrepâncias entre as curvas poderia não ser observada, caso sejam usados os métodos convencionais de obtenção de RTD.

Na Tabela 4.4 são apresentados os valores dos parâmetros hidráulicos obtidos nos ensaios, cujos perfis podem ser visualizados nas Figuras 4.8 e 4.9.

Tabela 4.4 - Valores de tempos de residência nominais, experimentais, tempos de pico, variância adimensional e eficiência hidráulica obtidos para SACs de diferentes declividades

\begin{tabular}{|c|c|c|c|c|c|c|c|c|c|c|}
\hline \multirow{2}{*}{ SAC } & & & & & \multirow{2}{*}{ RWT } & \multirow[b]{2}{*}{ FS } \\
\hline & RWT & FS & RWT & FS & RWT & FS & RWT & FS & & \\
\hline $\mathbf{A}$ & 4,5 & 3,9 & 4,9 & 4,5 & 4,3 & 4,3 & 0,078 & 0,093 & 0,97 & 1,10 \\
\hline C & 5,0 & 4,7 & 5,0 & 4,9 & 4,3 & 4,3 & 0,068 & 0,094 & 0,87 & 0,93 \\
\hline D & 5,0 & 4,6 & 5,0 & 4,7 & 4,3 & 4,5 & 0,087 & 0,075 & 0,87 & 0,99 \\
\hline
\end{tabular}

Observa-se que não houve variações consideráveis em relação aos parâmetros obtidos para diferentes inclinações de fundo. Os tempos de residência nominal estão semelhantes para as unidades mais inclinadas (C e D), e ligeiramente maiores que o SAC com menor inclinação de fundo. Quando observados os resultados obtidos no ensaio com a rodamina WT, verificase que os valores de tempo de residência experimental ficaram muito próximos. A eficiência hidráulica $\lambda$ para as três unidades atingiu valores acima de 0,87 . Segundo Persson, Somes e Wong (1999) wetlands $\operatorname{com} \lambda$ superior a 0,75 apresentam boa condição hidráulica e valores inferiores à 0,50 denotam uma $\lambda$ "pobre".

García et al. (2004) verificaram que sistemas de escoamento subsuperficial com razão L/B maior que 4 apresentaram boas eficiências e que o parâmetro $\lambda$ apresentou correlação com a dispersão. Nos SACs com números de dispersão d inferiores a 0,08 a $\lambda$ sempre foi maior que 0,75 . 


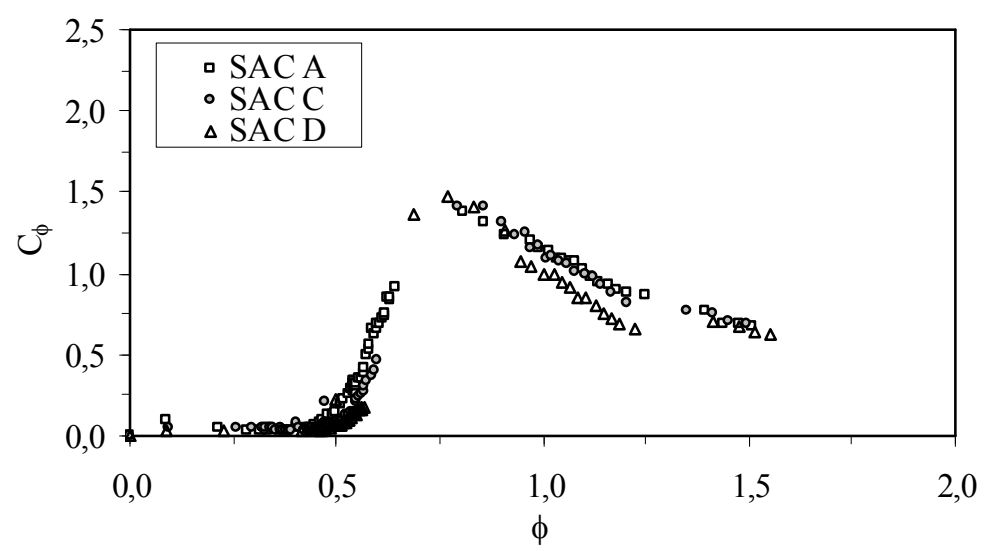

Figura 4.8 - Perfis de concentração de rodamina WT plotados usando o volume ponderado normalizado $\phi$ : comparação de SACs com diferentes inclinações de fundo e cargas hidráulicas aplicadas

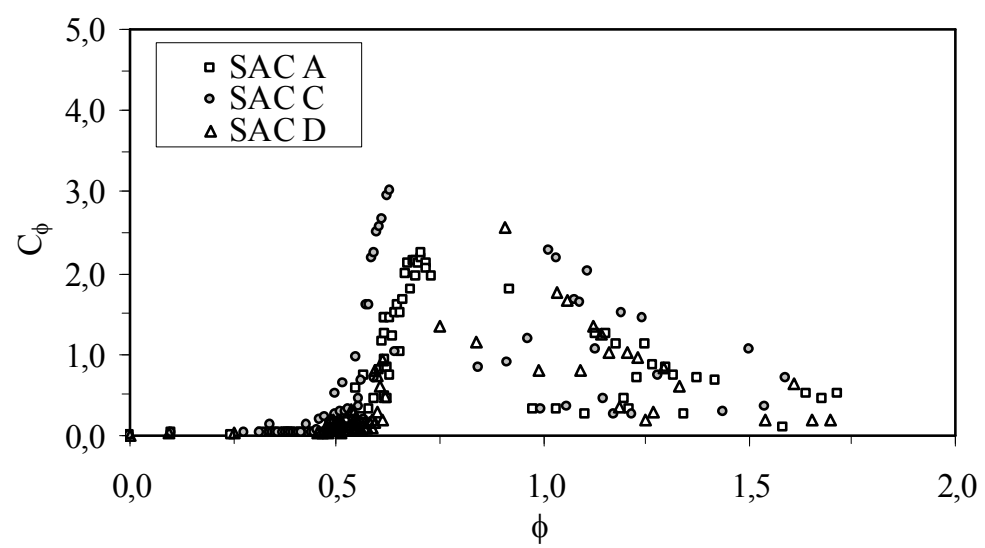

Figura 4.9 - Perfis de concentração de fluorescina sódica plotados usando o volume ponderado normalizado $\phi$ : comparação de SACs com diferentes inclinações de fundo e cargas hidráulicas aplicadas

Verifica-se que o tipo de corante utilizado no ensaio influencia, sobremaneira, os resultados dos parâmetros hidráulicos. De acordo com a natureza do material traçador, resultados diferentes podem ser produzidos. Em sistemas com biofilme fixo formado em suporte inerte como SACs de escoamento subsuperficial, a perda de quantidades por adsorção de difusão no suporte é maior que em SACs de escoamento livre.

O tempo de surgimento dos picos de concentração foi inferior ao $\tau_{R}$ em todas as curvas, tal fenômeno indica a formação de pequenos canais preferenciais e ocorrência de 
regiões de estagnação. Para o corante uranina, observa-se grande variação na curva após o pico de concentração do composto. Tal fato poderia ser atribuído à recirculação do fluido no sistema, o que não corresponde ao observado para a rodamina WT, portanto supõe-se que a fluorescina sofreu maior difusão nos poros da brita usada como substrato, já que sua massa molecular é inferior à da rodamina. Também se ressalta que a detecção desse corante em pequenas concentrações (menos que $5 \mu \mathrm{g} \mathrm{L}^{-1}$ ) é mais difícil, fato verificado quando são comparadas as curvas (retas) de calibração para detecção dos compostos.

O fenômeno de cauda observado advém principalmente de fenômenos de difusão e adsorção do traçador no substrato dos sistemas, resultante da retenção superficial e contenção do produto nos poros e em várias pequenas regiões estagnadas geradas pelo suporte poroso. Lima, Silveira e Zaiat (2004) observaram o mesmo fenômeno em um sistema anaeróbio de tratamento com volume útil de aproximadamente $90 \mathrm{~L}$.

Os valores observados para os tempos de residência nominais sempre foram inferiores aos estimados pelas curvas experimentais. Embora se saiba que valores $\tau_{N} / \tau_{R}$ inferiores à unidade indiquem presença de zonas mortas no sistema, cabe ressaltar que Harden et al. (2003), comparando rodamina WT e fluorescina com um traçador gasoso $\left(\mathrm{SF}_{6}\right)$ e um biológico (PRD-1) observaram que corantes fluorescentes superestimaram os tempos de residência nos sistemas de tratamento por disposição no solo (escoamento subsuperficial).

As estimativas da dispersão nos sistemas foram feitas com os números d, obtidos utilizando-se as equações sugeridas na Tabela 4.2. Como pode ser observado na Tabela 4.5, o uso dos dois corantes resulta em estimativas ligeiramente discrepantes, contudo, não há diferença observável para as unidades estudadas,

As expressões analíticas disponíveis para a determinação de d se diferem de acordo com as condições de contorno. O modelo de pequena intensidade não se apresenta como alternativa para análise, uma vez que sua curva resultante é elaborada em condições em que $\mathrm{d}<0,010$. Segundo Kadlec, Wallace e Vymazal (2004), os SACs horizontais geralmente se apresentam sob condições conhecidas como recipientes fechados. Nessa situação, as características do escoamento nas seções de entrada e de saída são diferentes das que ocorrem no interior da unidade.

A despeito das diferenças observadas entre as unidades e os traçadores, verifica-se que o grau de dispersão nos SACs estudados é baixo. Os valores do número de dispersão obtidos estão inferiores à média observada na literatura. Tal fato pode ser atribuído à considerável 
relação L/B nas células estudadas. Na implantação dos SACs em estudo, optou-se por dividir, com muretas de concreto, uma área vegetada total de $24 \mathrm{~m}$ por $4 \mathrm{~m}$ nas 4 unidades da estação.

Tabela 4.5 - Valores do número adimensional d, obtidos para os modelos de dispersão de pequena e grande intensidade

\begin{tabular}{|c|c|c|c|c|c|c|c|c|}
\hline \multirow[t]{2}{*}{ SAC } & \multicolumn{2}{|c|}{$\begin{array}{c}\text { Pequena } \\
\text { intensidade }\end{array}$} & \multicolumn{2}{|c|}{$\begin{array}{c}\text { Grande } \\
\text { intensidade } \\
\text { (fechado) }\end{array}$} & \multicolumn{2}{|c|}{$\begin{array}{c}\text { Grande } \\
\text { intensidade } \\
\text { (aberto) }\end{array}$} & \multicolumn{2}{|c|}{$\begin{array}{c}\text { Grande } \\
\text { intensidade } \\
\text { (aberto-fechado) }\end{array}$} \\
\hline & RWT & FS & RWT & FS & RWT & FS & RWT & FS \\
\hline $\mathbf{A}$ & 0,039 & 0,046 & 0,041 & 0,049 & 0,034 & 0,040 & 0,037 & 0,044 \\
\hline C & 0,034 & 0,047 & 0,035 & 0,049 & 0,030 & 0,040 & 0,032 & 0,044 \\
\hline D & 0,043 & 0,038 & 0,045 & 0,038 & 0,038 & 0,033 & 0,041 & 0,036 \\
\hline
\end{tabular}

Cothren, Chen e Pardue (2002), avaliando pequenos SACs de $4,32 \mathrm{~m}^{2}$, relataram que a dispersão observada em unidades operando em escoamento subsuperficial variou basicamente em função dos perfis de velocidades de escoamento e da razão comprimento/largura. García et al. (2004) verificaram decréscimo nos valores de dispersão com o aumento da razão L/B. Os pesquisadores obtiveram números de dispersão na ordem de 0,050 para unidades $\left(54 \mathrm{~m}^{2} \sim\right.$ $56 \mathrm{~m}^{2}$ ) com comprimento equivalente ao dobro da largura.

Os números de dispersão obtidos, na ordem de 0,040 , sugerem que o movimento dos traçadores no sistema foi governado por processos advectivos e dispersivos, de maneira semelhante às observadas em outros SACs de escoamento subsuperficial, tal como observado por García et al. (2004) e Grismer, Tausendschoen e Shepherd (2001). Outra observação importante é que, no caso estudado, o número obtido pela equação de von Sperling (2002), que iguala d à razão B/L, é equivalente a 0,041, o que indica haver grande correlação com os dados obtidos via perfis de DTR.

A obtenção dos parâmetros hidráulicos com confiabilidade mostra-se fator importante, aplicável no controle operacional, na verificação da adequação construtiva e na investigação de não conformidades do sistema. Ressalta-se, contudo, a necessidade da previsão de mudança no comportamento hidrodinâmico em SACs ao longo do tempo, devido a fatores 
como diminuição da porosidade efetiva no sistema e perdas na condutividade hidráulica nos primeiros metros das unidades.

\subsection{SUMÁRIO}

Nos ensaios realizados em três SACs com escoamento subsuperficial, verificou-se perda dos traçadores devido, principalmente, à adsorção ao substrato e ao leito orgânico presente. Os parâmetros hidráulicos d e $\lambda$ obtidos foram maiores, se consideradas as curvas DTR, para fluorescina, que se dispersou mais no meio. As curvas obtidas com o uso da rodamina WT apresentaram menor discrepância em seus valores; além disso, a detecção desse corante não foi prejudicada com mudanças ambientais, tais como no $\mathrm{pH}$ do meio.

As perdas de traçadores podem ser consideradas irreversíveis e a recuperação de quantidades de traçadores inferiores às adicionadas não afetou a obtenção dos parâmetros hidráulicos (tempo de residência experimental, números adimensionais de dispersão e eficiência hidráulica nos SACs). Corantes fluorescentes, como a rodamina WT, podem ser usados na predição do comportamento hidrodinâmico de SACs de escoamento subsuperficial.

A proposta modificada para obtenção de distribuição de tempos de residência para SACs operando sob chuvas em condições climáticas tropicais se mostrou satisfatória, com obtenção das variâncias adimensionais a partir de curvas $\phi$ normalizadas em ambos os eixos.

A ocorrência de escoamentos predominantemente pistonados foi devida, basicamente, à geometria das unidades; a predição de ocorrência de volumes mortos pode ter sido superestimada, devido à adsorção dos traçadores no leito, com conseqüente subestimativa das velocidades de escoamento. Não se observaram variações na hidrodinâmica devido à implantação de diferentes inclinações de fundo nos SACs e, de acordo com os parâmetros obtidos, as unidades estudadas, projetadas para tratamento de efluentes pontuais e difusos, apresentaram comportamento hidrodinâmico com boa eficiência hidráulica e dispersões muito pequenas $(\mathrm{d} \approx 0,040)$. 


\subsection{REFERÊNCIAS BIBLIOGRÁFICAS}

BRASIL, M. S. Desempenho de sistema alagado construído para tratamento de esgoto doméstico. 2005. 160f. Tese (Doutorado em Engenharia Agrícola) - Universidade Federal de Viçosa, Viçosa.

COTHREN, G. M.; CHEN, S.; PARDUE, J .H. Investigation of subsurface flow constructed wetlands designs. Public Works Management and Policy, Thousand Oaks, v.7, n.1., p.3245, 2002.

de NARDI, I. R. Influência das características do traçador nas curvas de distribuição de tempos de residência em reator anaeróbio horizontal de leito fixo (RAHLF). 1997. $91 \mathrm{f}$. Dissertação (Mestrado em Engenharia Hidráulica e Saneamento) - Universidade de São Paulo, São Carlos.

DIERBERG, F. E.; DeBUSK, T. A. An evaluation of two tracers in surface-flow wetlands: rhodamine-WT and lithium. Wetlands, Lawrence, v.25, n.1, p.8-25, 2005.

FERNÁNDEZ-SEMPERE, J., FONT-MONTESINOS, R., ESPEJO-ALCARAZ, O. Residence time distribution for unsteady-state systems. Chemical Engineering Science, Oxford, v.50, n.2, pp.223-230, 1995.

FOGLER, H. S. Elements of chemical reaction engineering. 3 ed. Englewood Cliffs: Prentice-Hall, 2001. 967p.

FONSECA, P. W. Avaliação do desempenho e caracterização de parâmetros em lagoas facultativa e de maturação. 2005. 124f. Dissertação (Mestrado em Engenharia Civil) Universidade Federal do Rio de Janeiro, Rio de Janeiro.

FLURY, M.; WAI, N. N. Dyes as tracer for vadose zone hydrology. Reviews of Geophysics, Washington, v.41, n.1, art.1002, 2003.

GARCÍA, J. et al. Hydraulic behaviour of horizontal subsurface flow constructed wetlands with different aspect ratio and granular medium size. Ecological Engineering, Amsterdam, v.23, n.3, p.177-187, 2004. 
GRISMER, M. E.; TAUSENDSCHOEN, M.; SHEPHERD, H. L. Hydraulic characteristics of a subsurface flow constructed wetland for winery effluent treatment. Water Environment Research, Alexandria, v.73, n.4, p.466-477, 2001.

HARDEN, H. S. et al. Comparison of sulfur hexafluoride, fluorescein and rhodamine dyes and the bacteriophage PRD-1 in tracing subsurface flow. Journal of Hydrology, Amsterdam, v.277, n.1-2, p.100-115, 2002.

HODGSON, C. J.; PERKINS, J.; LABADZ, J. C. The use of microbial tracers to monitor seasonal variations in effluent retention in a constructed wetland. Water Research, Oxford, v.38, n.18, p.3833-3844, 2004.

KADLEC, R. H.; WALLACE, S.; VYMAZAL, J. Treatment wetlands. 2 ed. Boca Raton: CRC-Lewis, 2004. 800p.

KING, A. C.; MITCHELL, C. A.; HOWES, T. Hydraulic tracer studies in a pilot scale subsurface flow constructed wetland. Water Science and Technology, Londres, v.35, n.5, p.189-196, 1997.

LEVENSPIEL, O. Chemical Reaction Engineering. 3 ed. Nova Iorque: Wiley, 1999. 668p.

LIMA, C. A. A. L.; SILVEIRA, A.; ZAIAT, M. Considerações sobre ensaios hidrodinâmicos em reator anaeróbio horizontal de leito fixo (RAHLF) tratando esgoto sanitário. In: SIMPÓSIO BRASILEIRO DE ENGENHARIA AMBIENTAL, 3, 2004, Brasília. Anais... Brasília: UCB, 2004. CD-ROM.

LIN, A. Y. C. et al. Comparison of rhodamine WT and bromide in the determination of hydraulic characteristics of constructed wetland. Ecological Engineering, Amsterdam, v.20, n. 1, p. $75-88,2003$.

METCALF e EDDY, Inc. Wastewater engineering treatment and reuse. 4 ed.

TCHOBANOGLOUS, G.; BURTON, F. L.; STENSEL, H. D. (eds.). Nova Iorque: McGrawHill, 2003. 1819p. 
NIEMI, A. J. Residence time distributions of variable flow processes. International Journal of Applied Radiation and Isotopes, Oxford, v.28, n.10-11, p.855-860, 1977.

PERSSON, J.; SOMES, N. L. G.; WONG, T. H. F. Hydraulics efficiency of constructed wetlands and ponds. Water Science and Technology, Londres, v.40, n.3, p.291-300, 1999.

SASSAKI, R. A. Distribuição de tempos de residência em sistemas alimentados com vazão variável. 2005. 89f. Dissertação (Mestrado em Engenharia Civil) - Universidade Federal do Rio de Janeiro, Rio de Janeiro.

SIMI, A. L.; MITCHELL, C. A. Design and hydraulic performance of a constructed wetland treating oil refinery wastewater. Water Science and Technology, Londres, v.40, n.3, p.301308, 1999.

SMITH, S. A.; PRETORIUS, W. A. The conservative behaviour of fluorescein. Water SA, Pretoria, v.28, n.4, p.203-206, 2002.

SHUTES, R. B. E. Artificial wetlands and water quality improvement, Environment International, Oxford, v.26, n.5-6, p.441-447, 2001.

US EPA [US ENVIRONMENTAL PROTECTION AGENCY]. Constructed wetlands treatment of municipal wastewaters. Cincinnati: US EPA, 2000. 165p. EPA/625/R-99/012.

von SPERLING, M. Princípios de tratamento biológico de águas residuárias, v.3: lagoas de estabilização, 2 ed. Belo Horizonte: DESA/UFMG, 2002. 196p.

VYMAZAL, J. Constructed wetlands for wastewater treatment. Ecological Engineering, Amsterdam, v.25, n.5, p.475-477, 2005.

WERNER, T. M.; KADLEC, R. H. Application of residence time distributions to stormwater treatment systems. Ecological Engineering, Amsterdam, v.7, n.3, p.213-234, 1996. 
ZALUSKI, M. Tracer test. In: WEIGHT, W. D.; SONDEREGGER, J. L. (eds.). Manual of applied field hydrogeology. Nova Iorque: McGraw-Hill, 2001. p.525-551. 


\section{CAPÍTULO 5}

USO DE ALAGADOS CONSTRUÍDOS DE ESCOAMENTO SUBSUPERFICIAL PARA MITIGAÇÃO DA CONTAMINAÇÃO DE ÁGUAS COM AMETRINA 


\section{USO DE ALAGADOS CONSTRUIIDOS DE ESCOAMENTO SUBSUPERFICIAL PARA MITIGAÇÃO DA CONTAMINAÇÃO DE ÁGUAS COM AMETRINA}

\section{RESUMO}

A viabilidade da utilização de sistemas alagados construídos (SACs) na mitigação da contaminação de águas poluídas com praguicidas vem sendo estudada na última década, no entanto, poucos são as pesquisas prevendo o uso de sistemas do tipo subsuperficial (SSF), com essa finalidade. $\mathrm{Na}$ presente proposta, avaliou-se a resposta de um conjunto de sistemas alagados com escoamento subsuperficial, quando adicionado o herbicida sistêmico ametrina diluído em água bruta. Um dos SACs foi preservado da contaminação, sendo usado como controle. O monitoramento do comportamento do sistema foi realizado por meio de análises das variáveis rotineiras de qualidade da água, acompanhamento das concentrações de ametrina por cromatografia gasosa e pela análise agronômica e nutricional da espécie cultivada (Typha latifolia). Após a adição contínua do composto durante 11 semanas, observou-se que 39\% da quantidade adicionada foi retida ou transformada; a metabolização e mineralização do composto foi realizada por via química e biológica. A importância da parte vegetal foi confirmada tendo em vista que os processos bióticos de fitoremediação e degradação microbiana contribuíram para a remoção de poluentes. Feito o corte raso nos sistemas, não foram notadas diferenças nutricionais entre as macrófitas do SAC controle e dos demais; além disso, verificou-se grande produção de biomassa (fonte de energia renovável) nas unidades. Os SACs foram capazes de mitigar a contaminação de água superficiais por praguicidas, podendo agir como filtros-tampão entre as fontes de emissão e os corpos hídricos.

PALAVRAS-CHAVE: herbicidas, ametrina, alagados construídos, bioremediação, mitigação. 


\title{
FEASIBILITY OF SUBSURFACE FLOW CONSTRUCTED WETLANDS FOR MITIGATION OF AMETRYN WATER CONTAMINATION
}

\begin{abstract}
\end{abstract}
The feasibility of constructed wetlands $(\mathrm{CW})$ use for pesticides effects mitigation on water bodies has been studied in the last decade. However, a lack is verified when subsurface flow wetland systems (SSF) are considered for this purpose. In the present work a system with SSF constructed wetlands submitted to ametryn herbicide addition was evaluated. One control CW cell was preserved of pesticide contamination. The system performance monitoring was realized by standard water quality parameters, chromatography ametryn quantification and the macrophyte (Typha latifolia) nutritional and agronomic properties analysis. At the end of the research, after 11 weeks of continuous ametryn addition in CWs, $39 \%$ of the total amount added was removed/ transferred or transformed; the metabolization and mineralization of the compost was made by chemistry and biologic ways. The vegetative part important role is confirmed when the phytoremediation and microbial degradation processes is accounted. No statistic differences in nutritional contents were observed after the T. latifolia crop in CWs; moreover, great biomass production (one valuable source of renewable energy) was observed in wetland cells. Constructed wetland systems are capable of to mitigate the water contamination effects due the pesticides addition. The CWs act as a buffer filters between the emission fonts and the superficial water bodies.

KEYWORDS: herbicides, ametryn, constructed wetlands, bioremediation, mitigation. 


\subsection{INTRODUÇÃO}

Em resposta à demanda crescente por maior produtividade agrícola, registrou-se, nos últimos 50 anos, aumento intensivo na produção e uso de agroquímicos, tais como fungicidas, inseticidas, nematicidas e, principalmente, herbicidas. Dentre os últimos, os compostos do grupo das triazinas são os mais comercializados, sendo usados no controle pré e pósemergência de plantas invasoras (ervas daninhas) nas mais variadas culturas. Alguns autores, como Solomon et al. (1996) e Spadotto et al. (2004) atestaram que o referido aumento no uso de praguicidas pode causar riscos ecológicos e sanitários às comunidades usuárias de corpos hídricos contaminados com ingredientes ativos desses compostos.

A ametrina (nome IUPAC: N-etil-N'-(1-metiletil)-6-(metiltio)-1,3,5-triazina-2,4diamina) é uma importante triazina, usada como herbicida sistêmico principalmente nas culturas de cana-de-açúcar, citrus, café e milho. O uso não controlado, somado às características físicas e químicas do composto (Tabela 5.1) resulta na detecção de concentrações potencialmente danosas nas águas escoadas de áreas de cultivo dessas espécies vegetais (Costa Queiroz et al., 1999; Cabral et al., 2003). Além disso, citam-se como prováveis fontes de contaminação aquática a não devolução das embalagens dos agroquímicos, o escoamento de viveiros de mudas e de gramados de atividades esportivas, possíveis contratempos na fabricação dos agroquímicos, a deriva durante a aplicação, por pulverização, de praguicidas e a emissão de esgotos contendo concentrações-traço desses produtos.

Em virtude da comprovada capacidade de depuração das wetlands naturais, sistemas alagados artificiais ou construídos (SACs) têm sido utilizados com bons resultados no tratamento de águas residuárias domésticas, agrícolas e industriais (IWA, 2000; Kadlec, Wallace e Vymazal, 2004). Embora utilizados na agropecuária para o tratamento de águas residuárias de criatórios de animais (Knight et al., 2000; Hunt e Poach, 2001), águas servidas de laticínios (Healy, Rodgers e Mulqueen, 2007) e nutrientes (Vymazal, 2001; Gottschall et al., 2004), o uso de SACs na mitigação da contaminação de águas por praguicidas ainda pode ser considerado incipiente.

No decorrer da última década, foram realizados estudos com grandes sistemas (naturais e construídos) de escoamento livre ou superficial (Kadlec e Hey, 1994; Detenbeck et al., 1996; Moore et al., 2000, 2001, 2002; Schulz, 2003a, 2003b, 2003c; Rose et al., 2006). Em relação à SACs do tipo de escoamento subsuperficial - também conhecidos como red bed 
systems - poucas experiências têm sido relatadas: McKinlay e Kasperek (1999), testando 4 espécies de macrófitas aquáticas, verificaram redução na concentração de atrazina em SACs com recirculação do líquido efluente; Cheng et al. (2002) verificaram que os sistemas verticais estudados removeram inseticidas com mais eficiência do que herbicidas, considerando-se coletas realizadas 4 meses após a aplicação dos agroquímicos. George et al. (2003) e Stearman et al. (2003), tratando o escoamento de viveiros de mudas para plantio, comprovaram a importância da parte vegetativa no tratamento de simazina e metolacloro.

Tabela 5.1 - Propriedades físicas, químicas e destino ambiental da ametrina

\begin{tabular}{|c|c|}
\hline & $\mathrm{SCH}_{3}$ \\
\hline Estrutura & $\mathrm{C}_{2} \mathrm{H}_{5}-\mathrm{N}_{1}$ \\
\hline Peso molecular $\left(\mathrm{g} \mathrm{mol}^{-1}\right)$ & 227,33 \\
\hline Solubilidade $\left(\mathrm{mg} \mathrm{L}^{-1}\right)$ & 204 \\
\hline Pressão de vapor $(\mathrm{mPa})$ & 0,37 \\
\hline $\log K_{\mathrm{OW}}$ & 1,13 \\
\hline $\mathrm{K}_{\mathrm{OC}}\left(\mathrm{mL} \mathrm{g}^{-1}\right)$ & $316 \sim 445$ \\
\hline 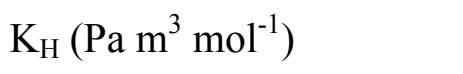 & $4,14 \mathrm{E}-04$ \\
\hline $\mathrm{pK}_{\mathrm{a}}$ & 4,1 \\
\hline Meia vida na água (d) & 22 \\
\hline Meia vida no solo (d) & $53 \sim 190$ \\
\hline Classe toxicológica & III \\
\hline Classe ambiental & II \\
\hline Toxicidade aguda aquática & Moderada \\
\hline Potencial de lixiviação & Potencial $\left(\mathrm{GUS}^{(\mathrm{a})}=2,71\right)$ \\
\hline
\end{tabular}

Dordio et al. (2007) reportam sobre a necessidade do uso de substratos mais eficientes na sorção de agroquímicos. Segundo os autores, em sistema sob escoamento subsuperficial, a ação conjunta entre a parte rizomatosa das plantas, o substrato escolhido e os microrganismos 
presentes, pode fazer com que concentrações de praguicidas decresçam a níveis não tóxicos para a biota aquática. Na Tabela 5.2 estão sumarizados os resultados reportados quando usados SACs de escoamento subsuperficial na redução de níveis de agroquímicos.

Tabela 5.2 - Resumo dos resultados experimentais obtidos em SACs de escoamento subsuperficial tratando praguicidas

\begin{tabular}{|c|c|c|c|c|c|}
\hline Praguicida & $\begin{array}{l}\tau^{(\mathrm{a})} \\
(\mathrm{d})\end{array}$ & $\begin{array}{l}\text { Área } \\
\left(\mathrm{m}^{2}\right)\end{array}$ & $\begin{array}{c}\mathrm{C}_{\mathrm{AF}}{ }^{(\mathrm{b})} \\
\left(\mathrm{mg} \mathrm{L}^{-1}\right)\end{array}$ & $\begin{array}{c}\text { Remoção } \\
(\%)\end{array}$ & Referência \\
\hline Atrazina & n.r. ${ }^{(c)}$ & 1,2 & $6,0 \sim 7,0$ & $>99$ & McKinlay e Kasperek (1999) \\
\hline Dicamba & n.r. & 1,0 & $1,5 \mathrm{E}-03$ & 0 & Cheng et al. (2002) \\
\hline MCPA & n.r. & 1,0 & $2,8 \mathrm{E}-03$ & 36 & Cheng et al. (2002) \\
\hline Paration & n.r. & 1,0 & $2,0 \mathrm{E}-03$ & 100 & Cheng et al. (2002) \\
\hline Metolacloro & $2,3 \sim 20$ & $5,9 \sim 11,8$ & n.r. & $82 \sim 90$ & Stearman et al. (2003) \\
\hline Simazina & $2,3 \sim 20$ & $5,9 \sim 11,8$ & n.r. & $77 \sim 83$ & Stearman et al. (2003) \\
\hline Metolacloro & $2,3 \sim 20$ & $5,9 \sim 11,8$ & 3,9 & $62 \sim 96$ & George et al. (2003) \\
\hline Simazina & $2,3 \sim 20$ & $5,9 \sim 11,8$ & 6,2 & $60 \sim 96$ & George et al. (2003) \\
\hline Lindano & $5 \sim 6$ & 55,0 & 2,5 & $>99$ & Matadoros et al. (2007) \\
\hline Simazina & $5 \sim 6$ & 55,0 & 2,5 & 20 & Matadoros et al. (2007) \\
\hline Alacloro & $5 \sim 6$ & 55,0 & 2,5 & 80 & Matadoros et al. (2007) \\
\hline
\end{tabular}

Tendo em vista que nas pesquisas a aplicação das cargas afluentes era feita com poucas aplicações pontuais, propôs-se, na presente investigação, a avaliação da capacidade de um SAC de escoamento superficial, quando operado sob carregamento contínuo de água contaminada com ametrina. Os objetivos do estudo incluíram: (1) determinar a eficiência do processo, com base na massa do composto removida nos SACs, (2) estudar a influência de fatores operacionais no desempenho dos SACs e (3) verificar a sanidade das macrófitas utilizadas após o período de estudo. 


\subsection{METODOLOGIA}

\section{Área de estudo e sistema de tratamento avaliado}

Quatro SACs experimentais, localizadas na Área Experimental de Tratamento de Resíduos (AETR) do DEA/CCA/UFV (Viçosa-MG) foram utilizadas no decorrer da pesquisa. As unidades experimentais (SACs) foram instalados paralelamente em muretas de blocos de cimento, formando canais de escoamento com $0,35 \mathrm{~m}$ de altura por 1,0 $\mathrm{m}$ de largura e 24,0 m de comprimento. $\mathrm{O}$ fundo e as laterais do canal de escoamento foram impermeabilizados com geomembrana de policloreto de vinila (PVC) com espessura de $0,50 \mathrm{~mm}$.

Como meio suporte, utilizou-se brita \# 0 e as unidades foram colonizadas com Typha latifolia (taboa). No decorrer do tempo, espécies invasoras foram observadas nos SACs experimentais. Na Figura 5.1 visualiza-se um diagrama esquemático do experimento, que possuíam declividades longitudinais e volumes úteis distintos.

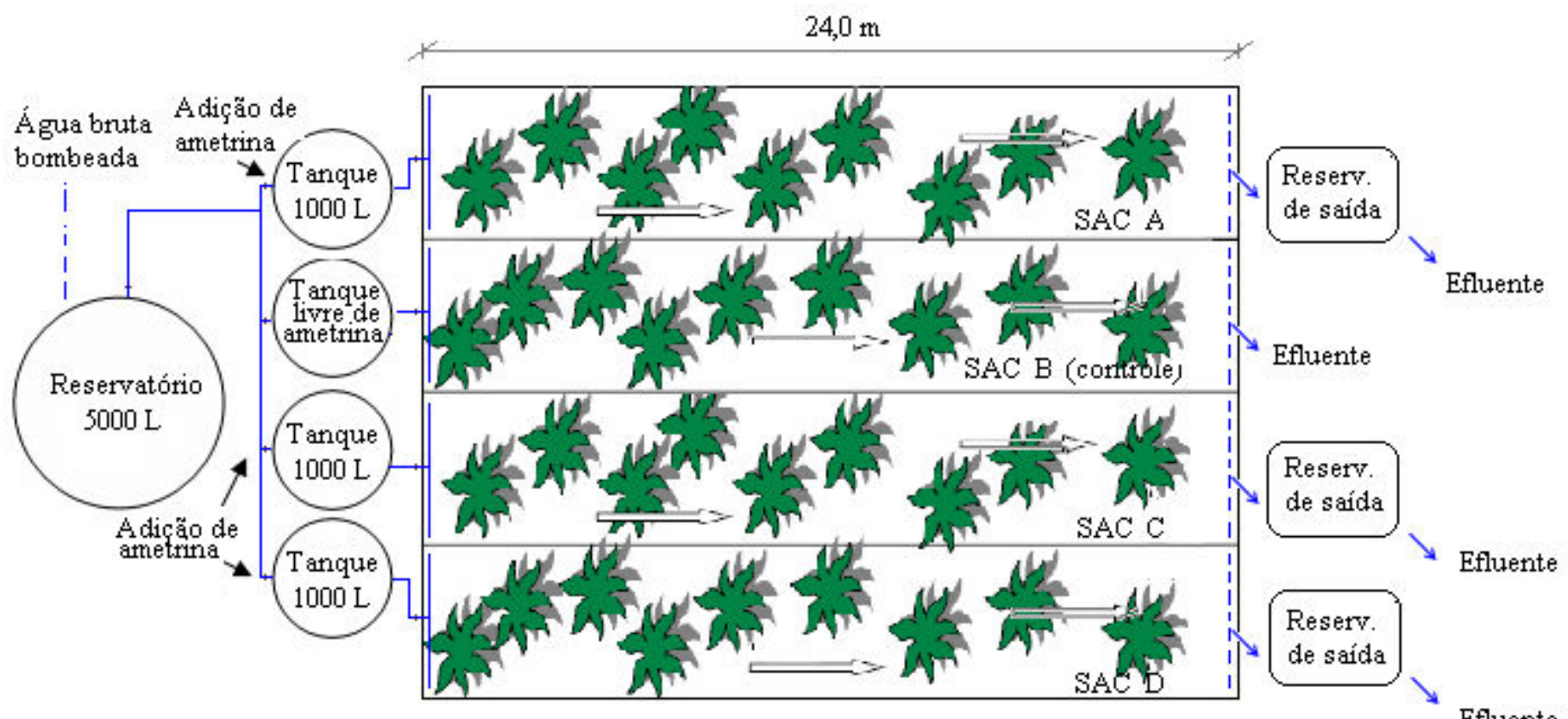

Figura 5.1 - Diagrama esquemático das unidades experimentais construídas na Área

Experimental de Tratamento de Resíduos, UFV, Viçosa-MG

Reservatórios para a distribuição e coleta da água contaminada com ametrina foram instalados a montante e a jusante de cada SAC. Dispositivos de distribuição constituídos de registros tipo gaveta e tubos de PVC foram conectados aos tanques de alimentação. Os tubos, que cobriam a largura dos SACs foram perfurados para que a aplicação do praguicida fosse 
feita de maneira uniforme. Os reservatórios posicionados a jusante dos canais de escoamento foram graduados para que fosse possível o cálculo diário do balanço hídrico nas células.

\section{Procedimento experimental}

Durante 11 semanas, aplicou-se água contaminada com ametrina em leitos com diferentes inclinações de fundo e volumes totais: SAC A $(0,5 \%$ e $5600 \mathrm{~L})$, SAC C $(1,0 \%$ e 4400 L) e SAC D (1,5\% e 3300 L). A unidade B (1,0\% e 4300 L) foi utilizada como controle, recebendo água bruta sem adição do herbicida.

Os sistemas foram operados sob um mesmo tempo de residência hidráulico, inicialmente estimado. Dessa maneira, as vazões aplicadas corresponderam a $770 \mathrm{~L} \mathrm{~d}^{-1}$ para o SAC A, $600 \mathrm{~L} \mathrm{~d}^{-1}$ para o SAC C e $450 \mathrm{~L} \mathrm{~d}^{-1}$ para o SAC D. Ressalta-se que, devido à evapotranspiração observada na cultura (taboa), parte do líquido residente nos SACs era perdida, portanto os valores de $\tau_{\mathrm{N}}$ eram superiores aos 3,5 $\mathrm{d}$ inicialmente propostos.

Aplicou-se, em cada unidade, água bruta contendo uma concentração teórica de $1 \mathrm{mg} \mathrm{L}^{-1}$ de ametrina. A mistura era preparada a partir de uma solução estoque do composto comercial Metrimex $500 \mathrm{SC}$ (Sipcam Agro S.A.), que possui concentração de $500 \mathrm{~g} \mathrm{~L}^{-1}$ do princípio ativo da triazina.

Foram coletadas, a cada 3,5 d, amostras no afluente, no ponto médio e no efluente dos SACs A, C e D, para análise laboratorial. Ao final do período de estudo, foram realizados cortes na parte vegetativa de todas as células para análise nutricional da macrófita utilizada. As amostragens realizadas no final do estudo foram feitas em parcelas de $2 \mathrm{~m}^{2}$, localizadas no início, meio e final de cada SAC.

$\mathrm{Na}$ ocasião do corte raso dos sistemas (final do período), também foram coletadas amostras do meio suporte (brita) para análises de matéria orgânica presente e para a realização de um ensaio de sorção/dessorção, que consistiu em submeter $50 \mathrm{~g}$ da brita oriunda do SAC B (controle) à presença de $200 \mathrm{~mL}$ de água com $\mathrm{CaCl}_{2}$ 0,01 mol $\mathrm{L}^{-1} \mathrm{e}$ ametrina em concentrações progressivas, seguida de substituição por água isenta de contaminação. As amostras foram agitadas (100 rpm) e coletas ao fim de 24 h (sorção) e 48 h (dessorção) foram realizadas. 


\section{Métodos analíticos}

As análises referentes à detecção de ametrina nas amostras foram realizadas no Laboratório de Química Analítica e Ambiental (LAQUA) do DEQ/CCE/UFV, conforme descrito no Capítulo 3. Todas as análises restantes foram feitas no Laboratório de Qualidade da Água (LQA) do DEA/CCA/UFV.

As medições de turbidez, condutividade elétrica, temperatura e potencial de oxiredução e as quantificações de DQO e , sólidos totais foram feitas de acordo com o Standard Methods for the Examination Water and Wastewater (APHA, AWWA e WEF, 2005); as análises de alcalinidade seguiram o descrito por Ripley, Boyle e Converse (1986).

As análises de nutrientes (nitrogênio, fósforo, potássio, cálcio e enxofre) no tecido vegetal da taboa foram feitas segundo Kiehl (1985). A quantificação da matéria orgânica nos substrato foi feita por meio da ignição das amostras em forno tipo mufla.

As possíveis diferenças significativas entre os dados $(\alpha=0,05)$ foram observadas com o uso dos testes estatísticos descritos no Capítulo 3.

\subsection{RESULTADOS E DISCUSSÃO}

\section{Balanço hídrico nos alagados construídos}

Os cálculos necessários para a obtenção do balanço hídrico nos SACs foram feitos com os dados da estação climatológica (Figura 5.2) e com a aferição diária dos volumes efluentes nos reservatórios a jusante das células.

O valor médio para a evapotranspiração da cultura nos SACs foi de 5,8 $\mathrm{mm} \mathrm{d}^{-1}$, enquanto os valores médios de ETo (segundo o método de Hargreaves) e ET (Classe A) foram de 4,6 e 3,7 $\mathrm{mm} \mathrm{d}^{-1}$, respectivamente. A ET da cultura foi ligeiramente maior na unidade menos inclinada e pode-se afirmar que mesmo com as fortes chuvas observadas durante o experimento, houve perda nos volumes de água contaminada aplicados. Os valores máximos de evapotranspiração de Typha latifolia nas células foram semelhantes aos observados para Typha angustifolia por Lim, Wong e Lim (2002) na Malásia.

A porcentagem de água perdida em relação à lâmina afluente se situou na faixa de $12 \%$ a $24 \%$, mostrando-se inferior a valores observados em regiões áridas ou em SACs 
operando sobre temperaturas mais elevadas. Em uma dessas observações, Sousa et al. (2004) estimaram valores de $50 \%$ de quantidade de água perdida em SACs em operação no nordeste brasileiro. Ressalta-se, no entanto, que a estimativa feita equivale à realizada no mesmo local por Brasil (2005), que cita porcentagens entre $11 \%$ e $27 \%$ de diminuição nos volumes de água.

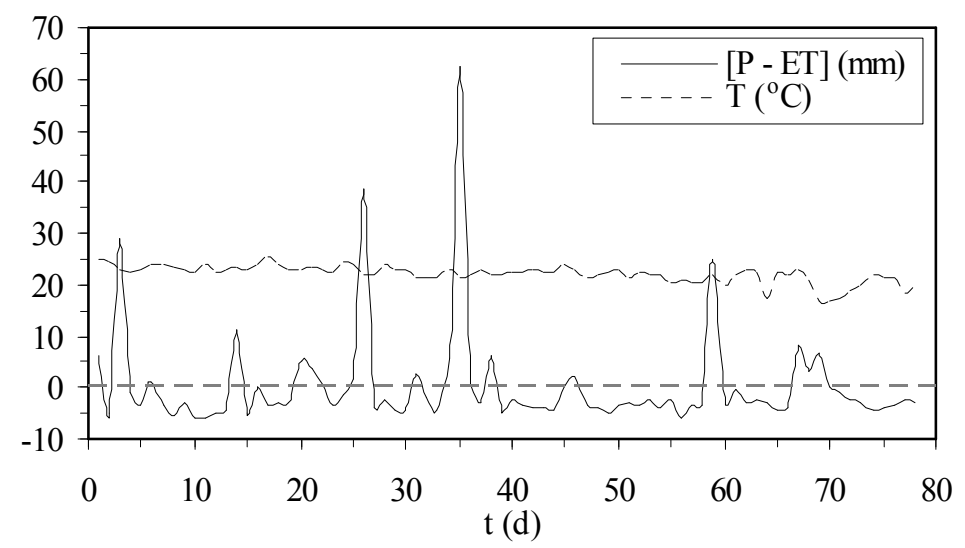

Figura 5.2 - Contribuição hídrica, considerados os valores de evaporação no tanque classe A subtraídos das precipitações, e temperatura média do ar no período de experimentação

A observação de perdas devido à evapotranspiração nos leitos, somadas às chuvas ocorridas, provocaram variações no tempo de residência nominal nos SACs. O perfil desses valores de $\tau_{\mathrm{N}}$, assim como o observado no Capítulo 4, foi semelhante para todos os SACs, que apresentaram tempos de residência médios de 3,8 d. Na Figura 5.3, visualiza-se a variação no $\tau_{\mathrm{N}}$ vigente no SAC C.

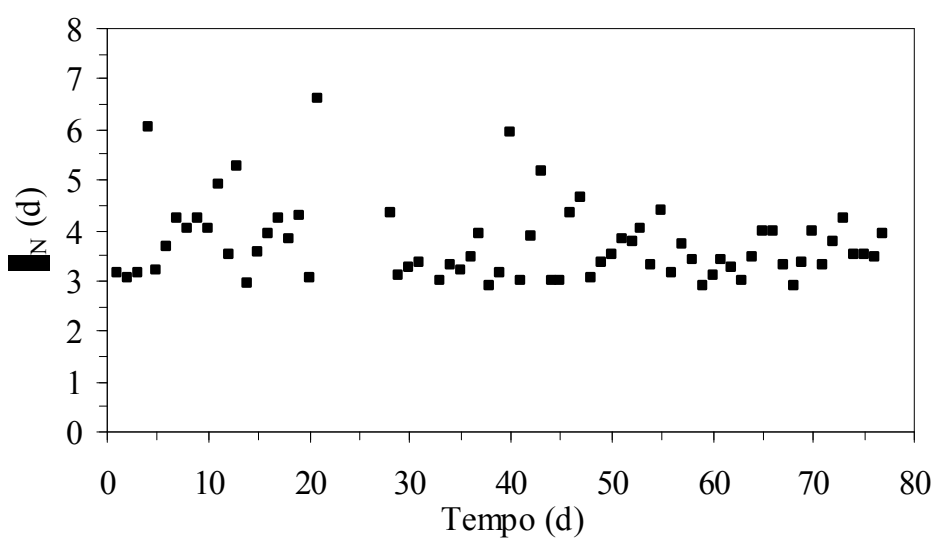

Figura 5.3 - Influência do balanço hídrico nos valores de $\tau_{\mathrm{N}}$ no SAC C 


\section{Variáveis de qualidade da água}

$\mathrm{Na}$ Tabela 5.3 estão apresentados os valores obtidos para as concentrações das variáveis de qualidade da água, monitoradas nos SACs que receberam cargas de ametrina.

Tabela 5.3 - Resultados obtidos para as variáveis de qualidade monitoradas durante o experimento no tanque a montante e nos pontos a $12 \mathrm{~m}$ e $24 \mathrm{~m}$ da aplicação

\begin{tabular}{|c|c|c|c|c|c|c|c|}
\hline \multirow{2}{*}{ Variável } & \multirow{2}{*}{ Afluente } & \multicolumn{2}{|c|}{ SAC A } & \multicolumn{2}{|c|}{ SAC C } & \multicolumn{2}{|c|}{ SAC D } \\
\hline & & $12 \mathrm{~m}$ & $\overline{\text { Efluente }}$ & $12 \mathrm{~m}$ & Efluente & $12 \mathrm{~m}$ & Efluente \\
\hline $\mathrm{DQO}^{(\mathrm{a})}\left(\mathrm{mg} \mathrm{L}^{-1}\right)$ & 19 & 32 & 40 & 40 & 22 & 36 & 27 \\
\hline Turbidez (uT) & 13 & 9 & 15 & 11 & 4 & 7 & 13 \\
\hline $\mathrm{CE}^{(\mathrm{b})}\left(\mu \mathrm{S} \mathrm{cm}{ }^{-1}\right)$ & 55 & 74 & 105 & 65 & 98 & 64 & 94 \\
\hline $\mathrm{pH}$ & 7,0 & 6,2 & 6,7 & 6,4 & 6,8 & 6,6 & 6,8 \\
\hline $\mathrm{AT}^{(\mathrm{c}}\left(\mathrm{mg} \mathrm{L}^{-1}\right)$ & 21 & 32 & 56 & 29 & 48 & 27 & 49 \\
\hline (a) Matéria orgânica & essa col & nda qu & ica de oxi & & & & \\
\hline (b) Condutividade $\mathrm{e}$ & trica; & & & & & & \\
\hline Alcalinidade tota & & & & & & & \\
\hline
\end{tabular}

A diluição do herbicida foi feita em água bruta, captada de uma das represas do ribeirão São Bartolomeu, no campus da universidade. Devido a esse fator, os valores afluentes de turbidez e condutividade elétrica, que indiretamente indicam teores de sólidos suspensos e dissolvidos, foram reduzidos. As concentrações afluentes apresentadas na Tabela 5.3 são relativas às médias nos tanques de montante, pois as condições de aplicação eram idênticas. Em relação aos efluentes, não se observou diferença estatística quando aplicado o teste de Kruskal-Wallis, considerando as coletas realizadas como repetições nos tratamentos.

Verifica-se que praticamente não houve remoção de turbidez das águas. Tal fato pode ser explicado em razão de fatores como pequenos valores afluentes (inferiores a $40 \mathrm{uT}$ ), concentração devido à evapotranspiração e arraste e revolvimento de sólidos nos eventos de precipitação. A mesma observação pode ser feita em relação à $\mathrm{CE}$, dada à reduzida condutividade elétrica medida na água bruta.

O monitoramento da alcalinidade total e pH indicou condições ecológicas equilibradas no meio. O potencial hidrogeniônico variou entre 6,5 e 7,6 (mínimo e máximo no período), 
nessa faixa de valores não há mudanças na ação e na meia vida do herbicida e não se observa condições adversas à comunidade microbiana em geral. Embora nos sistemas alagados verifiquem-se, preponderantemente, regiões facultativas, sabe-se que na zona radicular das macrófitas há aumento na concentração de oxigênio dissolvido, devido à captação de ar atmosférico e transferência (por meio dos aerênquimas) para os rizomas e raízes.

Em relação à matéria orgânica, verificou-se que a água de diluição apresentou DQO média de $19 \mathrm{mg} \mathrm{L}^{-1}$ e que, no efluente dos SACs, a DQO atingiu valor médio de $30 \mathrm{mg} \mathrm{L}^{-1}$. A reafirmação das proposições anteriores somada à questão da acurácia nas medidas conduz a observação de que esse fato não constituiu fator limitante na operação dos sistemas para o objetivo proposto.

\section{Remoção de ametrina nos alagados construídos}

Como observado anteriormente, a perda de parte das lâminas aplicadas proporcionou ligeira ampliação no tempo de residência médio nos SACs e aumento na concentração dos solutos no efluente. Tal fato foi recentemente observado e debatido por vários pesquisadores, como Lim, Wong e Lim (2001), Green (2006) e Mara (2006). Dessa maneira, a avaliação da eficiência de remoção do herbicida em estudo foi feita com base nas cargas mássicas aplicadas.

Para a comparação entre os SACs, consideraram-se as amostragens realizadas como repetições ao longo do tempo. As concentrações efluentes não apresentaram diferença significativa $(\alpha=0,05)$, quando aplicado o teste de Kruskal-Wallis. Diante disso, optou-se pela abordagem da eficiência média das células, uma vez que o número de análises válidas foi reduzido (entre 23 e 26 para cada SAC) devido à contaminação de alguns frascos nas ocasiões de coleta.

Na Figura 5.4 são visualizados os teores de ametrina removidos, com base no cômputo de médias móveis (2 semanas) das cargas mássicas.

Operando sob um $\tau_{\mathrm{N}}$ médio de $3,8 \mathrm{~d}$, os sistemas removeram/transformaram aproximadamente 39\% da ametrina adicionada. Quando comparados aos dados contidos na Tabela 5.2, esses valores podem ser considerados reduzidos. No entanto, torna-se importante ressaltar que na presente investigação aplicou-se ametrina continuamente e, portanto, em uma quantidade superior, devido aos carregamentos $\left[\mathrm{M} \mathrm{L}^{-2} \mathrm{~T}^{-1}\right]$, que às aplicadas por outros autores. 
Em uma tentativa semelhante, porém com escoamento vertical, Cheng et al. (2002) observaram que herbicidas foram removidos em taxas menores que os inseticidas. Os autores verificaram que o inseticida paration não era detectado na saída do sistema; já os herbicidas dicamba e MCPA apresentaram remoções de $0 \%$ (nula) e 36\%, respectivamente.

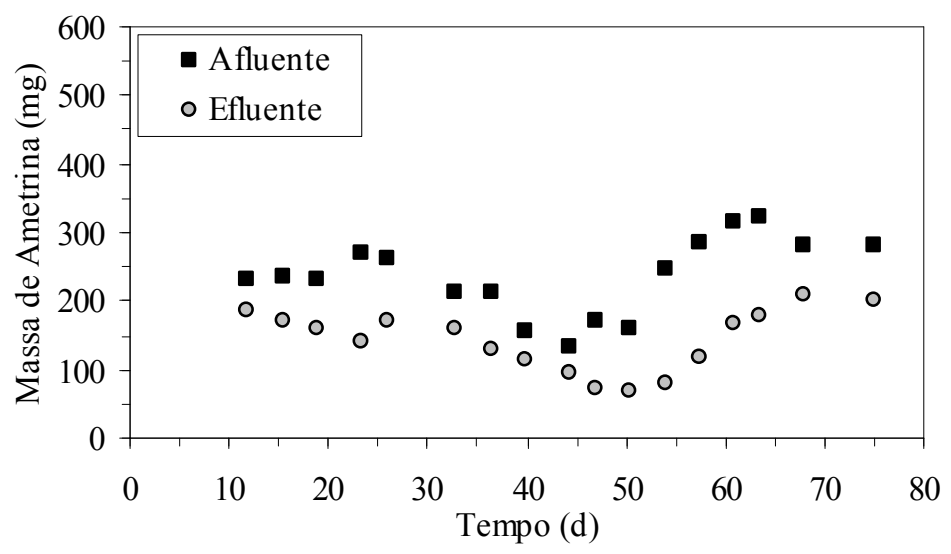

Figura 5.4 - Médias móveis referentes às quantidades de ametrina adicionadas e recuperadas nos SACs

Dentre as propriedades físicas e químicas da ametrina, destaca-se a sua solubilidade, equivalente a $204 \mathrm{mg} \mathrm{L}^{-1}$. Segundo Lavorenti, Prata e Regitano (2003), praguicidas altamente solúveis tendem a apresentar reduzidos valores de $\mathrm{K}_{\mathrm{OC}}$ e $\mathrm{K}_{\mathrm{OW}}$, facilitando os processos de absorção e translocação na planta. Essas propriedades conferem à ametrina baixa afinidade aos colóides do solo, sendo potencialmente lixiviável. Moore et al. (2000), estudando a mitigação dos efeitos da atrazina (a triazina mais usada em nível mundial) não detectaram concentrações do praguicida no sedimento dos SACs de escoamento livre usados; diante disso, os pesquisadores optaram pela análise da fase aquosa que, segundo Forner e Davis (1981), determina a toxicidade no meio. Ressalta-se que recentemente, Smith, Lizotte e Moore (2007), estudando a toxicidade do diazinon registraram a mesma observação (maior toxicidade na fase aquosa).

No presente estudo, foram realizadas análises de teor de matéria orgânica (MO) presente no substrato. $\mathrm{O}$ fato do SAC mais inclinado ter apresentado significativamente maior razão $\mathrm{MO} /$ brita em relação ao SAC A (menos inclinado) não implicou em maior eficiência na retenção da ametrina, em razão da possibilidade de maior adsorção ao meio suporte. Não foi possível uma análise apurada no teste de sorção/dessorção realizado. No entanto, verificou-se que após 24 h de agitação da solução com material do meio suporte, não havia diminuição nos 
teores de ametrina no sobrenadante, o que indica que a adsorção na brita pode ser negligenciada. Recentemente, Matadoros et al. (2007) registraram a mesma observação: a adsorção na brita participa com pouca intensidade no processo, considerando-se a ocorrência paralela de biodegradação, absorção pela planta e também a própria dessorção.

A volatilização e a fotólise também podem atuar como fatores importantes no decaimento de praguicidas em SACs. No entanto, o composto adicionado é pouco volátil $\left(\mathrm{P}<1,33 \mathrm{mPa}\right.$ e $\left.\mathrm{K}_{\mathrm{H}}<0,1 \mathrm{~Pa} \mathrm{~m}^{3} \mathrm{~mol}^{-1}\right)$ e quanto à fotólise, o fato da ametrina apresentar reduzida fotodegradação, somado ao tipo de escoamento implementado (subsuperficial), permite-se prever que tais perdas sejam muito pequenas.

O tempo de residência nas unidades é a variável operacional de maior influência no processo. Stearman et al. (2003) observaram que SACs de escoamento superficial operando sob $\tau_{\mathrm{N}}$ de 5,1 d foram mais eficientes em comparação com sistemas análogos com $\tau_{\mathrm{N}}$ de 2,3 d. A mesma observação pode ser feita em SACs de escoamento livre, no tratamento de atrazina (Moore et al., 2000; Runes et al., 2003). Em relação às vazões aplicadas e às diferentes inclinações de fundo dos canais de escoamento, acredita-se que a ausência de diferenças nos resultados deva-se a fatores como escala e magnitude dos valores observados (concentrações reduzidas e de difícil concentração).

\section{Desempenho agronômico das macrófitas}

O desempenho agronômico das plantas dos sistemas foi avaliado com base na produtividade de matéria seca e na análise de nutrientes na folha das plantas cultivadas em cada unidade experimental. Em relação à produtividade, o SAC com menor inclinação de fundo apresentou produtividade de 5,4 $\mathrm{t} \mathrm{ha}^{-1}$, valor ligeiramente superior ao encontrado nos demais. Freitas (2006) observou valores muito maiores em SACs com a mesma inclinação $(0,5 \%)$, no entanto a proposta consistia no tratamento de águas residuárias de suinocultura, com aporte de nutrientes muito maior. Brasil (2005), tratando efluente de um tanque séptico nos mesmos SACs utilizados no presente estudo, estimou a produtividade de matéria seca nos sistemas cultivados com taboa em $7,1 \mathrm{t} \mathrm{ha}^{-1}$.

Em relação aos teores de nutrientes contidos nas macrófitas, visualizam-se na Figura 5.5 os valores médios observados nos SACs com mesmas inclinações $(1,0 \%)$ e características: SAC B (controle) e SAC C. Observa-se que não há diferença aparente quanto aos teores de nutrientes nessas unidades. 
A afirmação feita anteriormente também procede quando se consideram todas as 4 unidades usadas (A, B, C e D). Quando comparadas estatisticamente, as médias relativas as coletas realizadas no final do período não apresentaram diferença significativa $(\alpha=0,05)$. Nesta análise foram comparadas não só as concentrações de nutrientes no tecido vegetal da taboa, mas também os dados de produtividade $\left[\mathrm{M} \mathrm{L}^{-2}\right]$ de matéria seca e nutrientes.

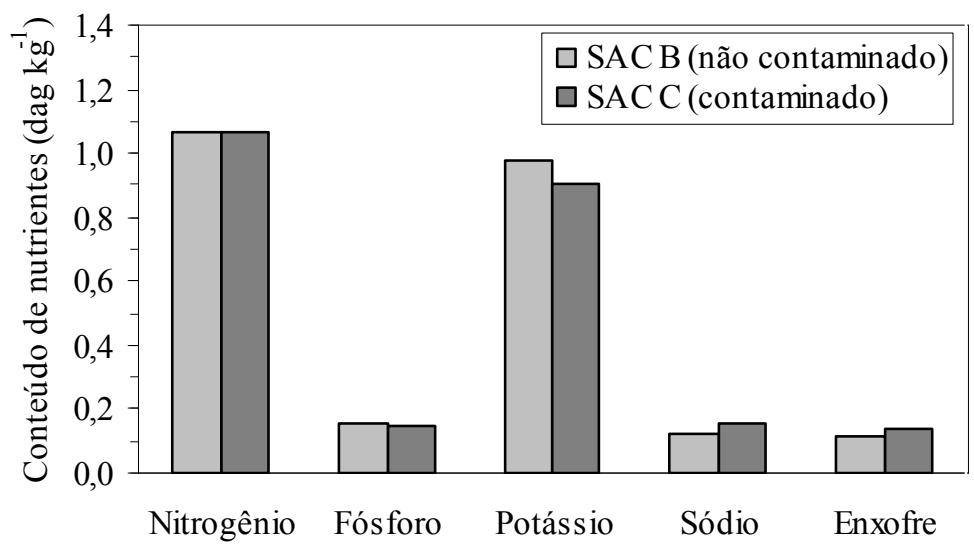

Figura 5.5 - Conteúdo de nutrientes na parte superior das macrófitas plantadas nos SACs B (controle) e C

No presente estudo, não foram observados efeitos danosos na parte vegetativa das plantas, quando realizada uma análise nutricional comparativa com um SAC controle. Com base nos resultados obtidos, a presença da ametrina na água não prejudicou a produtividade e nem a absorção de nutrientes pela taboa.

Embora tenham sua função algumas vezes contestada, as macrófitas desempenham papel importante no processo de tratamento de águas contaminadas. Além da absorção do agroquímico, a implantação da parte vegetativa proporciona ambiente favorável à sobrevivência de microrganismos na zona subsuperficial dos SACs. Recentemente, Moore et al. (2006) verificaram que SACs vegetados foram mais eficientes na mitigação de paration metílico; essas observações corroboram o exposto por Cheng et al. (2002) sobre o possível aproveitamento energético da biomassa produzida em SACs.

Com relação à degradação microbiana, citada por McKinlay e Kasperek (1999) como principal processo na degradação de atrazina em SACs, sabe-se que esse processo é incrementado nos SACs vegetadas, devido ao biofilme formado na região subsuperficial, e que o mesmo depende da disponibilidade de nutrientes e da capacidade de adaptação das espécies à substância contaminante da água. Após a hidrólise, microrganismos (fungos e 
bactérias) podem mediar etapas de dealquilação e a clivagem do anel heterocíclico da ametrina.

Observa-se a necessidade de mais estudos, contemplando também análises microbiológicas, para que as rotas de transformação da ametrina no ambiente sejam mais bem conhecidas; verifica-se que poucos são os estudos com tema nesse defensivo quando comparados com outros herbicidas com a atrazina, por exemplo.

\subsection{SUMÁRIO}

Conforme observado em campo, em sistemas de tratamento com perdas de lâminas de água aplicadas, faz-se necessário o cômputo do balanço hídrico, uma vez que os compostos estudados verterão no ponto efluente de maneira mais concentrada. Em SACs operando sob condições climáticas tropicais, nos quais evapotranspiração da cultura é componente de influência, duas são as alternativas para melhor avaliação das eficiências de remoção obtidas. $\mathrm{O}$ cálculo do $\tau_{\mathrm{N}}$ deve ser feito com base nas vazões de entrada e saída ou a avaliação em termos de carga mássica removida.

A quantidade de ametrina detectada na saída dos SACs foi estimada em $61 \%$ da quantidade adicionada. A fração restante foi transformada e retida por processos bióticos (biodegradação e fitorremediação) e abióticos nos SACs. Com base nas propriedades do composto e nas condições do experimento, supõe-se que a fotólise, a volatilização e a adsorção no substrato tenham ocorrido em níveis reduzidos.

Verificou-se que, recebendo água bruta contaminada, os SACs com diferentes inclinações de fundo não apresentaram diferenças significativas. $\mathrm{O}$ aumento do $\tau_{\mathrm{N}}$ vigente é uma estratégia operacional a ser considerada, dado o maior tempo de contato entre o praguicida e o sistema radicular com a população microbiana aderida. Com base no exposto anteriormente, nota-se a grande importância dos processos bióticos na mitigação dos efeitos da contaminação dos SACs com ametrina.

A degradação microbiana pode ser incrementada nas células cultivadas com macrófitas, devido à presença do biofilme formado na região rizomatosa dos sistemas alagados. 
No presente estudo, não foram observados efeitos danosos na parte vegetativa das plantas, quando realizada uma análise nutricional comparativa com as plantas cultivadas em uma unidade controle (sem a adição de água contaminada com ametrina). Cabe ressaltar que uma opção de reuso nos SACs vegetados é a possível conversão das grandes quantidades de biomassa produzidas em fontes de energia renovável.

Com os resultados obtidos na pesquisa, verificou-se a remediação da ametrina em três SACs de escoamento subsuperficial, que, por sua vez, não apresentaram diferenças entre si. Os sistemas foram cultivados com Typha latifolia, espécie vegetal que não apresentou alterações de produtividade e nutrição mineral com a aplicação do composto nas doses testadas. Observa-se que SACs podem ser utilizados para reter e transformar agroquímicos, agindo como filtros entre a fonte de emissão e os corpos de água superficiais. Planos de gestão ambiental, elaborados por órgãos do governo com o auxílio de proprietários rurais e demais empreendedores, poderão usar deste expediente na mitigação da poluição ambiental, observadas as necessidades de mais estudos sobre o processo e também de maior controle sobre as fontes de emissão destes contaminantes.

\subsection{REFERÊNCIAS BIBLIOGRÁFICAS}

APHA [AMERICAN PUBLIC HEALTH ASSOCIATION]; AWWA [AMERICAN WATER WORKS ASSOCIATION]; WEF [WATER ENVIRONMENT FEDERATION]. Standard methods for the examination of water and wastewater. $21 \mathrm{ed}$. Washington: APHA/ AWWA/ WEF, 2005. 1268p.

BRASIL, M. S. Desempenho de sistema alagado construído para tratamento de esgoto doméstico. 2005. 160f. Tese (Doutorado em Engenharia Agrícola) - Universidade Federal de Viçosa, Viçosa.

CHENG, S. et al. Xenobiotics removal from polluted water by a multifunctional constructed wetland. Chemosphere, Oxford, v.48, n.4, p.415-418, 2002.

CABRAL, M. F. et al. Estudo do comportamento eletroquímico do herbicida ametrina utilizando a técnica de voltametria de onda quadrada. Eclética Química, São Paulo, v.28, n.2, p.41-47, 2003. 
COSTA QUEIROZ, R. H. et al. Determination of ametryn herbicide by bioassay and gas chromatography-mass spectrometry in analysis of residues in drinking water. Bolletino Chimico Farmaceutico, Milão, v.138, n.6, p.249-252, 1999.

DETENBECK, N. E. et al. Fate and effects of the herbicide atrazine in flow-through wetland mesocosmos. Environmental Toxicology and Chemistry, Pensacola, v.15, n.6, p.937-946, 1996.

DORDIO, A. V. et al. Selection of a support matrix for the removal of some phenoxyacetic compounds in constructed wetlands systems. Science of the Total Environment, Amsterdam, v.380, n.1-3, p.237-246, 2007.

FORNEY, D. R.; DAVIS, D. E. Effects of low concentrations of herbicides on submersed aquatic plants. Weed Science, Lawrence, v.29, n.6, p.677-685, 1981.

FREITAS, W. S. Desempenho de sistemas alagados construídos, cultivados com diferentes espécies vegetais, no tratamento de águas residuárias da suinocultura. 2006. 159f. Tese (Doutorado em Engenharia Agrícola) - Universidade Federal de Viçosa, Viçosa.

GEORGE, D. B. et al. Simazine and metolachlor removal by subsurface flow constructed wetlands. Water Environmental Research, Alexandria, v.75, n.2, p.101-112, 2003.

GOTTSCHALL, N. et al. The role of plants in the removal of nutrients in a constructed wetland treating agricultural wastewater. In: IWA INTERNATIONAL CONFERENCE ON WETLAND SYSTEMS, 9, 2004, Avignon. Proceedings... Avignon: IWA, 2004. CR-ROM

GREEN, M. Response to: Comment on "Minimizing land requirement and evaporation in small wastewater treatment systems". Ecological Engineering, Amsterdam, v.28, n.2, p.182, 2006.

HEALY, M. G.; RODGERS, M.; MULQUEEN, J. Treatment of dairy wastewater using constructed wetlands and intermittent sand filters. Bioresource Technology, Oxford, v.98, n.12, p.2268-2281, 2007. 
HUNT, P. G.; POACH, M. E. State of the art for animal wastewater treatment in constructed wetlands. Water Science and Technology, Londres, v.44, n.11-12, p.19-25, 2001.

IWA [INTERNATIONAL WATER ASSOCIATION]. Constructed wetlands for pollution control: process, performance, design and operation. Londres: IWA, 2000. 156p.

KADLEC, R. H.; HEY, D. L. Constructed wetlands for river water quality improvement. Water Science and Technology, Londres, v.29, n.4, p.159-168, 1994.

KADLEC, R. H.; WALLACE, S.; VYMAZAL, J. Treatment wetlands. 2 ed. Boca Raton: CRC-Lewis, 2004. 800p.

KIEHL, E. J. Fertilizantes orgânicos. Piracicaba: Agronômica Ceres, 1985. 492p.

KNIGHT, R. L. et al. Constructed wetlands for livestock wastewater management. Ecological Engineering, Amsterdam, v.15, n.1-2, p.41-55, 2000.

LAVORENTI, A.; PRATA, F.; REGITANO, J. B. Comportamento de pesticidas em solos fundamentos. In: CURI, N. et al. Tópicos em ciência do solo, v.3, Viçosa: SBCS, 2003. p.291-334.

LIM, P. E.; WONG, T. F.; LIM, D. V. Oxygen demand, nitrogen and copper removal by freewater-surface and subsurface-flow constructed wetlands under tropical conditions.

Environment International, Oxford, v.26, n.5-6, p.425-431, 2001.

MARA, D. D. Comment on "Minimizing land requirement and evaporation in small wastewater treatment systems”. Ecological Engineering, Amsterdam, v.28, n.2, p.181, 2006.

MATADOROS, V. et al. Behavior of selected priority organic pollutants in horizontal subsurface flow constructed wetlands: a preliminary screening. Chemosphere, Oxford, no prelo, 2007. 
McKINLAY, R. G.; KASPEREK, K. Observations on decontamination of herbicide-polluted water by marsh plant systems. Water Research, Londres, v.33, n.2, p.505-511, 1999.

MOORE, M. T. et al. Constructed wetlands for mitigation of atrazine-associated agricultural runoff. Environmental Pollution, Oxford, v.110, n.3, p.393-399, 2000.

MOORE, M. T. et al. Mitigation of metolachlor-associated agricultural runoff using constructed wetlands in Mississippi, USA. Agriculture, Ecosystems and Environment, Amsterdam, v.84, n.2, p.169-176, 2001.

MOORE, M. T. et al. Mitigation of chlorpyrifos runoff using constructed wetlands. Chemosphere, Oxford, v.46, n.6, p.827-835, 2002.

MOORE, M. T. et al. Influence of vegetation in mitigation of methyl parathion runoff. Environmental Pollution, Oxford, v.142, n.2, p.288-294, 2006.

RIPLEY, L.E.; BOYLE, W.C.; CONVERSE, J.C. Improved alkalimetric monitoring for anaerobic digestion of high-strengh wastes. Journal of Water Pollution Control Federation, Washington, v.58, n.5, p.406-411, 1986.

ROSE, M. T. et al. Pesticide removal from cotton farm tailwater by a pilot-scale ponded wetland. Chemosphere, Oxford, v.63, n.11, p.1849-1858, 2006.

RUNES, H. B. et al. Treatment of atrazine in nursery irrigation runoff by a constructed wetland. Water Research, Oxford, v.37, n.3, p.539-550, 2003.

SCHULZ, R. et al. Acute toxicity of methyl-parathion in wetland mesocosms: assessing the influence of aquatic plants using laboratory testing with Hyalella azteca. Arquives of Environmental Contamination and Toxicology, Nova Iorque, v.45, n.3, p.331-336, 2003a.

SCHULZ, R. et al. Methyl parathion toxicity in vegetated and nonvegetated wetland mesocosms. Environmental Toxicology and Chemistry, Pensacola, v.22, n.6, p.1262-1268, $2003 b$. 
SCHULZ, R. et al. Fate and effects of azinphos-methyl in a flow-through wetland in South Africa. Environmental Science and Technology, Washington, v.37, n.10, p.2139-2144, 2003 c.

SOLOMON, K. R. et al. Ecological risk assessment of atrazine in north american surface waters. Environmental Toxicology and Chemistry, Pensacola, v.15, n.1, p.31-76, 1996.

SOUSA, J. T. et al. Utilização de wetland construído no pós-tratamento de esgotos domésticos pré-tratados em reatores UASB. Engenharia Sanitária e Ambiental, Rio de Janeiro, v.9, n.4, p.285-290, 2004.

SMITH, S., Jr.; LIZOTTE, R. E., Jr.; MOORE, M. T. Toxicity assessment of diazinon in a constructed wetland using Hyalella azteca. Bulletin of Environmental Contamination and Toxicology, Nova Iorque, v. 79, n.1, p.58-61, 2007.

SPADOTTO, C. A. et al. Monitoramento do risco ambiental de agrotóxicos: princípios e recomendações. Jaguariúna: EMBRAPA, 2004. 29p. Documentos, 42.

STEARMAN, G. K. et al. Pesticide removal from container nursery runoff in constructed wetland cells. Journal of Environmental Quality, Madison, v.32, n.4, p.1548-1556, 2003.

VYMAZAL, J. (ed.) Transformations of nutrients in natural and constructed wetlands. Leiden: Backhus Publishers, 2001. 510p. 



\section{CAPÍTULO 6}

EFEITOS DO HERBICIDA AMETRINA NO TEOR DE NUTRIENTES, NA MORFOANATOMIA E NA GERMINAÇÃO DE THYPHA LATIFOLIA 


\section{EFEITOS DO HERBICIDA AMETRINA NO TEOR DE NUTRIENTES, NA MORFO- ANATOMIA E NA GERMINAÇÃO DE TYPHA LATIFOLIA}

\section{RESUMO}

A taboa (Typha latifolia) é uma das espécies de uso corrente em sistemas alagados construídos (SACs) para a remoção de poluentes. Com a realização de testes de toxicidade de um contaminante específico à espécie, em seus diferentes estágios (sementes, exemplares adultos), é possível se avaliar as potencialidade no uso de SACs na remoção do composto em estudo de águas contaminadas. Uma pesquisa realizada em casa de vegetação e um teste de germinação foram realizados para a verificação de possíveis efeitos da presença do herbicida triazínico ametrina no teor de nutrientes e na morfo-anatomia de exemplares adultos e no desenvolvimento inicial de sementes de T. latifolia. Não foram observadas variações nos teores nutricionais e na morfo-anatomia dos exemplares avaliados; tal fato pode ser interpretado positivamente, visto que, mesmo sob perturbação ambiental, a planta conseguiu manter suas características. Verificou-se que o desenvolvimento inicial da taboa foi prejudicado por reduzidas concentrações $\left(0,1 \mathrm{mg} \mathrm{L}^{-1}\right)$ de ametrina, sendo que a zona radicular foi mais sensível à contaminação. Os resultados demonstraram que a planta pode ser usada como indicadora de contaminação e que SACs vegetados podem ser usados na mitigação de praguicidas.

PALAVRAS-CHAVE: alagados construídos, germinação, morfo-anatomia, praguicidas, taboa, toxicidade. 


\section{AMETRYN EFFECTS ON NUTRIENT CONTENT, MORPHO-ANATOMY AND GERMINATION OF TYPHA LATIFOLIA}

\section{ABSTRACT}

Common cattail (Typha latifolia) it is one of the species used in constructed wetland treatment systems $(\mathrm{CW})$. The accomplishment of toxicity tests of a specific pollutant to macrophytes in different life stages (i.e. seeds or mature plants) can results in data of $\mathrm{CW}$ potentiality use on this compound treatment. Green house and germination tests were performed with focus in the verification of possible effects of the ametryn herbicide presence in (i) nutrients contents and morpho-anatomy aspects of mature plants and (ii) cattail seed germination and early seedling growth. No observed effect in nutrients and morpho-anatomy were observed. This fact can be interpreted positively, because ever under environmental disturbance, the macrophyte maintained its characteristics. Aqueous 10-d germination and growth experiment indicate ametryn harmful effects to cattail ( $T$. latifolia) development. Shoot development was more sensitive to herbicide contamination $\left(0.1 \mathrm{mg} \mathrm{L}^{-1}\right)$. These results demonstrated that (i) T. latifolia can be used as a representative plant tests species and (ii) vegetated constructed wetlands can be used in pesticides mitigation.

KEYWORDS: constructed wetlands, germination, morpho-anatomy, pesticides, cattail, toxicity. 


\subsection{INTRODUÇÃO}

O uso não controlado de agroquímicos pode causar uma gama diversa de impactos negativos ao meio físico ambiental (ar, água e solo) e também à saúde humana. Nesse contexto, é sabido que o ecossistema aquático apresenta-se particularmente como um ambiente muito vulnerável a perturbações, como o aporte excessivo de praguicidas, por exemplo.

Estima-se que o uso indiscriminado de agroquímicos já seja a segunda mais importante causa de poluição hídrica no Brasil. A principal forma de aporte desses produtos em mananciais ocorre de maneira difusa (escoamento superficial em áreas agrícolas), contudo também devem ser consideradas as emissões pontuais, devidas a atividades como viveiros de mudas e lavagem/processamento de frutas e legumes, por exemplo.

Dentre os defensivos usados no país, cita-se a ametrina, um herbicida sistêmico, pouco estudado e aplicado nas culturas de cana-de-açúcar, citrus, café e milho. O uso não controlado desse praguicida, somado às características físicas e químicas do composto pode resultar na contaminação de corpos hídricos situados à jusante de áreas cultivadas com tais plantações (Costa Queiroz et al., 1999; Cabral et al., 2003).

Na busca de alternativas para a minimização da contaminação do meio físico, tem-se difundido o uso de vegetais na remoção de poluentes, em uma técnica conhecida como fitorremediação (Cunningham et al., 1996). Segundo Procópio et al. (2005), a tolerância apresentada por estes vegetais pode ser resultante de processos como a translocação diferencial para outros tecidos da planta, com subseqüente volatilização, degradação e transformação em outros compostos. Macek, Macková e Káš (2000) afirmam que os compostos orgânicos passam por transformações nas células das plantas e, posteriormente, são isolados em vacúolos ou ligam-se a estruturas celulares insolúveis.

Sistemas alagados construídos (SACs) são alternativas tecnológicas que utilizam a fitorremediação e a degradação microbiana como alguns dos mecanismos de mitigação da contaminação de águas. O uso de plantas resistentes à inundação periódica ou permanente é preferível, nesses casos, sendo a taboa (Typha latifolia), uma das espécies mais usadas nessa tecnologia de tratamento.

A taboa é uma macrófita pertencente à classe Pandanales, ordem das Typhales e família Typhaceae, que é monotípica, contendo o único gênero Typha, que é encontrado em 
ambos os hemisférios, em regiões temperadas e tropicais (Hussar, 2001). A planta apresenta caule mais ou menos cilíndrico e não lenhoso; folhas lineares de bainha bem desenvolvidas, esiformes, espessas, esponjosas, coriáceas, lineares oblongas de até 4 metros de comprimento.

Segundo Lorenzi (1982), a macrófita possui, no Brasil, variadas denominações regionais, tais como taboa, tabua, partasana, paineira-de-flecha, paineira-do-brejo, espadana, landim, capim-de-esteira, pau-de-lagoa, tabebuia, erva-de-esteira e paina-de-flecha. No exterior, a macrófita é conhecida como massette à larges feuilles (francês), breitblättriger rohrkolben (alemão) e cattail (inglês). O gênero apresenta um reduzido número de espécies, sendo as principais $T$. latifolia, T. angustifolia, e T. domingensis. A taboa apresenta várias utilidades: rizoma comestível, fibras excelentes para manufatura de alguns artefatos, tem aproveitamento viável para produção de álcool e biofertilizante, podendo também ser usada para fins medicinais (Pott e Pott, 2000). Na Figura 6.1 apresenta-se uma ilustração da Typha sp.

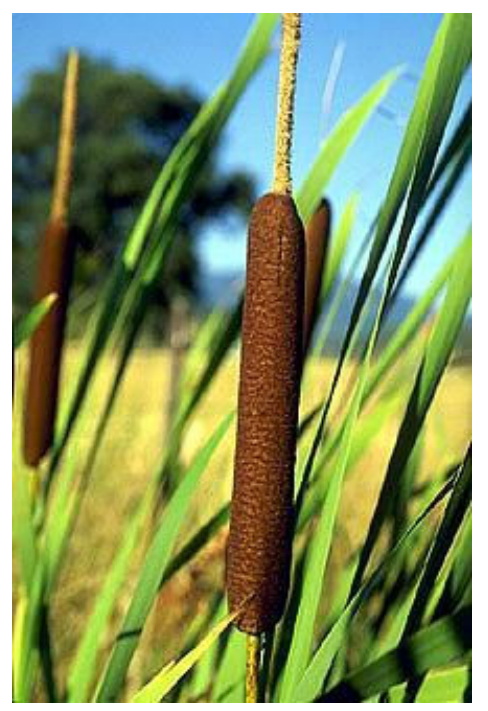

Figura 6.1 - Ilustração da macrófita Typha sp.

O uso de SACs nos quais o líquido escoa sob o leito no qual as plantas emergentes (como a taboa) são cultivadas, com a finalidade específica de mitigação de efeitos de praguicidas, é ainda incipiente, mas tem sido relatado na literatura especializada (McKinlay e Kasperek, 1999; Cheng et al., 2002; George et al., 2003; Stearman et al., 2003 e Matadoros et al., 2007). Em geral, os autores têm obtido resultados promissores, considerando esta, uma técnica simples, não onerosa e viável. 
Nos estudos supracitados, a avaliação da potencialidade dos SACs no tratamento de praguicidas é feita com base na eficiência de remoção dos compostos, com análises quantitativas realizadas por cromatografia ou por métodos imuno-enzimáticos. Não há, nesses casos, análise da influência da aplicação dos agroquímicos no desenvolvimento vegetativo das macrófitas usadas.

Estudos sobre o efeito de contaminantes em plantas aquáticas podem ser feitos com enfoques diversos, como influência na germinação, no desenvolvimento de raízes e caules, no crescimento e reprodução dos vegetais e na anatomia de estruturas das espécies. Ao final das investigações, geralmente se obtém os valores de concentrações para as quais estatisticamente não há efeitos observáveis. Na Tabela 6.1, podem ser visualizados os efeitos estudados em algumas pesquisas com exposição da taboa a praguicidas.

Tabela 6.1 - Alguns efeitos estudados em Typha spp. devido à exposição a agroquímicos

\begin{tabular}{ccc}
\hline Praguicida(s) & Efeito(s) & Referência \\
\hline Atrazina & Crescimento (altura) & Langan e Hoagland (1996) \\
Atrazina e Paraquat & $\begin{array}{c}\text { Germinação de sementes e } \\
\text { crescimento de raízes e brotos }\end{array}$ & Moore et al. (1999) \\
Metalaxil e Simazina & $\begin{array}{c}\text { Senescência, ganho de massa } \\
\text { Sulfato de cobre }\end{array}$ & Germinação de sementes e \\
& crescimento de raízes e brotos & Muller, Huggett e Rodgers (2001) \\
\hline
\end{tabular}

É sabido que espécies diferentes podem não tolerar doses de praguicidas igualmente. Langan e Hoagland (1996), analisando aspectos morfológicos de Typha latifolia e Scirpus acutus expostas à atrazina, verificaram que a taboa apresentou-se mais robusta. Estudando toxicidade à germinação e desenvolvimento inicial da T. latifolia, Moore et al. (1999) observaram que, quando expostas a concentrações de paraquat na ordem de $10 \mathrm{mg} \mathrm{L}^{-1}$, as sementes não mais germinavam.

Wilson, Whitwell e Klaine (2000) estudaram a tolerância da taboa à exposição à simazina e metalaxil. Os autores concluiram que o uso da espécie na fitorremediação desses agroquímicos é promissor, desde que aspectos relacionados a concentrações limitantes para o desenvolvimento da espécie sejam sempre considerados. 
Com base no exposto, verifica-se que a sustentabilidade do uso de SACs relaciona-se com a sanidade da macrófita cultivada no sistema. Diante de tal constatação, realizou-se o presente estudo com o objetivo de avaliar a resposta da taboa (em diferentes estágios de desenvolvimento) exposta à ametrina.

\subsection{METODOLOGIA}

\section{Experimento em casa de vegetação}

O experimento foi realizado durante 4 semanas (novembro de 2006) em uma estufa localizada no Laboratório de Hidráulica do DEA/CCA/UFV. Foram utilizadas 11 recipientes cilíndricos, cada um com dimensões aproximadas de $28 \mathrm{~cm}$ de altura e $58 \mathrm{~cm}$ de diâmetro. Os SACs foram alimentados com água contaminada com ametrina, seguindo concentrações progressivas a fim de que a presença/ausência das macrófitas e a sustentabilidade do processo fosse avaliada; foram utilizadas concentrações consideradas reduzidas $\left(1 \mathrm{mg} \mathrm{L}^{-1}\right)$, médias $\left(3 \mathrm{mg} \mathrm{L}^{-1}\right)$ e altos $\left(9 \mathrm{mg} \mathrm{L}^{-1}\right)$. Na Figura 6.2 está apresentado um diagrama esquemático do experimento.

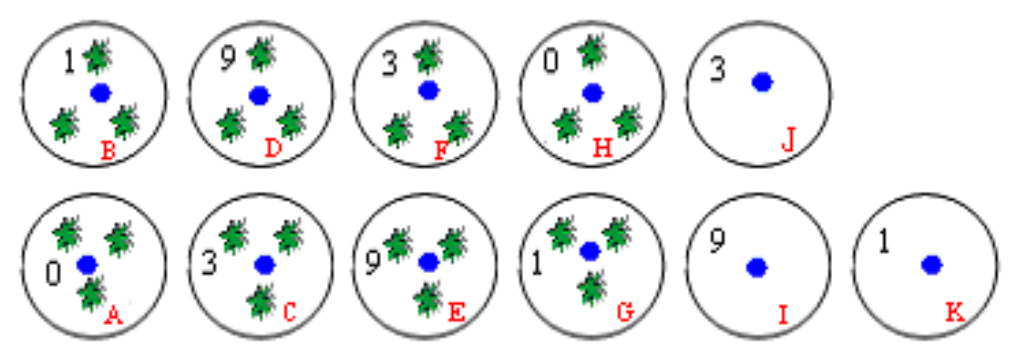

Figura 6.2 - Diagrama esquemático do experimento realizado em microcosmo: os números correspondem às concentrações de ametrina $\left(\mathrm{mg} \mathrm{L}^{-1}\right)$ adicionadas às wetlands vegetadas (pontos verdes) e não vegetadas

Após a adição de $20 \mathrm{~L}$ de água contaminada com as diferentes concentrações de ametrina, foram monitoradas as concentrações do agroquímico e as variáveis turbidez, $\mathrm{pH}$ e condutividade elétrica. $\mathrm{O}$ valor da evapotranspiração e as variações de temperatura na casa de vegetação também foram computados. 
Ao final do período de 4 semanas, foi realizado o corte completo das taboas e foram realizadas análises de concentrações de nutrientes (nitrogênio, fósforo, potássio, enxofre, cobre, zinco, cálcio, magnésio, ferro e manganês) e massa de matéria seca, tanto na parte aérea quanto na parte subterrânea (raízes) das plantas.

Para o melhor entendimento dos efeitos da prática também foram realizadas análises morfo-anatômicas das plantas e quantificadas as taxas de respiração microbiana no substrato.

\section{Teste de germinação e crescimento inicial de T. latifolia}

Para a realização de estudo com Typha latifolia em sua germinação (primeiro estágio do seu ciclo), foram coletadas, em meados de junho de 2007, inflorescências da planta em uma área alagável natural (wetland) situada no distrito de Paula, Viçosa, Minas Gerais. O material foi acondicionado em sacos plásticos e levado ao laboratório, onde a separação de sementes viáveis foi realizada. Para tanto, se utilizou o procedimento descrito por McNaughton (1968): após agitação em liquidificador comercial por 20 s, as sementes mais escuras e que sedimentam são consideradas viáveis.

Soluções estoque com concentrações teóricas de 0,$0 ; 0,1 ; 1,0 ; 10,0$ e $100,0 \mathrm{mg} \mathrm{L}^{-1}$ de ametrina foram preparadas. Para tal, foi utilizado o herbicida Metrimex (Sipcam S.A.) dissolvido em solução nutriente de Hoagland à meia-força (Hoagland e Arnon, 1950).

Foram usadas 3 repetições para cada concentração adicionada. Em cada repetição (béqueres contendo $100 \mathrm{~mL}$ das soluções) foram acondicionadas 50 sementes, com auxílio de pipetas. O material foi alocado em uma câmara, sob um fotoperíodo de $16 \mathrm{~h} \mathrm{~d}^{-1}$ de iluminação. Para tanto, foram usadas 2 lâmpadas fluorescentes Taschibra 21 W (2000 3000 Lux) e um temporizador analógico marca Starlux. A variação de temperatura na câmara foi registrada em um termômetro de máxima e mínima marca Polimed e para a manutenção das concentrações nominais, os volumes perdidos por evaporação eram repostos todos os dias.

Após 10 dias de período de exposição, as sementes foram coletadas e foram quantificados todos os comprimentos das raízes e brotos das plantas. Foram consideradas germinadas as sementes nas quais se observaram tecido clorofilado visível (Grace, 1983). Foram utilizados câmera fotográfica de alta resolução e software específico para análises de imagens. Ao final do experimento, foram realizadas análises estatísticas para a observação da influência da adição de ametrina no desenvolvimento inicial da macrófita. 


\subsection{RESULTADOS E DISCUSSÃO}

\section{Evapotranspiração e qualidade da água nos SACs em casa de vegetação}

A temperatura do ar na estufa variou entre 17,1 e $37,7{ }^{\circ} \mathrm{C}$, sendo a média no período igual a $27,0{ }^{\circ} \mathrm{C}$. Os 3 recipientes não vegetados apresentaram $\mathrm{ET}$ de $1,7 \pm 0,8 \mathrm{~mm} \mathrm{~d}^{-1}$, enquanto os recipientes cultivados com taboa apresentaram perdas entre $7,1 \pm 0,5 \mathrm{~mm} \mathrm{~d}^{-1}$ (SACs expostos à concentração inicial de $9 \mathrm{mg} \mathrm{L}^{-1}$ de ametrina) e 7,7 $\pm 0,4 \mathrm{~mm} \mathrm{~d}^{-1}$ (SACs expostos a $1 \mathrm{mg} \mathrm{L}^{-1}$ de ametrina). Não se observou diferença estatística entre os grupos de SACs vegetados, mas a diferença entre perdas em sistemas cultivados e não cultivados foi significativa. Na Figura 6.3, visualizam-se os valores médios de perdas devido à evaporação e evapotranspiração nas células. A comparação com as médias do tanque classe A também pode ser realizada.

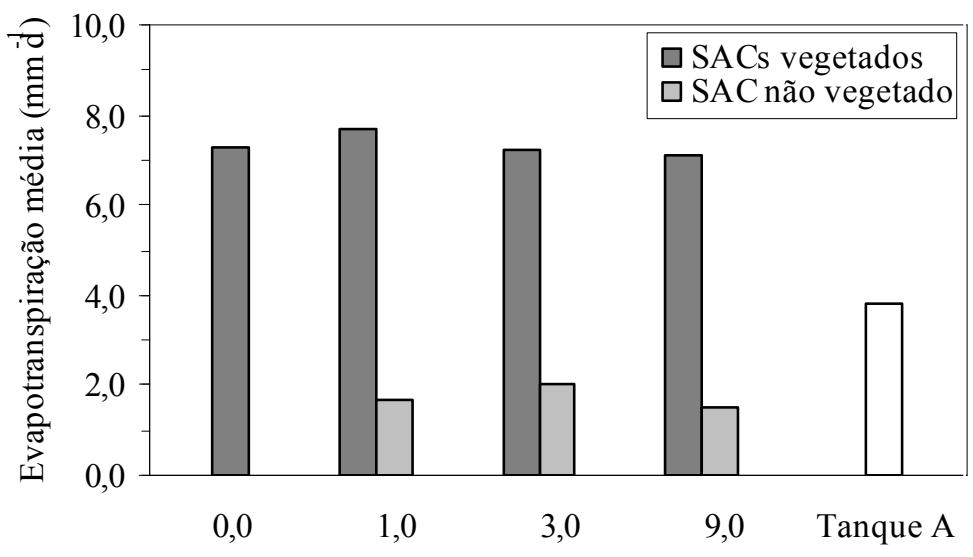

Figura 6.3 - Perda de líquido residente no período de experimentação, os números contidos no eixo das abscissas denotam as concentrações de ametrina aplicadas inicialmente

Os valores médios de evapotranspiração foram estimados com boa precisão e se apresentaram maiores que os observados em campo aberto, de 5,8 $\mathrm{mm} \mathrm{d}^{-1}$ (Capítulo 5); o fato pode ser explicado pela maior temperatura na casa de vegetação (no estudo anterior a temperatura média registrada foi de $22,1^{\circ} \mathrm{C}$ ).

No presente estudo, foi feita a reposição diária dos volumes evaporados. Dessa maneira, o controle da disponibilidade hídrica para as plantas era realizado, sem prejudicar a interpretação dos dados, tanto em termos de concentração quanto em termos de balanço de massa. 
Quanto às variáveis de qualidade da água, não foram observadas discrepâncias entre os tratamentos. No entanto, quando a presença/ausência de vegetação foi avaliada, observaram-se pequenas diferenças: A remoção da turbidez inicial (40 uT) foi mais rápida nos SACs vegetados, que apresentaram condutividade elétrica ligeiramente superior e $\mathrm{pH}$ menor do que as unidades sem vegetação (Figura 6.4).

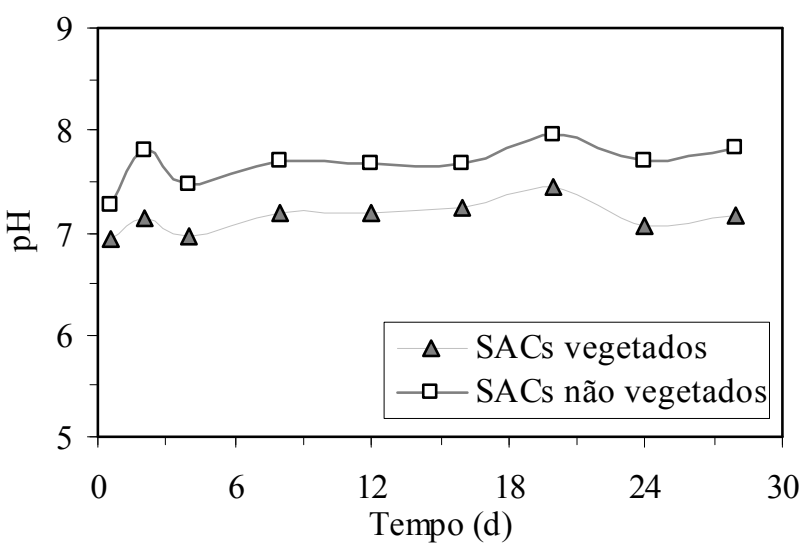

(a)

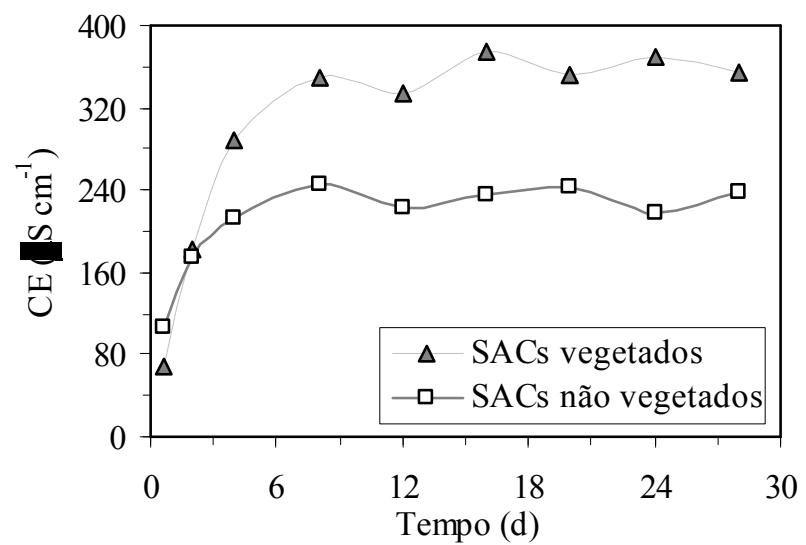

(b)

Figura 6.4 - Variação dos valores de: (a) potencial hidrogeniônico e (b) condutividade elétrica nos 8 SACs vegetados e nos 3 SACs não vegetados

A avaliação quantitativa do decréscimo na concentração de ametrina ao longo dos 28 dias não pode ser realizada. Problemas como contaminação de frascos de coleta e perda por evaporação de amostras acondicionadas por tempo excessivo contribuíram para baixa precisão nas análises cromatográficas.

Mesmo com os referidos contratempos, verificou-se que, ao final do experimento, a ametrina se encontrava em concentrações inferiores ao limite de detecção em todas as unidades. Testes de organismos-sentinela, como Daphnia magna certamente teriam contribuído para uma análise mais simples e não menos eficaz.

\section{Teor de nutrientes na macrófita}

A análise dos nutrientes na taboa foi realizada em termos de concentração (porcentagem do nutriente em relação à matéria seca) e de produtividade agronômica (massa do nutriente por área, extrapolando-se a área para 1 hectare). Foram avaliados os valores de teores de nutrientes e metais no tecido clorofilado (parte aérea) e nas raízes (parte 
subterrânea). Em relação às porcentagens de nutrientes acumuladas na parte aérea das plantas, verifica-se que apenas um dado apresentou diferença estatística. Como se tratava de um experimento com variação qualitativa (doses de ametrina adicionadas inicialmente), a comparação estatística foi realizada somente entre cada par "presença/ausência" de ametrina, ou seja, mesmo apresentando valores distintos, os tratamentos com 1,0; 3,0 e 9,0 mg L $\mathrm{L}^{-1}$ não foram comparados entre si, sendo pareados apenas com o controle $\left(0,0 \mathrm{mg} \mathrm{L}^{-1}\right.$ de ametrina).

De uma maneira geral, os valores médios, visualizados na Tabela 6.2, equivalem aos reportados em estudos sobre teores de nutrientes na taboa em SACs sob clima tropical: Brasil, Matos e Fia (2003); Barros (2005), Brasil (2005) e Martins et al. (2007). Barros (2005) verificou que cálcio e potássio foram os elementos expressivos na parte aérea dos controles usados em seu experimento.

Tabela 6.2 - Concentrações médias $\left(\right.$ dag $\left.\mathrm{kg}^{-1}\right)$ de nutrientes na matéria seca (parte aérea) da taboa

\begin{tabular}{ccccc}
\hline \multirow{2}{*}{ Constituinte } & \multicolumn{4}{c}{ Concentrações nominais aplicadas $\left(\mathrm{mg} \mathrm{L}^{-1}\right)$} \\
\cline { 2 - 5 } & 0,0 & 1,0 & 3,0 & 9,0 \\
\hline Nitrogênio & 1,407 & 1,362 & 1,283 & 1,339 \\
Fósforo & 0,286 & 0,279 & 0,275 & $0,403^{* *}$ \\
Potássio & 6,806 & 6,522 & 6,724 & 6,133 \\
Sódio & 0,175 & 0,160 & 0,133 & 0,108 \\
Enxofre & 0,531 & 0,659 & 0,774 & 0,588 \\
Cálcio & 2,007 & 2,032 & 2,335 & 2,003 \\
Magnésio & 0,326 & 0,357 & 0,357 & 0,366 \\
Manganês & 0,030 & 0,034 & 0,038 & 0,038 \\
Ferro & 0,035 & 0,043 & 0,035 & 0,058 \\
Zinco & 0,005 & 0,005 & 0,005 & 0,008 \\
Cobre & $0,583 \mathrm{E}-03$ & $0,615 \mathrm{E}-03$ & $0,340 \mathrm{E}-03$ & $0,592 \mathrm{E}-03$ \\
& & & & \\
\hline ** Diferente estatisticamente $(\alpha=0,05)$ do controle, pelo teste de Tukey. &
\end{tabular}

Os níveis de metais observados na parte subterrânea estão maiores, em comparação com a parte aérea (Tabela 6.3). A importância na quantificação de nutrientes nas raízes e 
caules é ressaltada, uma vez que a produtividade de matéria seca $\left(8,1 \mathrm{t} \mathrm{ha}^{-1}\right)$ nessa região é considerável.

Tabela 6.3 - Concentrações médias $\left(\mathrm{dag} \mathrm{kg}^{-1}\right)$ de nutrientes na matéria seca (parte subterrânea) da taboa

\begin{tabular}{ccccc}
\hline \multirow{2}{*}{ Constituinte } & \multicolumn{4}{c}{ Concentrações nominais aplicadas $\left(\mathrm{mg} \mathrm{L}^{-1}\right)$} \\
\cline { 2 - 5 } & 0,0 & 1,0 & 3,0 & 9,0 \\
\hline Nitrogênio & 0,533 & 0,434 & 0,417 & 0,771 \\
Fósforo & 0,322 & 0,307 & 0,478 & 0,400 \\
Potássio & 2,974 & 4,001 & 2,732 & 4,047 \\
Sódio & 0,367 & 0,270 & 0,297 & 0,202 \\
Enxofre & 0,461 & 0,333 & 0,460 & 0,282 \\
Cálcio & 1,889 & 1,370 & 1,535 & 1,666 \\
Magnésio & 0,376 & 0,427 & 0,419 & 0,527 \\
Manganês & 0,039 & 0,025 & 0,056 & 0,025 \\
Ferro & 1,266 & 0,693 & 1,542 & 1,127 \\
Zinco & 0,025 & 0,014 & 0,025 & 0,013 \\
Cobre & 0,015 & 0,010 & 0,015 & 0,007 \\
\hline
\end{tabular}

Nas Tabelas 6.4 e 6.5 podem ser visualizados as quantidades $\left(\mathrm{M} \mathrm{L}^{-2}\right)$ de nutrientes para a parte aérea e a parte subterrânea, respectivamente. Como observado por diversos autores (Motta Marques, 1999; Pott e Pott, 2000), as macrófitas contribuem na remoção e ciclagem de nutrientes e outros constituintes presentes no meio aquático. Os valores observados são inferiores aos obtidos por Freitas (2006), que relata quantidades equivalentes a $533 \mathrm{~kg} \mathrm{ha}^{-1}$ de nitrogênio total, $88 \mathrm{~kg} \mathrm{ha}^{-1}$ de fósforo e $650 \mathrm{~kg} \mathrm{ha}^{-1}$ de potássio. Como observado no Capítulo 5, o estudo do autor citado consistiu no tratamento de águas residuárias de atividade suinícola que, sabidamente, têm grande quantidade desses nutrientes em sua constituição. 
Tabela 6.4 - Quantidade $\left(\mathrm{kg} \mathrm{ha}^{-1}\right)$ de nutrientes (parte aérea) da taboa

\begin{tabular}{ccccc}
\hline \multirow{2}{*}{ Constituinte } & \multicolumn{4}{c}{ Concentrações nominais aplicadas $\left(\mathrm{mg} \mathrm{L}^{-1}\right)$} \\
\cline { 2 - 5 } & 0,0 & 1,0 & 3,0 & 9,0 \\
\hline Nitrogênio & 191,25 & 184,46 & 160,85 & 188,50 \\
Fósforo & 38,34 & 37,59 & 34,97 & 57,61 \\
Potássio & 912,97 & 879,18 & 845,49 & 866,06 \\
Sódio & 22,95 & 21,64 & 17,12 & 15,42 \\
Enxofre & 72,16 & 87,87 & 96,11 & 85,34 \\
Cálcio & 267,74 & 271,18 & 286,47 & 293,86 \\
Magnésio & 44,56 & 48,11 & 44,48 & 51,91 \\
Manganês & 4,11 & 4,67 & 4,80 & 5,58 \\
Ferro & 4,67 & 5,74 & 4,27 & 8,66 \\
Zinco & 0,64 & 0,68 & 0,60 & 1,11 \\
Cobre & 0,08 & 0,08 & 0,04 & 0,086 \\
& & &
\end{tabular}

Tabela 6.5 - Quantidade $\left(\mathrm{kg} \mathrm{ha}^{-1}\right)$ de nutrientes (parte subterrânea) da taboa

\begin{tabular}{ccccc}
\hline \multirow{2}{*}{ Constituinte } & \multicolumn{4}{c}{ Concentrações nominais aplicadas $\left(\mathrm{mg} \mathrm{L}^{-1}\right)$} \\
\cline { 2 - 5 } & 0,0 & 1,0 & 3,0 & 9,0 \\
\hline Nitrogênio & 35,41 & 40,75 & 33,23 & 63,65 \\
Fósforo & 20,87 & 29,25 & 38,25 & 32,98 \\
Potássio & 194,17 & 377,08 & 220,85 & 333,76 \\
Sódio & 24,30 & 25,84 & 23,65 & 16,69 \\
Enxofre & 30,44 & 29,99 & 36,16 & 23,30 \\
Cálcio & 126,84 & 130,80 & 119,41 & 137,56 \\
Magnésio & 24,99 & 40,53 & 33,05 & 43,56 \\
Manganês & 2,53 & 2,47 & 4,23 & 2,08 \\
Ferro & 85,84 & 69,06 & 118,69 & 93,19 \\
Zinco & 1,60 & 1,35 & 1,83 & 1,07 \\
Cobre & 1,02 & 1,05 & 1,19 & 0,60 \\
\hline
\end{tabular}




\section{Morfologia e anatomia da parte aérea da taboa}

Em relação à morfologia da planta, não foram observadas alterações significativas (Tabela 6.6). A ametrina adicionada poderia causar clorose foliar seguida de necrose e morte nas plantas. Contudo, os aspectos de senescência observados se apresentaram em todos os tratamentos, o que pode ser atribuído ao desbalanço químico de nutrientes.

Mesmo sem diferenças estatisticamente significantes, observa-se que a largura média das folhas amostradas diminuiu com a aplicação da ametrina. Em condições favoráveis, a taboa pode alcançar mais de 3 metros de altura; no entanto os comprimentos observados foram de cerca de 1,5 m: valores semelhantes aos observados por Barros (2005) em um estudo sobre morfo-anatomia da planta.

Tabela 6.6 - Comprimento e largura média do limbo foliar de Typha latifolia

\begin{tabular}{ccccc}
\hline Aspecto morfológico & \multicolumn{4}{c}{ Concentrações nominais aplicadas $\left(\mathrm{mg} \mathrm{L}^{1}\right)$} \\
\cline { 2 - 5 } & 0,0 & 1,0 & 3,0 & 9,0 \\
\hline Comprimento (m) & 1,51 & 1,46 & 1,54 & 1,59 \\
Largura (cm) & 1,02 & 1,02 & 0,97 & 0,92 \\
\hline
\end{tabular}

Quando a espécie foi cultivada em água contaminada com ametrina, sua anatomia não expressou mudanças significativas (Tabela 6.7).

Tabela 6.7 - Características anatômicas da parte aérea da T. latifolia

\begin{tabular}{ccccc}
\hline \multirow{2}{*}{ Aspecto anatômico } & \multicolumn{5}{c}{ Concentrações nominais aplicadas $\left(\mathrm{mg} \mathrm{L}^{1}\right)$} \\
\cline { 2 - 5 } & 0,0 & 1,0 & 3,0 & 9,0 \\
\hline Espessura do limbo $(\mathrm{mm})$ & 1,58 & 1,17 & 1,25 & 1,31 \\
Espessura do epiderme adaxial $(\mu \mathrm{m})$ & 15,23 & 15,25 & 15,47 & 15,23 \\
Espessura do epiderme abaxial $(\mu \mathrm{m})$ & 12,78 & 14,42 & 17,64 & 16,72 \\
Esp. do parênquima paliçádico adaxial $(\mu \mathrm{m})$ & 88,37 & 102,33 & 92,13 & 89,16 \\
Esp. do parênquima paliçádico abaxial $(\mu \mathrm{m})$ & 82,00 & 84,24 & 95,52 & 82,35 \\
Tamanho da lacuna aerífera $(\mathrm{mm})$ & 1,30 & 0,83 & 0,95 & 1,54 \\
\hline
\end{tabular}


O fato dos exemplares da macrófita não terem apresentado alterações significativas pode ser interpretado positivamente, visto que mesmo sob perturbação ambiental a planta conseguiu manter suas características morfológicas e anatômicas, indicando certo grau de tolerância. Nas Figuras 6.5, 6.6 e 6.7 podem ser visualizados detalhes anatômicos nas lâminas foliares de plantas do tratamento controle (preservadas da contaminação com ametrina).

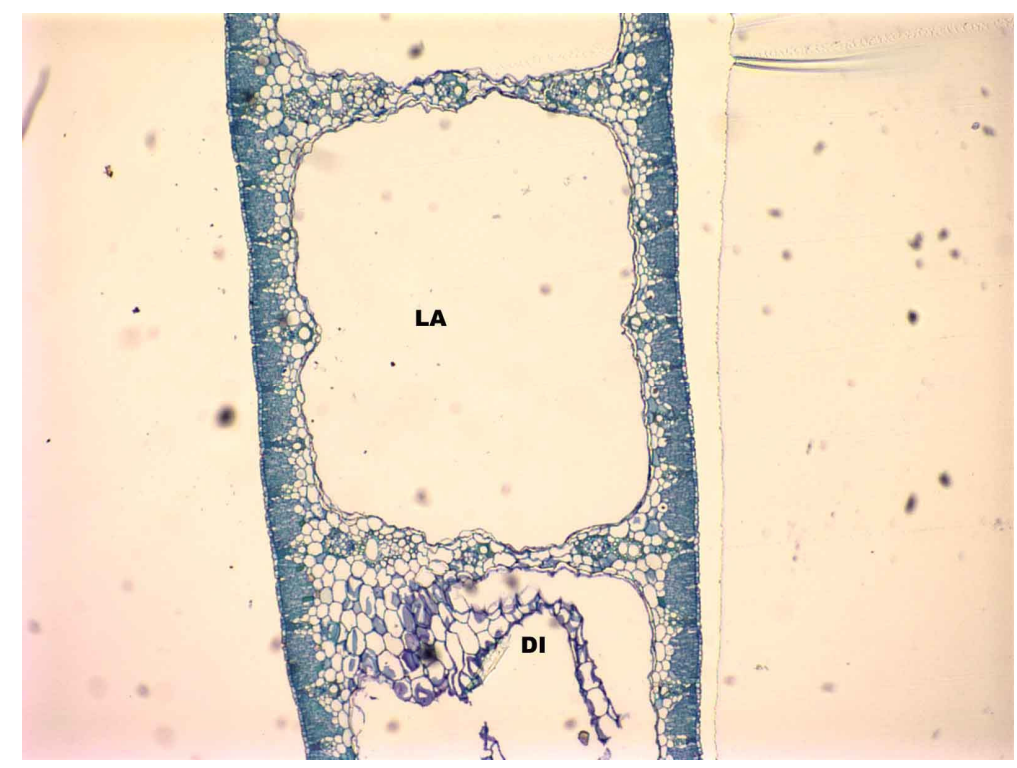

Figura 6.5 - Lâmina foliar de Typha latifolia, visão geral; LA: lacuna aerífera, DI: Diafragma

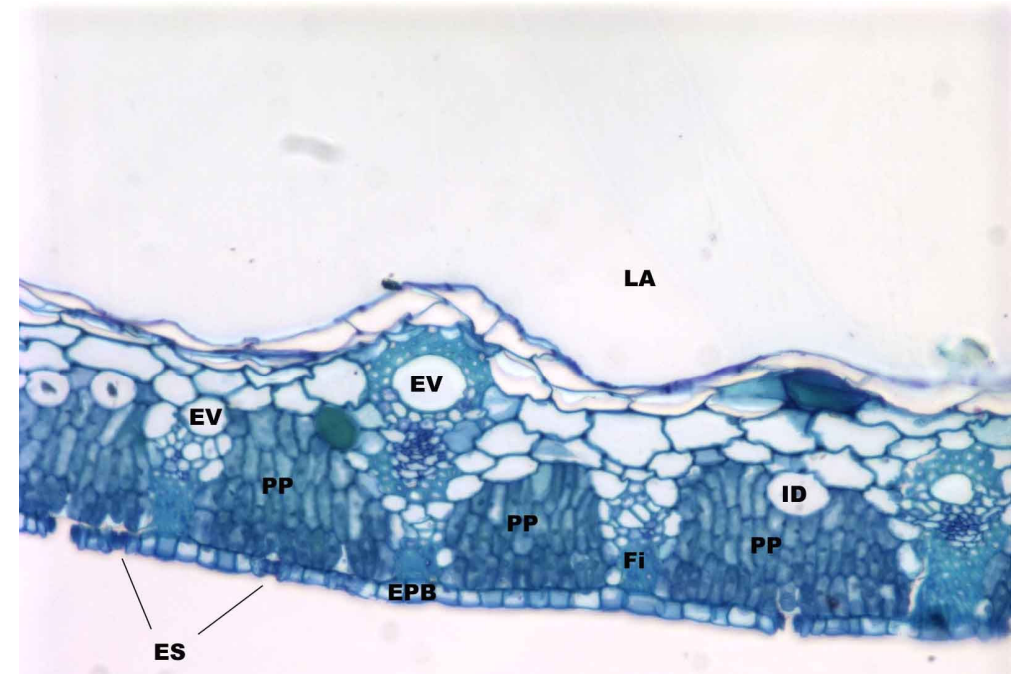

Figura 6.6 - Lâmina foliar de Typha latifolia, face abaxial; LA: lacuna aerífera, ID: idioblasto do diafragma, PP: parênquima paliçádico, Fi: fibras, EV: elemento de vaso, ES: estômato, EPB: epiderme abaxial 


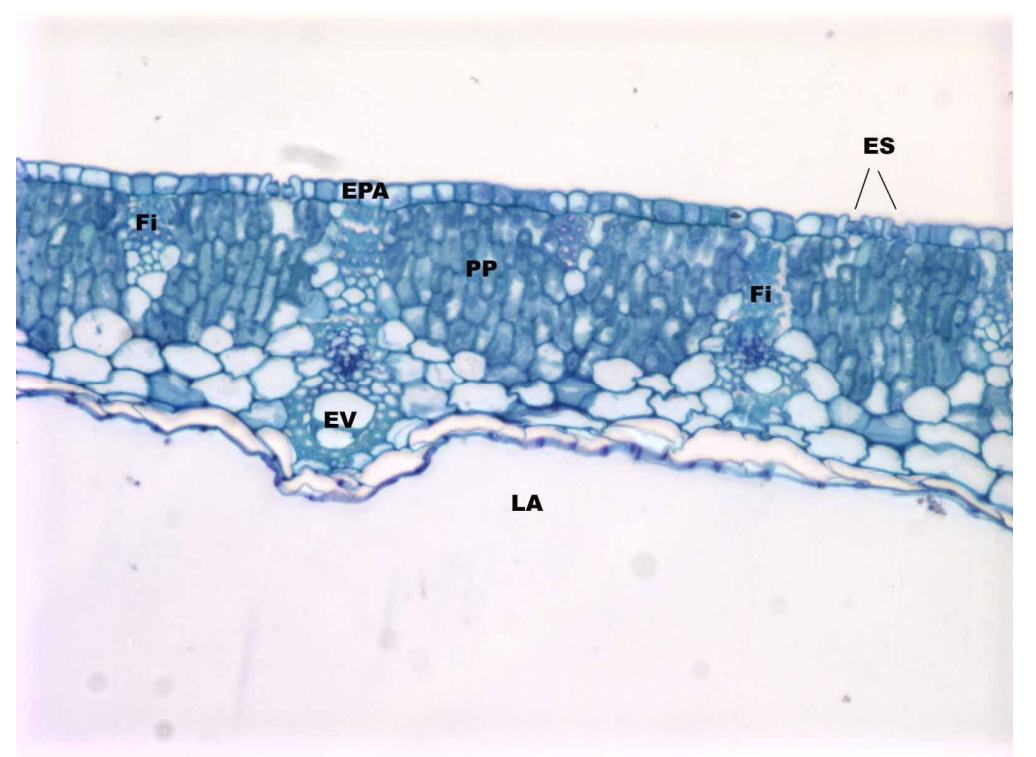

Figura 6.7 - Lâmina foliar de Typha latifolia, face adaxial; LA: lacuna aerífera, PP: parênquima paliçádico, Fi: fibras, EV: elemento de vaso, ES: estômato, EPA: epiderme adaxial

\section{Testes de evolução de $\mathrm{CO}_{2}$ emitido na região rizosférica}

A taxa de evolução de $\mathrm{CO}_{2}$ emitido na região subterrânea (100 gramas de substrato, caules e raízes) foi usada para avaliar a atividade microbiológica rizosférica nos SACs.

Apesar da análise das taxas médias de respiração obtidas em todas os SACs (Tabela 6.8) se mostrar complicada, verifica-se que nas células sem vegetação não houve praticamente nenhuma presença de microrganismos, ponderando-se que a respiração é diminuta.

Tabela 6.8 - Valores médios de respiração obtidos nos SACs não vegetados (I, J e K) e nos SACs cultivados com taboa, valores em $\left(\mu \mathrm{mol} \mathrm{h}^{-1}\right)$

\begin{tabular}{ccccccccccc}
\hline A & B & C & D & E & F & G & H & I & J & K \\
51,19 & 107,15 & 70,86 & 115,90 & 40,20 & 83,96 & 56,51 & 117,02 & 0,10 & 0,19 & 0,26 \\
\hline
\end{tabular}

Diferenças entre os tratamentos são notadas quando observada a evolução da emissão de $\mathrm{CO}_{2}$ nos SACs (Figura 6.8). Percebe-se que a respiração é semelhante em todos os casos, contudo, a possível microbiota presente nos SACs sem contaminação (A e H) decai mais lentamente. 


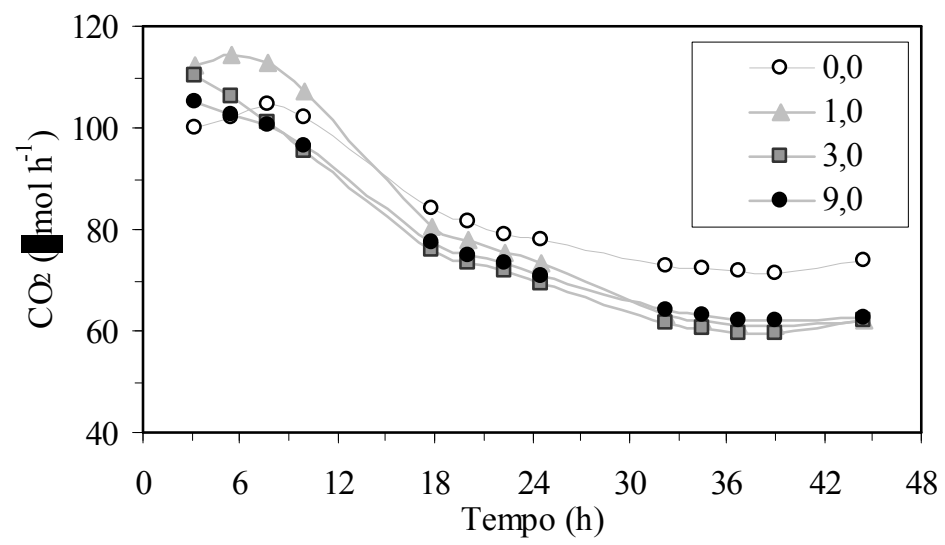

Figura 6.8 - Valores médios da taxa de evolução de $\mathrm{CO}_{2}$ na rizosfera de alagados vegetados com T. latifolia

Segundo a EXTOXNET (1998) e Rodrigues e Almeida (2005), a degradação biológica é de grande importância na dissipação da ametrina. A literatura científica registra que microrganismos diversos (como, por exemplo, Pseudomonas spp., Rhodococcus spp., Ralstonia spp.; Clavibacter spp., Agrobacterium spp. e Streptomyces spp.) são capazes de degradar a atrazina (triazina mais usada em nível mundial). Farré et al. (2002) reduziram a toxicidade de ametrina por biodegradação com microrganismos de estações de tratamento de esgotos do tipo lodo ativado; é de se esperar, portanto, que as espécies citadas também degradem ametrina. Outro aspecto a ser ressaltado é que o bioaumento - adição de sedimento enriquecido com biota adaptada à degradação do praguicida - pode se mostrar uma alternativa interessante para aplicação em wetlands construídos.

\section{Teste de germinação de sementes e crescimento inicial}

No estudo realizado, a porcentagem de germinação das sementes foi inferior às verificadas por Lombardi et al. (1997), Moore et al. (1999) e Muller, Huggett e Rodgers (2001). As sementes foram coletadas em um período anterior a realização do teste, sendo que algumas podem ter perdido a viabilidade. Tal fato não impediu a avaliação do efeito da presença de ametrina.

$\mathrm{Na}$ Tabela 6.9 estão contidos os resultados obtidos no ensaio de toxicidade à germinação e desenvolvimento de raízes e brotos. Os valores referentes às medias de todos os tratamentos submetidos à contaminação com ametrina foram diferentes estatisticamente 
$(\alpha=0,05)$ do tratamento controle. Dessa maneira, o menor valor com efeitos observáveis foi igual a $0,1 \mathrm{mg} \mathrm{L-}{ }^{1}$ de ametrina.

Tabela 6.9 - Crescimento de raízes e brotos ( \pm desvio padrão) e porcentagem de germinação de T. latifolia exposta a ametrina durante os 10 dias iniciais do desenvolvimento

\begin{tabular}{cccccc}
\hline $\begin{array}{c}\text { Concentração } \\
\left(\mathrm{mg} \mathrm{L}^{-1}\right)\end{array}$ & Raízes & $\begin{array}{c}\text { Brotos } \\
(\mathrm{mm})\end{array}$ & $\begin{array}{c}\text { Plântulas } \\
(\mathrm{mm})\end{array}$ & $\begin{array}{c}\text { Sementes } \\
\text { germinadas }\end{array}$ & $\begin{array}{c}\text { Porcentagem } \\
\text { de germinação }\end{array}$ \\
\hline 0,0 & $7,0 \pm 1,6$ & $7,6 \pm 1,6$ & $14,6 \pm 2,0$ & 59 & 39,3 \\
0,1 & $3,9 \pm 1,0$ & $6,7 \pm 1,0$ & $10,6 \pm 1,4$ & 36 & 24,0 \\
1,0 & $4,2 \pm 1,0$ & $6,2 \pm 0,7$ & $10,4 \pm 1,0$ & 46 & 30,7 \\
10,0 & $3,3 \pm 1,2$ & $6,1 \pm 0,9$ & $9,4 \pm 1,5$ & 58 & 38,7 \\
100,0 & $0,3 \pm 0,3$ & $5,1 \pm 0,9$ & $5,5 \pm 0,7$ & 60 & 40,0 \\
\hline
\end{tabular}

Uma vez que os testes foram realizados atendendo-se os requisitos para o desenvolvimento inicial da planta, como iluminação, temperatura e disponibilidade de nutrientes (Grace, 1983; Lombardi et al., 1997), pode-se afirmar que o crescimento das raízes foi afetado de maneira mais evidente nos tratamentos. A mesma constatação foi feita por Moore et al. (1999) e Muller, Huggett e Rodgers (2001).

Todas as concentrações de ametrina presentes nos béqueres afetaram a parte radicular das mudas, mas percebe-se que a exposição das sementes a teores de $100 \mathrm{mg} \mathrm{L}^{-1}$ inibiu praticamente qualquer desenvolvimento de raízes na taboa. Moore et al. (1999) verificaram que a exposição de sementes à concentração de $10,0 \mathrm{mg} \mathrm{L}^{-1}$ de paraquat causaram o mesmo efeito citado (não ocorrência de raízes). A fotografia ilustrada na Figura 6.9 permite uma comparação entre as condições extremas $\left(0,0\right.$ e $\left.100,0 \mathrm{mg} \mathrm{L}^{-1}\right)$ usadas no teste.

O uso deste tipo de teste é recomendado por autores como Boutin, Freemark e Keddy (1995), que ressaltam a maior sensibilidade das plantas em seu estágio inicial de desenvolvimento. Os resultados obtidos conduzem à indicação de que a presença de ametrina, mesmo em concentrações reduzidas, prejudica o desenvolvimento da taboa. Não obstante à predominância da reprodução por propágulos (rebrota) em alagados construídos., verifica-se que a reprodução da Typha latifolia pode ser afetada pela ametrina, fato que deve ser ponderado quando estudos sobre sustentabilidade da prática forem realizados. 


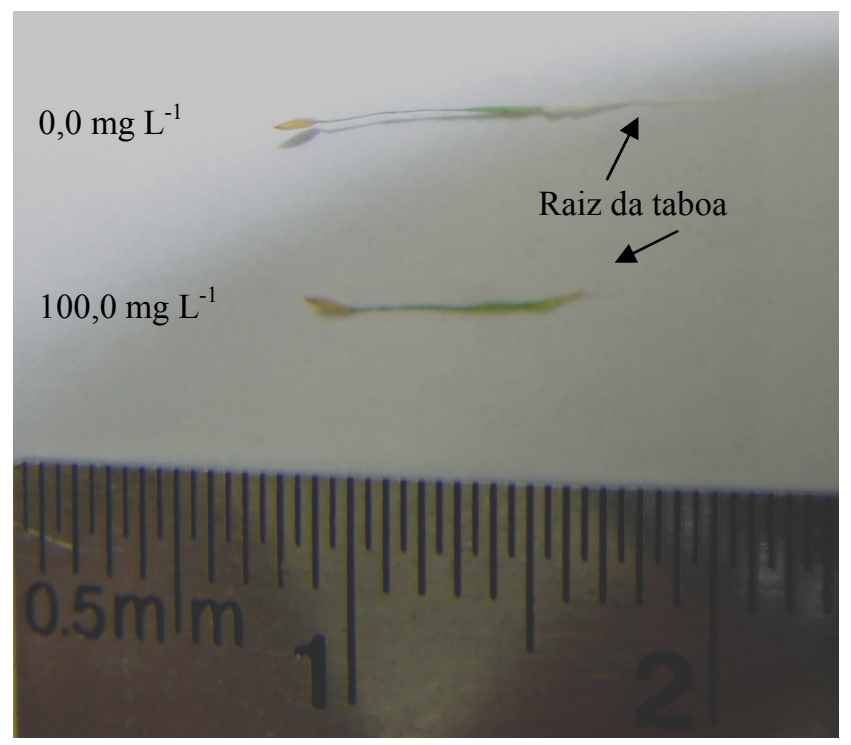

Figura 6.9 - Fotografia das plântulas após 10 dias de desenvolvimento

\subsection{SUMÁRIO}

No estudo em microcosmo, observou-se que ao final de 28 dias, a quantidade de ametrina nos SACs foi considerada como muito reduzida (valores próximos a zero). Em relação ao teor de nutrientes, não foram observadas variações significativas entre os tratamentos. Reafirma-se a potencialidade da parte vegetativa como fonte energética e na ciclagem de compostos como nutrientes e metais.

O fato de não terem sido observadas variações nos teores nutricionais e na morfoanatomia dos exemplares pode ser interpretado positivamente, visto que mesmo sob perturbação ambiental a planta adulta conseguiu manter suas características.

A não detecção de taxas de produção de gás carbônico nas células sem vegetação indica que nessas unidades não há atividade microbiana. Por outro lado, a presença de microrganismos na região rizosférica dos SACs vegetados confirmou-se com fator a ser considerado quando da discussão sobre o papel das macrófitas aquáticas nesses sistemas.

Apesar das indicações positivas citadas, verificou-se que o desenvolvimento inicial da taboa é prejudicado por reduzidas concentrações de ametrina. O não desenvolvimento das raízes no teste de germinação foi de uma maneira geral, o efeito observável em relação à 
presença de ametrina em sistemas alagados construídos. Tal fato deve ser ponderado em estudos futuros.

\subsection{REFERÊNCIAS BIBLIOGRÁFICAS}

BARROS, A. L. Morfo-anatomia e teor de nutrientes em três espécies vegetais cultivadas em sistema "wetland construído". 2005. 70f. Dissertação (Mestrado em Botânica) Universidade Federal de Viçosa, Viçosa.

BOUTIN, C.; FREEMARK, K. E.; KEDDY, C. J. Overview and rationale for developing regulatory guidelines for nontarget plant testing with chemical pesticides. Environmental Toxicology and Chemistry, Pensacola, v.14, n.9, p.1465-1475, 1995.

BRASIL, M. S. Desempenho de sistema alagado construído para tratamento de esgoto doméstico. 2005. 160f. Tese (Doutorado em Engenharia Agrícola) - Universidade Federal de Viçosa, Viçosa.

BRASIL, M. S.; MATOS, A. T.; FIA, R. Eficiência e impactos ambientais do tratamento de águas residuárias da lavagem e despolpa de frutos do cafeeiro em áreas alagadas naturais. Engenharia na Agricultura, Viçosa, v.11, n.1-4, p.43-51, 2003.

CABRAL, M. F. et al. Estudo do comportamento eletroquímico do herbicida ametrina utilizando a técnica de voltametria de onda quadrada. Eclética Química, São Paulo, v.28, n.2, p.41-47, 2003.

CHENG, S. et al. Xenobiotics removal from polluted water by a multifunctional constructed wetland. Chemosphere, Oxford, v.48, n.4, p.415-418, 2002.

COSTA QUEIROZ, R. H. et al. Determination of ametryn herbicide by bioassay and gas chromatography-mass spectrometry in analysis of residues in drinking water. Bolletino Chimico Farmaceutico, Milão, v.138, n.6, p.249-252, 1999. 
CUNNINGHAM, S. D. et al. Phytoremediation of soils contaminated with organic coumponds. Advances in Agronomy, San Diego, v.56, p.55-114, 1996.

EXTOXNET [THE EXTENSION TOXICOLOGY NETWORK]. The EXTOXNET

InfoBase, 1998. Disponível em <http://extoxnet.orst.edu>. Acesso em 15 ago. 2007.

FARRÉ et al. Analysis and toxicity of methomyl and ametryn after biodegradation. Analytical and Bioanalytical Chemistry, Heidelberg, v.373, n.8, p.704-709, 2002.

FREITAS, W. S. Desempenho de sistemas alagados construídos, cultivados com diferentes espécies vegetais, no tratamento de águas residuárias da suinocultura. 2006. 159f. Tese (Doutorado em Engenharia Agrícola) - Universidade Federal de Viçosa, Viçosa.

GEORGE, D. B. et al. Simazine and metolachlor removal by subsurface flow constructed wetlands. Water Environmental Research, Alexandria, v.75, n.2, p.101-112, 2003.

GRACE, J. B. Autotoxic inhibition of seed germination by Typha latifolia: an evaluation. Oecologia, Nova Iorque, v.59, n.2-3, p.366-269, 1983.

HOAGLAND, D. R.; ARNON, D. I. The water-culture method for growing plants without soil. Berkeley: Califórnia Agricultural Experiment Station, 1950. 32p.

HUSSAR, G. J. Avaliação do desempenho de leitos cultivados no tratamento de águas residuárias de suinocultura. 2001. 118f. Dissertação (Mestrado em Engenharia) Universidade Estadual de Campinas, Campinas.

LANGAN, M. M.; HOAGLAND, K. D. Growth responses of Typha latifolia and Scirpus acutus to atrazine contamination. Bulletin of Environmental Contamination and Toxicology, Nova Iorque, v.57, n.2, p.2096-2103, 1996.

LOMBARDI, T.; et al. Germination requirements in a population of Typha latifolia. Aquatic Botany, Amsterdam, v.56, n.1, p.1-10, 1997. 
LORENZI, H. Plantas daninhas do Brasil: terrestres, aquáticas, parasitas, tóxicas e medicinais. Nova Odessa: Ed. do Autor, 1982. 425p.

MACEK, T.; MACKOVÁ, M.; KÁŠ, J. Exploitation of plants for the removal of organics in environmental remediation. Biotechnology Advances, Oxford, v.18, n.1, p.23-34, 2000.

MARTINS, A. P. L. et al. Capacidade da Typha dominguensis na fitorremediação de efluentes de tanques de piscicultura na Bacia do Iraí - Paraná. Revista Brasileira de Engenharia Agrícola e Ambiental, Campina Grande, v.11, n.3, p.324-330, 2007.

MATADOROS, V. et al. Behavior of selected priority organic pollutants in horizontal subsurface flow constructed wetlands: a preliminary screening. Chemosphere, Oxford, no prelo, 2007.

MOTTA MARQUES, D. M. L. Terras úmidas de fluxo subsuperficial. In: CAMPOS, J. R. (ed.) Tratamento de esgotos sanitários por processo anaeróbio e disposição controlada no solo. Rio de Janeiro: PROSAB/FINEP, 1999. p.409-435.

McKINLAY, R. G.; KASPEREK, K. Observations on decontamination of herbicide-polluted water by marsh plant systems. Water Research, Oxford, v.33, n.2, p.505-511, 1999.

McNAUGHTON, S. J. Autotoxic feedback in relation to germination and seedling growth in Typha latifolia. Ecology, Washington, v.49, n.2, p.367-69, 1968.

MOORE, M. T. et al. Herbicide effects on Typha latifolia (Linneaus) germination and root and shoot development. Chemosphere, Oxford, v.38, n.15, p.3637-3647, 1999.

MULLER, S. L.; HUGGETT, D. B.; RODGERS, J. H., Jr. Effects of copper sulfate on Typha latifolia seed germination and early seedling growth in aqueous and sediment exposures. Archives of Environmental Contamination and Toxicology, Nova Iorque, v.40, n.2, p.192197, 2001.

POTT, V. J.; POTT, A. Plantas aquáticas do Pantanal. Corumbá: EMBRAPA, 2000. 404p. 
PROCÓPIO, S. O. et al. Potencial de espécies vegetais para a remediação do herbicida trifloxysulfuron-sodium. Planta Daninha, Viçosa, v.23, n.1, p.9-16, 2005.

RODRIGUES, B. N.; ALMEIDA, F. S. Guia de herbicidas. 5 ed. Londrina: Ed. dos autores, 2005. 592p.

STEARMAN, G. K. et al. Pesticide removal from container nursery runoff in constructed wetland cells. Journal of Environmental Quality, Madison, v.32, n.4, p.1548-1556, 2003.

WILSON, P. C.; WHITWELL, T.; KLAINE, S. J. Metalaxyl and simazine toxicity to and uptake by Typha latifolia. Archives of Environmental Contamination and Toxicology, Nova Iorque, v.39, n.3, p.282-288, 2000. 



\section{CAPÍTULO 7}

CONCLUSÕES E SUGESTÕES 


\subsection{CONCLUSÕES GERAIS}

Os resultados obtidos nas diferentes etapas da pesquisa, somados à experiência com a condução dos experimentos permitem a elaboração das seguintes conclusões gerais:

- Com a realização do experimento em campo, utilizando-se SACs de $24 \mathrm{~m}^{2}$ de área superficial, operando sob um tempo de residência hidráulica média de 3,8 dias, constatou-se a diminuição da quantidade de ametrina dissolvida na água que vertia nos sistemas alagados construídos (SACs).

- Os alagados construídos, operando com escoamento do tipo subsuperficial removeram, retiveram ou transformaram $39 \%$ da massa total do composto, que foi aplicado de maneira contínua durante 11 semanas.

- Em todos os experimentos foi observada a importância do cômputo das taxas de evapotranspiração da cultura. A presença da taboa causa a perda de parte do volume aplicado e isso implica em indução a equívocos quando análises são feitas exclusivamente em termos de concentração.

- As variáveis limnológicas monitoradas apresentaram-se em faixas consideradas como ambientalmente favoráveis à biota em geral, não influenciando negativamente na retenção/transformação do praguicida estudado.

- Não se observaram variações na hidrodinâmica e no desempenho, devido à implantação de diferentes inclinações de fundo nos SACs. De acordo com os parâmetros obtidos no ensaio com traçadores fluorescentes, as unidades estudadas apresentam comportamento hidrodinâmico com boa eficiência hidráulica e dispersões muito pequenas.

- Não foram observadas diferenças significativas entre os SACs que receberam ametrina e a testemunha no campo (SAC B). Com base no desempenho agronômico e nutricional, pode-se afirmar que não houve danos à sanidade das macrófitas utilizadas no estudo. Contudo, no estudo em casa de vegetação foi observado que a parte subterrânea apresenta-se mais propensa a danos, se comparada à parte superior das plantas.

- Não foram observadas alterações nos aspectos morfo-anatômicos das macrófitas quando exemplares adultos foram submetidos à exposição de ametrina (concentrações de 1, 3 e $\left.9 \mathrm{mg} \mathrm{L}^{-1}\right)$. 
- Por meio de teste de respirometria, foi observado que o substrato de alagados vegetados possui atividade microbiológica intensa, quando comparado ao meio suporte de SACs não cultivados com macrófitas. No entanto, as dificuldades na quantificação da ametrina (de uma maneira geral) e a não quantificação do herbicida nos tecidos das plantas (especificamente) não permitiram que a contribuição da $T$. latifolia no processo fosse avaliada de maneira quantitativa.

- O desenvolvimento inicial é a etapa mais afetada pela exposição ao composto. Embora sementes tenham se desenvolvido, reduzidas concentrações $\left(0,1 \mathrm{mg} \mathrm{L}^{-1}\right)$ de ametrina afetam o crescimento das raízes das plantas. Tal observação é importante para futuras investigações sobre sustentabilidade e comportamento em longo prazo de SACs contaminados com esse herbicida.

Sistemas alagados construídos podem ser capazes de tratar águas poluídas com praguicidas, agindo como filtros para corpos hídricos a jusante de fontes de emissão desses produtos. De maneira geral, foi observado que o uso de SACs de escoamento subsuperficial na mitigação da contaminação de águas superficiais com agroquímicos é uma técnica não onerosa e viável, podendo fazer parte das chamadas best management practices ou boas praticas agrícolas e ambientais, observadas as necessidades de estudos mais aprofundados sobre o tema.

\subsection{SUGESTÕES PARA ESTUDOS FUTUROS}

No presente estudo foi possível verificar que sistemas alagados construídos podem mitigar os efeitos danosos da contaminação de águas com praguicidas. A constatação da diminuição da quantidade de ametrina dissolvida na água e a observação da não ocorrência de danos aparentes às macrófitas permitem que tal afirmação seja feita. No entanto, observou-se que vários aspectos devem ser melhor estudados e pesquisas futuras sobre o tema certamente contribuirão para um maior entendimento do processo. Nesse sentido sugere-se que tais iniciativas contemplem tópicos que preencham lacunas observadas neste estudo, tais como:

- Adoção sistemática de células não vegetadas (controles) para comprovação da participação (até mesmo em termos de porcentagem) das macrófitas no processo. 
- Possível uso de outras espécies nesses sistemas. No caso de alagados construídos, o destino da massa vegetal é questão importante.

- Verificação da potencialidade da aplicação para mitigação de outros agroquímicos usados em lavouras brasileiras, como fungicidas por exemplo.

- Uso de outras técnicas para detecção das concentrações dos praguicidas, tais como cromatografia líquida e métodos imunoenzimáticos de detecção desses compostos.

- Quantificação dos possíveis subprodutos formados a partir dos agroquímicos estudados. No caso da ametrina, a quantificação de metabólitos como hidroxiametrina e desetilametrina pode ser importante para melhor compreensão de rotas de degradação em SACs.

- Verificação da eficiência da mitigação por aproximações simplificadas, tais como uso de microcrustáceos-sentinelas (Daphnia magna, Ceriodaphnia dubia e Pimephales promelas).

- Estudo das demais variáveis dos sistemas alagados, tais como sistemas de escoamento vertical (ascendente ou descendente), sistemas híbridos ou conjugados.

- Estudo da viabilidade de substratos mais comuns na região de estudo e verificação do papel destes componentes no comportamento do sistema.

- Identificação dos microrganismos presentes no processo, por meio de técnicas avançadas de microbiologia.

- Pesquisas com monitoramento por maiores tempos e com verificação de bioacúmulo dos agroquímicos na cadeia do sistema.

- Projetos que contemplem a interdisciplinaridade do assunto, com a participação de profissionais de engenharia, biologia vegetal, microbiologia e química.

- Possível implantação de sistemas pilotos para verificação da mitigação de agroquímicos com wetlands em escala plena.

Os tópicos supracitados configuram-se apenas como sugestões. Sabe-se que existem muitos outros problemas a serem abordados em relação ao destino ambiental de agroquímicos. Tal constatação deve ser vista pelos cientistas como motivação para novas pesquisas sobre o tema. 